\title{
Autophagy in the Neuronal Ceroid Lipofuscinoses (Batten Disease)
}

\begin{abstract}
William D. Kim ${ }^{1}$, Morgan L. D. M. Wilson-Smillie ${ }^{1}$, Aruban Thanabalasingam ${ }^{1}$, Stephane Lefrancois ${ }^{2,3,4}$, Susan L. Cotman ${ }^{5}$ and Robert J. Huber ${ }^{6 *}$

${ }^{1}$ Environmental and Life Sciences Graduate Program, Trent University, Peterborough, ON, Canada, ${ }^{2}$ Centre Armand-Frappier Santé Biotechnologie, Institut National de La Recherche Scientifique, Laval, QC, Canada, ${ }^{3}$ Department of Anatomy and Cell Biology, McGill University, Montreal, QC, Canada, ${ }^{4}$ Centre D'Excellence en Recherche sur Les Maladies Orphelines-Fondation Courtois (CERMO-FC), Université Du Québec à Montréal (UQAM), Montréal, QC, Canada, ${ }^{5}$ Department of Neurology, Center for Genomic Medicine, Massachusetts General Hospital Research Institute, Harvard Medical School, Boston, MA, United States, ${ }^{6}$ Department of Biology, Trent University, Peterborough, ON, Canada
\end{abstract}

The neuronal ceroid lipofuscinoses (NCLS), also referred to as Batten disease, are a family of neurodegenerative diseases that affect all age groups and ethnicities around the globe. At least a dozen NCL subtypes have been identified that are each linked to a mutation in a distinct ceroid lipofuscinosis neuronal (CLN) gene. Mutations in CLN genes cause the accumulation of autofluorescent lipoprotein aggregates, called ceroid lipofuscin, in neurons and other cell types outside the central nervous system. The mechanisms regulating the accumulation of this material are not entirely known. The CLN genes encode cytosolic, lysosomal, and integral membrane proteins that are associated with a variety of cellular processes, and accumulated evidence suggests they participate in shared or convergent biological pathways. Research across a variety of non-mammalian and mammalian model systems clearly supports an effect of CLN gene mutations on autophagy, suggesting that autophagy plays an essential role in the development and progression of the NCLs. In this review, we summarize research linking the autophagy pathway to the NCLs to guide future work that further elucidates the contribution of altered autophagy to NCL pathology.

Keywords: autophagosome, autophagy, Batten disease, lysosome, model system, mTOR, neurodegeneration, neuronal ceroid lipofucinosis

\section{THE NEURONAL CEROID LIPOFUSCINOSES}

The neuronal ceroid lipofuscinoses (NCLs) are a family of neurodegenerative diseases that affect all ethnicities and ages but predominantly affect children (Williams, 2011; Mole and Cotman, 2015). Commonly known as Batten disease, the different subtypes are each caused by a mutation in a distinct ceroid lipofuscinosis neuronal (CLN) gene (PPT1/CLN1, TPP1/CLN2, CLN3, DNAJC5/ CLN4, CLN5, CLN6, MFSD8/CLN7, CLN8, CTSD/CLN10, PGRN/CLN11, ATP13A2/CLN12, CTSF/ CLN13) (Table 1). In addition to these genes, previous research indicates that mutations in potassium channel tetramerization domain containing 7 (KCTD7)/CLN14 may also cause a subtype of NCL called CLN14 disease (Staropoli et al., 2012) (Table 1). However, recent evidence points towards the majority of CLN14 disease cases being progressive myoclonus epilepsy with an autophagy-lysosome defect but without the classic NCL-type storage material present (Kousi et al., 2012; Metz et al., 2018). In addition, recent work suggests that mutations in TBC1 domain-containing kinase (TBCK)/CLN15 may cause a new subtype of NCL referred to as 
TABLE 1 | Genes associated with the NCL subtypes, as well as the localizations and molecular functions of proteins encoded by those genes.

\begin{tabular}{|c|c|c|c|c|}
\hline Gene & NCL subtype & Disease onset & Localization of protein encoded by gene & Molecular function of protein \\
\hline PPT1 & CLN1 disease & $\begin{array}{l}\text { Infantile } \\
\text { Late-infantile Juvenile } \\
\text { Adult }\end{array}$ & $\begin{array}{l}\text { Lysosomal lumen } \\
\text { Extracellular }\end{array}$ & Protein thioesterase \\
\hline TPP1 & CLN2 disease & Late-infantile Juvenile & $\begin{array}{l}\text { Lysosomal lumen } \\
\text { Extracellular }\end{array}$ & Serine protease \\
\hline CLN3 & CLN3 disease & Juvenile & $\begin{array}{l}\text { Lysosomal membrane } \\
\text { Endosomal membrane } \\
\text { Golgi complex }\end{array}$ & Not well defined ${ }^{a}$ \\
\hline DNAJC5 & CLN4 disease & Adult & $\begin{array}{l}\text { Perinuclear } \\
\text { Lysosome } \\
\text { Endo-lysosomal lumen } \\
\text { Cytoplasm } \\
\text { Plasma membrane }\end{array}$ & Co-chaperone protein \\
\hline CLN5 & CLN5 disease & $\begin{array}{l}\text { Late-infantile Juvenile } \\
\text { Adult } \\
\text { Extracellular }\end{array}$ & $\begin{array}{l}\text { ER } \\
\text { Lysosomal lumen }\end{array}$ & Glycoside hydrolase $^{b}$ \\
\hline CLN6 & CLN6 disease & Late-infantile Adult & ER membrane & ER-Golgi protein transport \\
\hline MFSD8 & CLN7 disease & Late-infantile & Lysosomal membrane & Not well defined \\
\hline CLN8 & CLN8 disease & Late-infantile & $\begin{array}{l}\text { ER membrane } \\
\text { Membranes between ER and Golgi }\end{array}$ & ER-Golgi protein transport \\
\hline CTSD & CLN10 disease & $\begin{array}{l}\text { Congenital } \\
\text { Neonatal } \\
\text { Late-infantile Juvenile } \\
\text { Adult }\end{array}$ & Lysosomal lumen Extracellular & Aspartyl endopeptidase \\
\hline GRN & CLN11 disease & Adult & $\begin{array}{l}\text { Lysosomal lumen } \\
\text { Extracellular }\end{array}$ & Not well defined \\
\hline ATP13A2 & CLN12 disease & Juvenile & $\begin{array}{l}\text { Multivesicular bodies Lysosomal membrane } \\
\text { Membranes of early and late endosomes }\end{array}$ & Not well defined \\
\hline CTSF & CLN13 disease & Adult & $\begin{array}{l}\text { Lysosomal lumen } \\
\text { Extracellular }\end{array}$ & Cysteine protease \\
\hline KCTD7 & CLN14 disease & Infantile & Plasma membrane & Not well defined \\
\hline TBCK & CLN15 disease & Infantile & Perinuclear Centrosome & Rab GTPase-activating protein \\
\hline
\end{tabular}

${ }^{a}$ See Cotman and Lefrancois (2021) for a recent review of CLN3-dependent processes.

${ }^{b}$ See Basak et al. (2021b) for a recent review of CLN5-dependent processes.

CLN15 disease (Table 1) (Liu et al., 2013; Chong et al., 2016; Beck-Wödl et al., 2018). Mutations in CLN genes cause the lysosomal accumulation of ceroid lipofuscin, which is an autofluorescent material composed of lipid-protein aggregates (Palmer et al., 1992; Radke et al., 2015). NCL patients experience a variety of clinical symptoms including seizures, progressive loss in vision, movement, and cognitive capability, and premature death (Schulz et al., 2013). The proposed functions of CLN proteins are varied, where some function as lysosomal enzymes, others are predicted to regulate intracellular trafficking or transport across membranes (Cárcel-Trullols et al., 2015). Unfortunately, the cellular roles of most of the CLN proteins are not fully understood, which has motivated the use of a diversity of model systems to study the NCLs, ranging from lower eukaryotic model organisms such as yeast and the social amoeba Dictyostelium discoideum to animal models and patient-derived cell lines (Huber et al., 2020; Minnis et al., 2020).

Accumulated research across a variety of model systems supports autophagy as a central process disrupted in multiple NCL subtypes. Autophagy is a cellular process that provides cells with energy during periods of stress, degrades unnecessary or dysfunctional intracellular material (e.g., organelles and misfolded proteins), and plays a role in neuroprotection
(Tsukada and Ohsumi, 1993; Thumm et al., 1994; Mizushima et al., 2002; Cuervo, 2004; Levine and Klionsky, 2004; Yorimitsu and Klionsky, 2005; Bossy et al., 2008; Glick et al., 2010). In this review, we summarize the impact of loss-of-function mutations in $C L N$ genes on the autophagy pathway, and we describe how further studies on this pathway in NCL model systems will establish important mechanistic insights and the potential for autophagy as a therapeutic target. Since research on KCTD7 and TBCK in the context of the NCLs and autophagy is limited, they will not be discussed in this review.

\section{AUTOPHAGY}

Autophagic dysregulation has been studied in several neurodegenerative diseases and accumulated evidence indicates it contributes to NCL pathology (Croce and Yamamoto, 2019; Hou et al., 2020; Festa et al., 2021). There are many forms of autophagy, but three main forms in mammals are microautophagy (cytoplasmic material taken up directly by lysosomes/cytoplasmic vacuoles), chaperone-mediated autophagy (selective lysosomal uptake of cytoplasmic macromolecules), and macroautophagy (reviewed in Majeski 


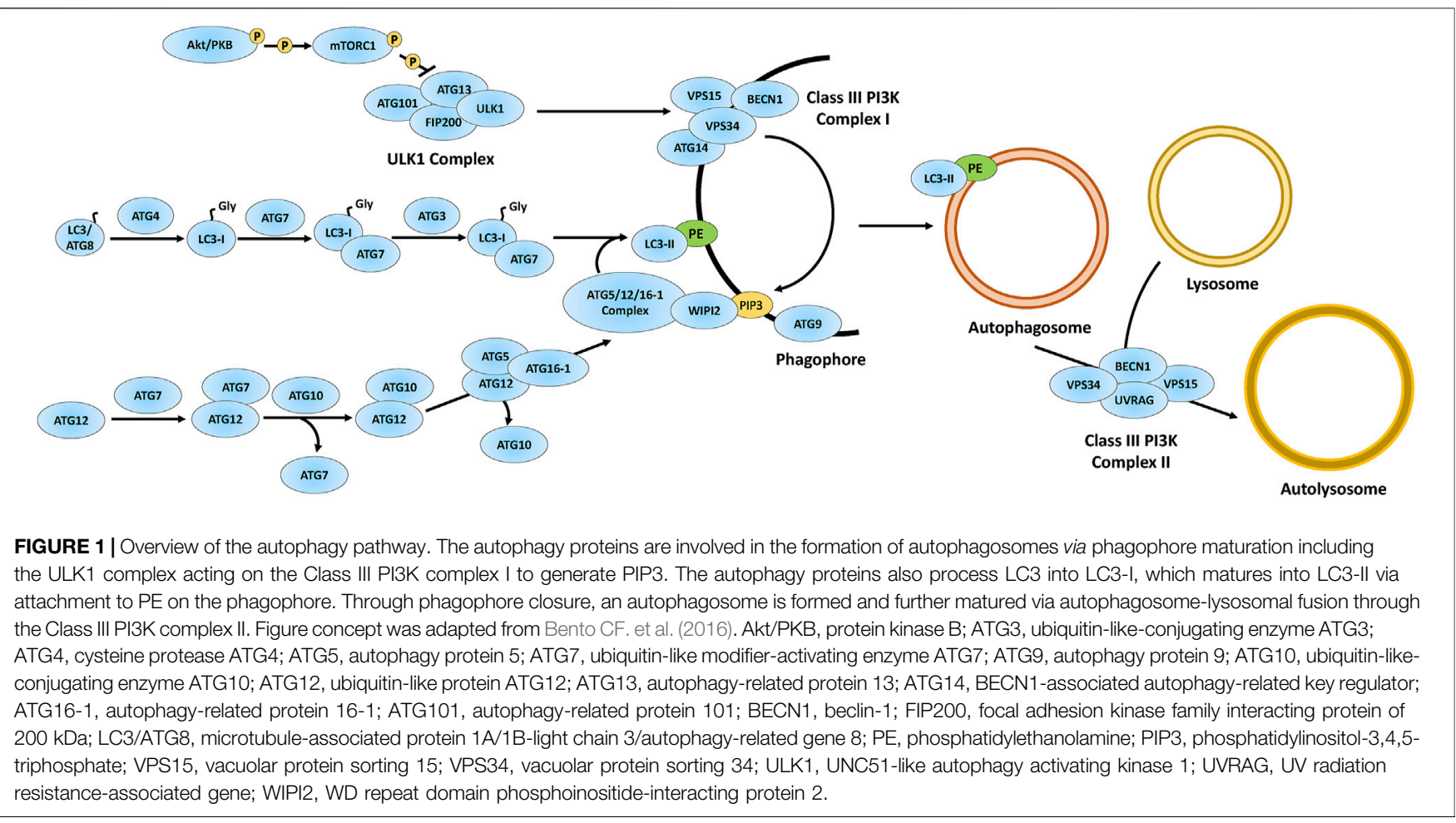

and Dice, 2004; Li et al., 2012; Feng et al., 2014; Riebisch et al., 2021). Macroautophagy involves the degradation of cytoplasmic macromolecules and organelles during times of cellular stress such as starvation, and this form of autophagy will be the focus of this review. Hereafter, we will use "autophagy" only to refer to macroautophagy. In autophagy, a double-membrane vesicle called an autophagosome forms around intracellular material slated for degradation. The autophagosome is formed through a series of steps that starts with the Unc-51 like autophagy activating kinase 1 (ULK1) complex (Figure 1) (Mizushima, 2010; Quan and Lee, 2013; Bento CF. et al., 2016; Hurley and Young, 2017). The ULK1 complex is composed of four proteins; serine/threonine-protein kinase ULK1, autophagy-related protein 101 (ATG101), autophagy-related protein 13 (ATG13), and focal adhesion kinase family interacting protein of $200 \mathrm{kDa}$ (FIP200), which initiate the formation of the autophagosomal membrane (also known as a phagophore) (Mizushima, 2010; Quan and Lee, 2013; Bento CF. et al., 2016; Hurley and Young, 2017). The ULK1 complex is regulated by mammalian target of rapamycin (mTOR) complex 1 (mTORC1) and protein kinase B (PKB, also known as Akt), whose activation are dependent upon the availability of nutrients, particularly free amino acids (Mizushima, 2010; Mrschtik and Ryan, 2015; Hurley and Young, 2017). Akt is a serine/threonine protein kinase that is activated by phosphatidylinositol-3,4,5-triphosphate (PIP3), which is generated by phosphoinositide-3-kinase (PI3K) signal transduction (Alessi and Cohen, 1998; Dibble and Cantley, 2015). Activated Akt indirectly activates mTORC1 through a series of protein interactions, including dissociation of the tuberous sclerosis complex and GTPase Ras homolog enriched in brain (RHEB) in its GDP form (Dibble and Cantley, 2015). After dissociation occurs, GTP-bound RHEB is formed, which initiates mTORC1 activity (Dibble and Cantley, 2015). mTORC1 is a serine/threonine kinase in the mTOR pathway that is involved in many cellular processes including, but not limited to, autophagy, protein synthesis, and lysosomal biogenesis (Mrschtik and Ryan, 2015; Saxton and Sabatini, 2017). In nutrient-rich conditions, Akt is phosphorylated, which leads to mTORC1 activation (Figure 1) (Mizushima, 2010; Quan and Lee, 2013; Hurley and Young, 2017; Saxton and Sabatini, 2017). Activated mTORC1 then phosphorylates ATG13, which inhibits ULK1 complex kinase activity, consequently preventing autophagosome formation (Mizushima, 2010; Quan and Lee, 2013; Hurley and Young, 2017; Saxton and Sabatini, 2017). Conversely, starvation inhibits mTORC1 activity, which facilitates autophagosomal formation via the ULK1 complex.

The kinase activity of ULK1 in the ULK1 complex causes vacuolar protein sorting (VPS) 34 (VPS34) to associate with the phagophore (Figure 1) (Bento CF. et al., 2016). VPS34 is part of a tetramer complex composed of serine/threonine-protein kinase VPS15, beclin-1 (BECN1), and either BECN1-associated autophagy-related key regulator (ATG14) or UV radiation resistance-associated gene (UVRAG) (denoted as Class III PI3K complex I or Class III PI3K complex II, respectively) (Kang et al., 2011; Quan and Lee, 2013; Bento CF. et al., 2016). The Class III PI3K complex I generates PI3P at the phagophore, which is required for the attachment of microtubule-associated protein 1A/1B-light chain 3 (LC3, also referred to as both LC3-b and autophagy-related protein 8, ATG8, but will be referred to as LC3 from hereon) to the phagophore for autophagosome formation. The Class III PI3K 
complex II is involved in autophagosome maturation (Figure 1) (Dooley et al., 2014; Bento CF. et al., 2016).

Phagophore closure is regulated by several autophagy proteins (Figure 1) (Kang et al., 2011; Quan and Lee, 2013; Bento CF. et al., 2016). Cysteine protease ATG4 (ATG4) is a cysteine protease that cleaves LC3 to expose the C-terminal glycine which results in the formation of LC3-I (Figure 1) (Bento CF. et al., 2016; Maruyama and Noda, 2018). Ubiquitin (Ub)-like modifier-activating enzyme ATG7 (ATG7) further processes LC3-I through ATP-dependent adenylation, thus forming an ATG7-LC3-I thioester-linked intermediate (Bento CF. et al., 2016; Maruyama and Noda, 2018). Subsequently, LC3 in the ATG7-LC3-I intermediate is transferred and thioester-linked to ubiquitin-like-conjugating enzyme ATG3 (ATG3) (Maruyama and Noda, 2018). Finally, through the actions of the autophagy protein 5 (ATG5)/ ubiquitin-like protein ATG12 (ATG12)/autophagy-related protein 16-1 (ATG16-1)/WD repeat domain phosphoinositide-interacting protein 2 (WIPI2) complex, LC3-I in the ATG3-LC3-I intermediate attaches to phosphatidylethanolamine $(\mathrm{PE})$ at the phagophore via an amide bond, forming LC3-II (Dooley et al., 2014; Bento CF. et al., 2016; Maruyama and Noda, 2018).

The ATG5/ATG12/ATG16-1/WIPI2 complex is formed through a series of protein conjugation steps, which includes ATG7 cleaving the C-terminal end of ATG12 to expose a glycine residue (Bento CF. et al., 2016). Like the ATG3-LC3-I intermediate, ATG12 is conjugated to ubiquitin-likeconjugating enzyme ATG10 (ATG10), forming an ATG10ATG12 intermediate, which is then linked with ATG5. Lastly, the ATG5-ATG12 intermediate binds with ATG16-1 and WIPI2 at the phagophore, which then interacts with ATG16-1 to form a complex at the phagophore (Bento CF. et al., 2016). The ATG5/ ATG12/ATG16-1/WIPI2 complex facilitates LC3 PE lipidation at the phagophore, which closes the phagophore leading to the formation of an autophagosome (Figure 1) (Fujita et al., 2008; Romanov et al., 2012; Walczak and Martens, 2013; Bento CF. et al., 2016). Finally, the autophagosome fuses with a lysosome via the aforementioned Class III PI3K complex II, ultimately forming an autolysosome (Figure 1) (see Bento et al., 2016b for detailed mechanism). LC3-II is attached on the cytosolic side of the autophagosome and functions as a receptor for p62 (also referred to as sequestosome 1, SQSTM1), which directs protein cargo for autophagic degradation (Kang et al., 2011; Quan and Lee, 2013; Lippai and Low, 2014). Overall, autophagy proteins are essential for initiating autophagosome formation and generating autolysosomes for autophagic degradation. Previous research indicates that impaired autophagy contributes to the neurodegeneration associated with several neurological diseases, including, but not limited to, Huntington's disease, Alzheimer's disease, and Parkinson's disease (Guo et al., 2018). The examination of these autophagyrelated processes, among others, resulted in a considerable amount of research indicating that autophagic dysregulation is a pathological mechanism of the NCLs. In this review, we will discuss the impact of loss-of-function of each CLN gene and protein on autophagy using research gathered from multiple model systems, starting from the effects of CLN gene mutation on transcription and ending with the roles of CLN proteins on lysosomal reformation.

\section{THE ROLES OF CLN GENES AND PROTEINS IN AUTOPHAGY \\ PPT1/CLN1}

Palmitoyl protein thioesterase 1 (PPT1) is a protein thioesterase that cleaves S-acetylated palmitate (fatty acid chain linkage via thioester bonds) from substrates and localizes to lysosomes, but also has been detected in synaptosomes, synaptic vesicles, axons, and extracellularly (Table 1) (Hellsten et al., 1996; Lu et al., 1996; Verkruyse and Hofman, 1996; Lehtovirta et al., 2001; Ahtiainen et al., 2003; Kohan et al., 2005; Cárcel-Trullols et al., 2015). Mutations in PPT1 cause CLN1 disease, an NCL subtype that occurs at the infantile, late-infantile, juvenile, and adult stages of life (Table 1) (Schulz et al., 2013; Mole and Cotman, 2015). The function of PPT1 has been linked to lipid/cholesterol metabolism, exocytosis, endocytosis, and apoptosis, as well as synaptic recycling in neuronal cells (Cho and Dawson, 2000; Ahtiainen et al., 2003; Ahtiainen et al., 2006; Kim et al., 2008; Lyly et al., 2008). In mice, the human PPT1 homolog, PPT1 (Table 2), is involved in the mTOR pathway, which plays an essential role in autophagy (Sardiello et al., 2009; Settembre et al., 2011; Yun et al., 2020). mTORC1 has regulatory roles in lysosomal acidification, lysosomal enzyme activity, and autophagic-lysosome reformation (ALR) (Puertollano, 2014). The mTOR pathway also modulates the activity of transcription factor EB (TFEB), the principal autophagy and lysosomal biogenesis regulator (Di Malta et al., 2019). Specifically, mTORC1 inhibits TFEB through phosphorylation, which prevents nuclear translocation of TFEB thereby inhibiting TFEB and inducing a transcriptional response in nutrient-rich environments (Martina et al., 2012; Roczniak-Ferguson et al., 2012; Napolitano et al., 2018; Di Malta et al., 2019). Ppt1-deficiency significantly decreases mTORC1 expression and lysosomal translocation, thus impairing mTORC1 function and altering autophagic signalling (Figure 2) (RabanalRuiz et al., 2017; Yun et al., 2020). Additionally, Ppt1 expression is increased in mouse $\mathrm{C} 2 \mathrm{C} 12$ muscle cells during differentiation, and when knocked down, there is a significant increase in lysosomal $\mathrm{pH}$, as well as an increase in lysosomal-associated membrane glycoprotein (LAMP) 2 (LAMP2) and TFEB expression and activity (Yun et al., 2020). Loss of Ppt1 in mice also leads to the mislocalization and reduced activity of vacuolartype ATPase (v-ATPase), which consequently, elevates lysosomal pH and impairs autophagic flux (Figure 3) (Bagh et al., 2017). Furthermore, Overall, these studies suggest that PPT1 regulates lysosomal processes, and ultimately autophagy, by modulating TFEB and mTORC1.

The fruit fly, Drosophila melanogaster, encodes a homolog of human PPT1, denoted as Ppt1 (Table 2). In D. melanogaster, Ppt1 and phosphatidylserine decarboxylase $(P s d)$ interact at the gene level, thus suppressing the activity of both genes and negatively impacting retinas (Midorikawa et al., 2010). Psd is a protein that generates $\mathrm{PE}$ through a decarboxylation reaction with phosphatidylserine (Vance and Guergana, 2013). As PE is a 
TABLE 2 | Model organisms used to study the roles of CLN genes and proteins in autophagy. Alignments were generated using NCBI, Protein BLAST (default search parameters) and the Uniprot ID, of each homolog as query sequences.

\begin{tabular}{|c|c|c|c|c|c|c|c|}
\hline Human protein & Size (aa) & Model organism & Homolog & Uniprot ID & Size (aa) & $\%$ identity $^{\mathbf{b}}$ & $\%$ similarity $^{c}$ \\
\hline \multirow[t]{2}{*}{ PPT1 } & 306 & D. melanogaster & Ppt1 & Q9W3C7 & 314 & 55 & 72 \\
\hline & & M. musculus & PPT1 & O88531 & 306 & 86 & 92 \\
\hline \multirow[t]{2}{*}{ TPP1 } & 563 & D. discoideum & Tpp1A & Q55CT0 & 600 & 37 & 52 \\
\hline & & M. musculus & TPP1 & O89023 & 562 & 88 & 94 \\
\hline \multirow[t]{3}{*}{ CLN3 } & 438 & S. pombe & Btn1p & Q9US09 & 396 & 32 & 47 \\
\hline & & D. discoideum & $\mathrm{Cln} 3$ & Q54F25 & 421 & 27 & 45 \\
\hline & & M. musculus & CLN3 & Q61124 & 438 & 86 & 90 \\
\hline \multirow[t]{2}{*}{ DNAJC5 } & 198 & C. elegans & DNJ-14 & E5QCE7 & 217 & 51 & 68 \\
\hline & & M. musculus & DNAJC5 & P60904 & 198 & 99 & 99 \\
\hline \multirow[t]{3}{*}{ CLN5 } & 358 & D. discoideum & Cln5 & Q553W9 & 322 & 30 & 47 \\
\hline & & M. musculus & CLN5 & Q3UMW8 & 341 & 78 & 86 \\
\hline & & O. aries & CLN5 & A2TJ54 & 361 & 86 & 91 \\
\hline \multirow[t]{2}{*}{ CLN6 } & 311 & M. musculus & CLN6 & Q3U466 & 308 & 90 & 93 \\
\hline & & O. aries & CLN6 & Q1PAG8 & 310 & 91 & 93 \\
\hline \multirow[t]{2}{*}{ MFSD8 } & 518 & D. melanogaster & $\mathrm{Cln} 7$ & Q9VS51 & 546 & 35 & 57 \\
\hline & & M. musculus & MFSD8 & Q8BH31 & 519 & 82 & 91 \\
\hline CLN8 & 286 & M. musculus & CLN8 & Q9QUK3 & 288 & 85 & 90 \\
\hline \multirow[t]{3}{*}{ CTSD } & 412 & D. discoideum & CtsD & 076856 & 383 & 48 & 65 \\
\hline & & H. armigera & CtsD & AYP72766 ${ }^{\mathrm{a}}$ & 384 & 54 & 68 \\
\hline & & M. musculus & CTSD & P18242 & 410 & 83 & 91 \\
\hline GRN & 593 & M. musculus & GRN & P28798 & 589 & 75 & 84 \\
\hline \multirow[t]{5}{*}{ ATP13A2 } & 1,180 & C. elegans & CATP-6 & F5GUA7 & 1,207 & 40 & 57 \\
\hline & & D. melanogaster & Dmel/Anne & LOMLL1 & 1,290 & 37 & 54 \\
\hline & & D. rerio & Atp13a2 & A1A5E5 & 1,170 & 52 & 67 \\
\hline & & O. latipes & Atp13a2 & H2L3J0 & 1,143 & 50 & 65 \\
\hline & & M. musculus & ATP13A2 & Q9CTG6 & 1,169 & 85 & 90 \\
\hline
\end{tabular}

${ }^{a} \mathrm{NCBI} /$ GenBank identifier.

${ }^{b}$ Exact amino acid match

'Similar amino acid match (e.g., both polar).

key lipid in autophagosome formation, Psd knockdown causes reduced levels of the LC3-PE conjugate (Midorikawa et al., 2010). In a Ppt1-deficient mouse model, LC3-II levels and autophagosome formation are increased, resulting in an increase in the numbers of autophagosomes (Sarkar et al., 2020; Yun et al., 2020). In another study, LC3-II lipidation experiments showed lysosomal inhibition and a decrease in autophagosome accumulation in PPT1-deficient human cells treated with autophagy inhibitors (e.g., chloroquine (CQ) or a chloroquine-derived molecule DC661), indicating that loss of PPT1 inhibits autophagy (Rebecca et al., 2019). In patient-derived PPT1-deficient fibroblasts, studies revealed that LC3-II levels did not differ with inhibition of lysosomal acidification in PPT1deficient cells but increased in fibroblasts derived from CLN1 disease patients, suggesting that autophagic vesicle turnover independent of lysosomal acidification is reduced (Sarkar et al., 2020). Patient-derived PPT1-deficient fibroblasts also display decreased LC3 colocalization with both LAMP1 and LAMP2, suggesting altered autophagosomal-lysosomal fusion (Figure 3) (Sarkar et al., 2020). In CLN1 disease models, including mice and human fibroblasts, co-localization of rasrelated protein (RAB) 7 (RAB7) with LAMP2 is decreased, as well as poor interactions between RAB7 and RAB7-interacting lysosomal protein (RILP) (Figure 3) (Sarkar et al., 2020). RAB7 is a GTPase that plays a role in endo-lysosomal trafficking, autophagosomal-lysosomal fusion, and lysosomal biogenesis (Cantalupo et al., 2001; Jordens et al., 2001; Zhang et al., 2009; Kuchitsu and Fukuda, 2018; Stroupe, 2018). The loss of PPT1 in human fibroblasts also reveals both suppressed GTPase activity and elevated amounts of RAB7 (Sarkar et al., 2020). COS-1 cells display reduced RAB7 palmitoylation at mutated cysteine residues (Sarkar et al., 2020). Furthermore, the loss of PPT1 in humans causes elevated S-palmitoylation along with reduced endo-lysosomal localization of RAB7. These data suggest that the function of PPT1 is important for RAB7 localization (Sarkar et al., 2020). Therefore, PPT1 may be linked to autophagy and autophagic-related processes through its interactions with RAB7, which influences autolysosomal formation. Furthermore, these studies indicate that the function of PPT1 in removing palmitate from its substrates is essential for autophagic function.

Loss of Ppt1 in mice, as well as PPT1 in various human models (melanoma cells, patient-derived fibroblasts, patient brain tissues), elevates both p62-positive aggregates and Ub-positive proteins (Figure 3) (Atiskova et al., 2019; Rebecca et al., 2019; Sarkar et al., 2020; Yun et al., 2020). p62 influences the movement of cargo delivery to the proteasome, thus impacting the rate of protein turnover (Liu et al., 2016). Since protein delivery is affected, Atiskova et al. (2019) showed that loss of Ppt1 in mice impairs autophagosomal-lysosomal fusion, which consequently blocks autophagic cargo degradation. In Ppt1deficient mice, autophagic degradation is elevated (Figure 3) (Yun et al., 2020). While autophagy is one mechanism of protein degradation, protein degradation also occurs via the proteasome. 


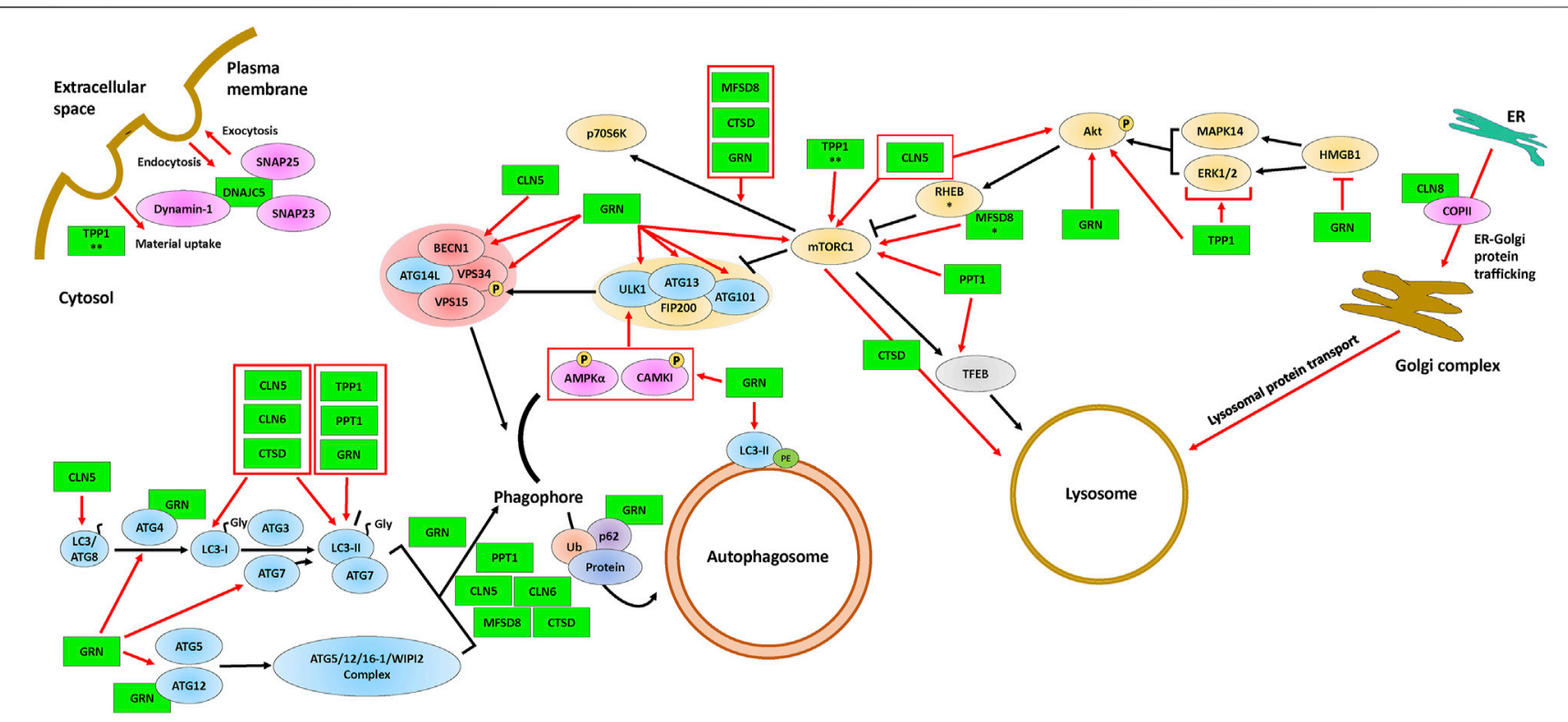

FIGURE 2 | The involvement of CLN proteins in endocytosis, exocytosis, ER-Golgi protein trafficking, autophagosome formation, and lysosome formation. The ULK1 complex (proteins above the yellow background), the Class III PI3K complex I (proteins above the red background), and the autophagy proteins (blue) are required for the formation and maturation of autophagosomes. Some of the CLN proteins (green) affect mTORC1, a protein complex that regulates autophagosome formation and lysosomal biogenesis via TFEB. The black arrows indicate the autophagy pathway and red arrows indicate supporting evidence of an effect of a CLN protein on a given autophagic process. Protein overlaps are representative of protein-protein interactions. * indicates the observation was made only for the $D$. melanogaster homolog and ${ }^{* *}$ indicates the observation was made only for the $D$. discoideum homolog. Note that the positions of the CLN proteins depicted in the figure are not necessarily representative of their actual localization in the cell. Please refer to Table 1 for information on the localizations of the different CLN proteins. Akt, protein kinase B; AMPKa, AMP-activated protein kinase a1/2; ATG3, ubiquitin-like-conjugating enzyme ATG3; ATG4, cysteine protease ATG4; ATG5, autophagy protein 5; ATG7, ubiquitin-like modifier-activating enzyme ATG7; ATG9, autophagy protein 9; ATG12, ubiquitin-like protein ATG12; ATG13, autophagy-related protein 13; ATG14L, BECN1-associated autophagy-related key regulator-like; ATG16-1, autophagy-related protein 16-1; ATG101, autophagy-related protein 101; BECN1, beclin-1; CAMKI, calmodulin-dependent protein kinase I; CLN5, ceroid lipofuscinosis neuronal 5; CLN6, ceroid lipofuscinosis neuronal 6; CLN8, ceroid lipofuscinosis neuronal 8; COPII, coat protein complex II; CTSD, cathepsin D; DNAJC5, DnaJ heat shock protein family Hsp40 member C5; Dynamin-1, dynamin-1; ER, endoplasmic reticulum; ERK1/2, extracellular signal-regulated protein kinase 1/2; FIP200, focal adhesion kinase family interacting protein of $200 \mathrm{kDa}$; GRN, progranulin; HMGB1, high mobility group box 1; LC3/ATG8; microtubule-associated protein 1A/1B-light chain 3/autophagy-related gene 8; LC3-I, processed LC3; LC3-II, lipid-attached membranebound LC3; MAPK14, mitogen-activated protein kinase 14; MFSD8, major facilitator superfamily domain containing 8; mTORC1, mammalian target of rapamycin complex 1; P, phosphate; p62, p62/sequestosome 1; p70S6K, p70 S6 kinase; PE, phosphatidylethanolamine; Protein, protein cargo; PPT1, palmitoyl protein thioesterase 1; RHEB, ras homolog enriched in the brain; SNAP23, synaptosomal-associated protein 23; SNAP25, synaptosomal-associated protein 25; TFEB, transcription factor EB; TPP1, tripeptidyl peptidase 1; Ub, ubiquitin; VPS15, vacuolar protein sorting 15; VPS34, vacuolar protein sorting 34. ULK1, UNC51-like autophagy activating kinase 1; WIPI2, WD repeat domain phosphoinositide-interacting protein 2.

Interestingly, proteasome activity is elevated in human fibroblasts with the loss of PPT1 (Sarkar et al., 2020). Thus, cargo degradation via autophagy is impacted by the loss of PPT1 and may be compensated via the proteasome. Collectively, work in fruit flies, mice, and humans indicates that PPT1 plays a role in lysosomal biogenesis, autophagosomal and autolysosomal formation, as well as autophagic cargo turnover.

\section{TPP1/CLN2}

Tripeptidyl peptidase 1 (TPP1) is a serine protease that cleaves tripeptides from the $\mathrm{N}$-terminus of proteins and localizes to lysosomes and extracellularly (Table 1) (Sleat et al., 1997; Vines and Warburton, 1998; Lin et al., 2001; Kohan et al., 2005). Mutations in TPP1 cause late infantile and juvenileonset forms of NCL known as CLN2 disease (Table 1) (Schulz et al., 2013; Mole and Cotman, 2015). TPP1 has been linked to various cellular processes including apoptosis, endocytosis, and autophagy (Vines and Warburton, 1998; Junaid et al., 2000; Smith et al., 2019). The role of TPP1 in autophagy has been explored in non-human model systems including mice and $D$. discoideum. In mice, loss of the TPP1 ortholog, TPP1 (Table 2), leads to the differential expression of multiple genes associated with autophagy. For example, cathepsin (CTS) genes $(\mathrm{Ctsc} / \mathrm{d} / \mathrm{h} / \mathrm{s} / \mathrm{w} /$ $z$ ) and autophagy-related protein $9 \mathrm{~b}(\operatorname{Atg} 9 \mathrm{~b})$ are differentially expressed in Tpp1-deficient mice (Table 3) (Domowicz et al., 2019). Cathepsins play important roles in autophagy by modulating lysosomal biogenesis, autophagosomal-lysosomal fusion, and autophagic degradation (Yang et al., 2014; Qi et al., 2016; Yadati et al., 2020). In mouse hepatocytes, loss of Atg9b suppresses autophagy (Wang et al., 2017; Domowicz et al., 2019). Genes associated with autophagosomal formation and maturation are also differentially expressed in Tpp1-deficient mice (Domowicz et al., 2019). For example, there is altered expression of phosphoinositide 3-kinase (phosphatidylinositol4,5-bisphosphate 3-kinase catalytic subunit gamma, $P i k 3 c g$ ), as well as multiple phospholipase $\mathrm{C}(\mathrm{Plc})$ genes $(\mathrm{Plcb} 2, \mathrm{Plcl} 2, \mathrm{Plch} 2$, 


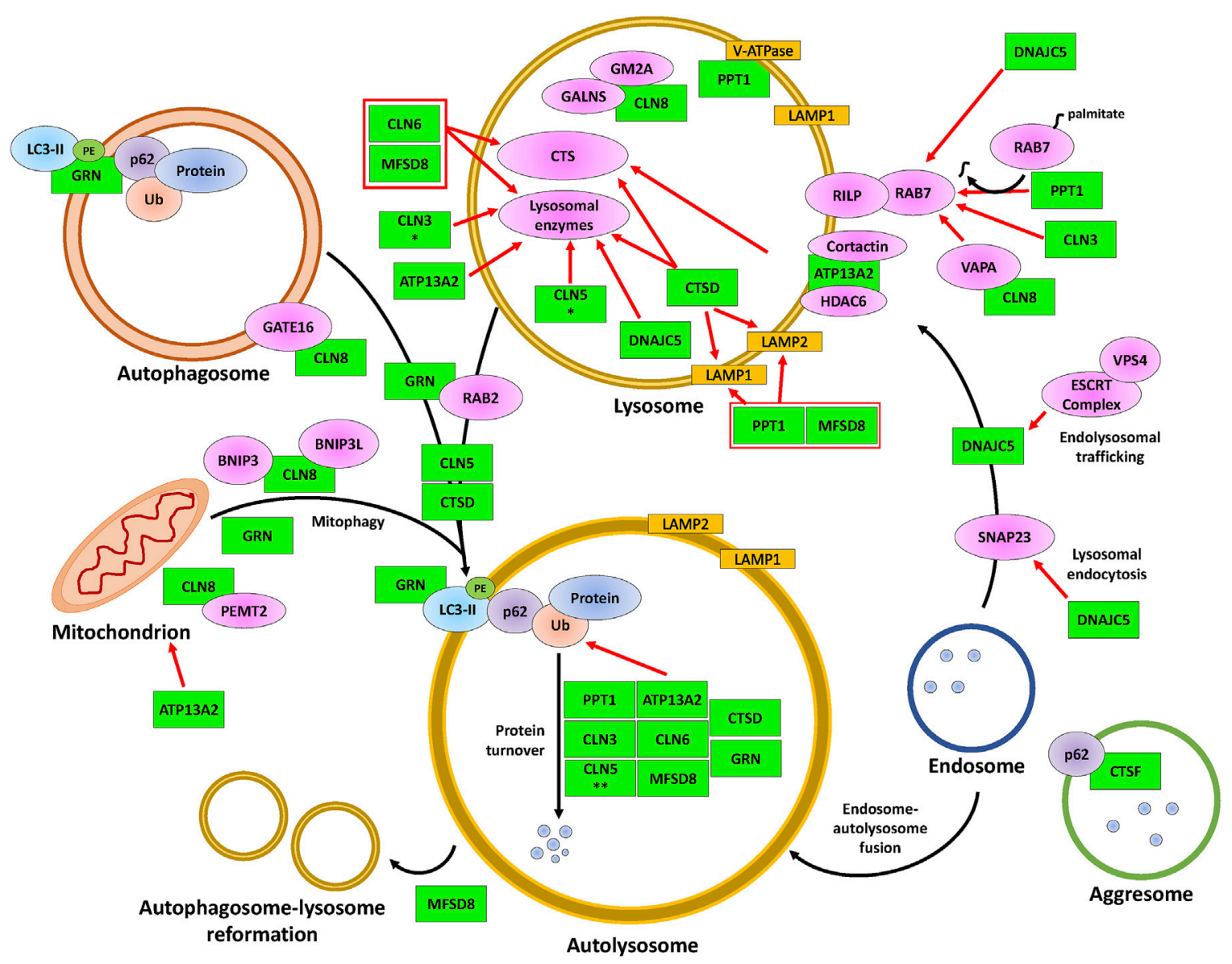

FIGURE 3 | The involvement of CLN proteins in autolysosome formation, cargo degradation, autophagic lysosome reformation, and mitophagy. The CLN proteins (green) modulate various proteins (magenta, yellow, orange) that impact the indicated processes within lysosomes, such as intraluminal acidification and enzymatic degradation, and the fusion of lysosomes with autophagosomes (denoted as autolysosomes) or with mitochondria (known as mitophagosomes, not represented here). While DNAJC5 is involved in regulating endolysosomal trafficking and the fusion between endosomes and autolysosomes, MFSD8 is involved in ALR. The black arrows indicate the autophagic processes starting from autolysosome/mitophagosome formation to ALR. Red arrows indicate supporting evidence of the involvement of a CLN protein within the latter processes of autophagy. Protein overlaps are representative of protein-protein interactions. * indicates the observation was made only for the $D$. melanogaster homolog and ${ }^{* *}$ indicates the observation was made only for the $D$. discoideum homolog. Note that the positions of the CLN proteins depicted in the figure are not necessarily representative of their actual localization in the cell. Please refer to Table $\mathbf{1}$ for information on the localizations of the different CLN proteins. ATP13A2, polyamine transporting ATPase 13A2; BNIP3, BCL2/adenovirus E1B 19 kDa protein-interacting protein 3; BNIP3L, BCL2/adenovirus E1B 19 kDa proteininteracting protein 3-like; CLN3, ceroid lipofuscinosis neuronal 3; CLN5, ceroid lipofuscinosis neuronal 5; CLN6, ceroid lipofuscinosis neuronal 6; CLN8, ceroid lipofuscinosis neuronal 8; Cortactin, cortactin; CTS, cathepsin B/D/Z; CTSD, cathepsin D; CTSF, cathepsin F; DNAJC5, DnaJ heat shock protein family Hsp40 member C5; ESCRT complex, endosomal sorting complex required for transport complex; GALNS, N-acetylgalactosamine-sulfate; GATE16, GABA type A receptor-associated protein-like 2; GM2A, GM2 ganglioside activator; GRN, progranulin; HDAC6, histone deacetylase 6; LAMP1, lysosomal-associated membrane 1; LAMP2, lysosomalassociated membrane 2; LC3-II, lipid-attached membrane-bound LC3; Lysosomal proteins, PPT1/TPP1/ $\beta$-glucuronidase/ $\beta$-hexosaminidase/Saposin C/D; MFSD8, major facilitator superfamily domain containing 8; p62, p62/sequestosome 1; PE, phosphatidylethanolamine; Protein, protein cargo; PEMT2, phosphatidylethanolamine $\mathrm{N}$-methyltransferase 2; PPT1, palmitoyl protein thioesterase 1; RAB2, ras-related protein Rab-2A; RAB7, ras-related protein Rab-7A; RILP, RAB-7A-interacting lysosomal protein; SNAP23, synaptosomal-associated protein 23; Ub, ubiquitin; V-ATPase, vacuolar-type ATPase; VAPA; vesicle-associated membrane protein A; VPS4; vacuolar protein sorting 4.

Plcg2) (Table 3) (Domowicz et al., 2019). Rab7b, which is associated with autophagosome maturation, is also differentially expressed in Tpp1-deficient mice (Table 3) (Domowicz et al., 2019). RAB7B is a GTPase that functions in late endosome-trans-Golgi network vesicular trafficking (Bucci et al., 2010; Progida et al., 2010). In U2OS cells, RAB7B interacts with ATG4B, which regulates autophagic degradation (Kjos et al., 2017). ATG4B is involved in autophagosome maturation via LC3 cleavage which RAB7B modulates (Xie et al., 2008; Yang et al.,
2015; Kjos et al., 2017). Thus, loss of Tpp1 in mice leads to the differential expression of proteins associated with autophagy, but further analysis at a protein level is required to validate the connection to autophagy.

The social amoeba $D$. discoideum presents a unique model system for studying the role of TPP1 in autophagy since it is the only classical lower eukaryote model that encodes a TPP1-like gene (Huber, 2016). In fact, the $D$. discoideum genome encodes six homologs of human TPP1, denoted as Tpp1A, Tpp1B, Tpp1C, 
TABLE 3 | Effects of mutations in CLN genes on the expression of autophagy-related genes.

\begin{tabular}{|c|c|c|c|c|c|}
\hline Gene & $\begin{array}{l}\text { Model } \\
\text { organism }\end{array}$ & $\begin{array}{l}\text { Autophagy- } \\
\text { related } \\
\text { gene }\end{array}$ & Protein & Protein function & $\begin{array}{l}\text { Transcriptional } \\
\text { effect }\end{array}$ \\
\hline \multirow[t]{13}{*}{ TPP1 } & M. musculus & $R a b 7 b$ & Ras-related protein Rab7b & $\begin{array}{l}\text { GTPase that regulates endosome-trans-Golgi } \\
\text { network vesicular trafficking }\end{array}$ & Upregulated \\
\hline & & Atg9b & Autophagy-related gene 9B & Regulates lipid transport and autophagy & \\
\hline & & Ctsc & Cathepsin C & Cysteine protease & \\
\hline & & Ctsd & Cathepsin D & & \\
\hline & & Ctsh & Cathepsin $\mathrm{H}$ & & \\
\hline & & Ctss & Cathepsin S & & \\
\hline & & Ctsw & Cathepsin W & & \\
\hline & & Ctsz & Cathepsin Z & & \\
\hline & & Pik3cg & $\begin{array}{l}\text { Phosphatidylinositol-4,5-bisphosphate 3- } \\
\text { kinase catalytic subunit gamma }\end{array}$ & Phosphoinositide kinase & Downregulated \\
\hline & & Plcb2 & $\begin{array}{l}\text { 1-phosphtidylinositol 4,5-bisphosphate } \\
\text { phospodiesterase beta-2 }\end{array}$ & Phospholipase & \\
\hline & & $\mathrm{Plcl} 2$ & Inactive phopholipase C-like protein 2 & & \\
\hline & & Plcg2 & $\begin{array}{l}\text { 1-phosphatidylinositol 4,5-bisphosphate } \\
\text { phosphodiesterase gamma-2 }\end{array}$ & & \\
\hline & & Plch2 & $\begin{array}{l}\text { 1-phosphatidylinositol 4,5-biphosphate } \\
\text { phosphodiesterase eta-2 }\end{array}$ & & \\
\hline \multirow[t]{7}{*}{ CLN3 } & S. pombe & atg3 & Autophagy-related gene 3 & Ubiquitin-like transferase & Upregulated \\
\hline & & $\operatorname{atg} 8$ & Autophagy-related gene 8 & Phophatidylethanolamine binding protein & \\
\hline & & sst2 & Ubiquitin specific protease & Peptidase & Downregulated \\
\hline & & vps28 & ESCRTI complex subunit Vps28 & Vesicular trafficking regulator & \\
\hline & & fis 1 & Putative mitochondrial fission protein Fis1 & Mitochondrial and outer membrane fission & \\
\hline & & mcs4 & Response regulator Mcs4 & Oxidative stress signal- transducing protein & \\
\hline & & pek1 & MAP kinase Pek1 & Kinase & \\
\hline DNAJC5 & C. elegans & $\begin{array}{l}\text { E3 ubiquitin } \\
\text { ligase }\end{array}$ & E3 ubiquitin ligase & Ubiquitin-tagging protein & Downregulated \\
\hline \multirow[t]{5}{*}{ CLN6 } & M. musculus & Ctsa & Cathepsin A & Cysteine protease & Downregulated \\
\hline & & Ctsb & Cathepsin B & & \\
\hline & & Ctsd & Cathepsin D & & \\
\hline & & Tpp1 & Tripeptidyl peptidase 1 & Serine protease & Downregulated \\
\hline & O. aries & LAMP1 & LAMP1 & Lysosome biogenesis & No change \\
\hline \multirow[t]{2}{*}{ MFSD8 } & M. musculus & Ctsd & Cathepsin D & Cysteine protease & Downregulated \\
\hline & & Ctss & Cathepsin S & & Upregulated \\
\hline CTSD & M. musculus & p62 & p62 & $\begin{array}{l}\text { Autophagic and ubiquitin-proteasome system } \\
\text { receptor }\end{array}$ & Upregulated \\
\hline \multirow[t]{4}{*}{ GRN } & M. musculus & Gabarap & $\begin{array}{l}\text { Gamma-aminobutyric acid receptor- } \\
\text { associated protein-like } 1\end{array}$ & Gamma-aminobutyric acid receptor & Upregulated \\
\hline & & Tom1 & Target of Myb1 membrane trafficking protein & Protein trafficking & \\
\hline & & Tfeb & Transcription factor EB & $\begin{array}{l}\text { Lysosome biogenesis and autophagy regulating } \\
\text { protein }\end{array}$ & \\
\hline & & $\operatorname{Atg} 7$ & $\begin{array}{l}\text { Ubiquitin-like modifier-activating enzyme } \\
\text { ATG7 }\end{array}$ & Ubiquitin-like modifier activating protein & $\begin{array}{l}\text { Upregulated (with GRN } \\
\text { addition) }\end{array}$ \\
\hline ATP13A2 & H. sapiens & SYT11 & Synaptotagmin 11 & $\begin{array}{l}\text { Calcium membrane trafficking and ubiquitin } \\
\text { substrate protein }\end{array}$ & Downregulated \\
\hline
\end{tabular}

Tpp1D, Tpp1E, and Tpp1F (Huber et al., 2020). Of these six proteins, only Tpp1A, Tpp1B, and Tpp1F have been studied. Tpp1A localizes to lysosomes, while Tpp1B and Tpp1F localize to the Golgi complex (Phillips and Gomer, 2015; Stumpf et al., 2017). Tpp1F also localizes to the endoplasmic reticulum (ER) and lysosomes (Stumpf et al., 2017). Of the three TPP1-like proteins studied in $D$. discoideum, only Tpp1A has so far been shown to influence processes related to autophagy (Table 2) (Phillips and Gomer, 2015). Loss of tpp1A in D. discoideum reduces cell proliferation, decreases the viability of cells in autophagy-stimulating media (i.e., media lacking arginine and lysine), causes cells to develop precociously, and impacts the development of cells in the presence of the autophagy inhibitors ammonium chloride and CQ (Phillips and Gomer, 2015; Smith et al., 2019). Reduced cell proliferation and precocious development are key indicators of aberrant autophagy in $D$. discoideum and can be explained by the inability of cells to either sense nutrients in their environment or process nutrients that have been internalized (Mesquita et al., 2017). During growth, the outcome is reduced proliferation, while during development, this defect prematurely places cells in a starved state and causes them to progress through the developmental program faster. tpp1A knockdown also increases phagocytosis suggesting tpp1A-deficient cells may increase the uptake of material to compensate for their reduced ability to break down internal reserves (Smith et al., 
2019). Overall, the loss of tpp1A displays phenotypes of altered autophagy, however, further experimentation is needed to reveal the molecular basis of the relationship between tpp1A and autophagy.

Work in humans has provided support for a role for TPP1 in autophagy where TPP1-deficient fibroblasts display reduced LC3-II when starved or when exposed to lysosomal inhibitors (Figure 2) (Vidal-Donet et al., 2013). Consistent with this finding, LAMP1 is also decreased during starvation in TPP1-deficient fibroblasts (Vidal-Donet et al., 2013). Conversely, Van Beersel and others suggested that TPP1-deficiency does not affect autophagosome formation since they observed normal conversion of LC3-I to LC3-II (Van Beersel et al., 2013). As the Akt-mTOR pathway prevents autophagosome biogenesis via negatively regulating autophagy, Vidal-Donet and others showed that loss of TPP1 enhances the levels of phosphorylated Akt (Figure 2) (Jung et al., 2010; Vidal-Donet et al., 2013). Also shown in $D$. discoideum, loss of tpp1A may affect mTOR signalling (Figure 2) (Smith et al., 2019). In addition, TPP1-deficient fibroblasts also display increased expression of two mitogen-activated protein kinases (MAPKs), including mitogen-activated protein kinase 14 (MAPK14) and extracellular signal-regulated kinase (ERK1/2), both of which modulate the Akt-mTOR pathway (Figure 2) (Vidal-Donet et al., 2013). Finally, mTOR-mediated autophagy is often triggered by cellular stress such as an increase in reactive oxygen species (e.g., peroxide and superoxide radicals) (Spencer et al., 2009; Jung et al., 2010). TPP1-deficient fibroblasts demonstrate poor catalase activity leading to increased superoxide and peroxide levels, which may be another explanation for the impaired autophagy in CLN2 disease (Vidal-Donet et al., 2013). Overall, these findings show that TPP1 impacts processes mediated by the mTOR pathway including lysosomal biogenesis and signalling that regulates autophagy.

In a separate study, loss of atg16 (the D. discoideum ATG16 homolog) (increases Tpp1F) or both autophagy protein 9 (atg9) and atg16 (decreases Tpp1B, Tpp1C, and Tpp1F) alters Tpp1 protein levels in D. discoideum (Xiong et al., 2021). Atg9 is a transmembrane protein that localizes to small vesicles and is thought to play a role in membrane trafficking to autophagosomes (Calvo-Garrido et al., 2010; Tung et al., 2010). atg9-deficiency disrupts growth, phagocytosis, and multicellular development (Tung et al., 2010; Yamada and Schaap, 2019). ATG16 is thought to link autophagy to the Ubproteasome system and loss of atg16 impacts growth, pinocytosis, phagocytosis, and multicellular development (Xiong et al., 2015; Xiong et al., 2018). These data, combined with work on Tpp1A, suggest that Tpp1 proteins in D. discoideum may play important roles in membrane trafficking to autophagosomes (Atg9) or linking autophagy to the Ub-proteasome system (Atg16). In total, work in D. discoideum, mice, and humans suggests multiple roles for TPP1 in the autophagy pathway, including lysosomal biogenesis, autophagic vesicle trafficking, and cargo degradation.

\section{CLN3}

Mutations in CLN3 cause a juvenile-onset form of NCL that is the most common subtype of the disease (Table 1) (The International Batten disease Consortium, 1995; Schulz et al., 2013; Mole and Cotman, 2015). The CLN3 protein contains multiple transmembrane domains and localizes primarily to compartments of the endo-lysosomal pathway and the Golgi complex in model organisms (e.g., yeast and D. discoideum) and a variety of mammalian cell lines (Table 1) (Järvelä et al., 1998; Haskell et al., 1999; Kida et al., 1999; Kremmidiotis et al., 1999; Chattopadhyay et al., 2003; Ezaki et al., 2003; Persaud-Sawin et al., 2004; Metcalf et al., 2008; Codlin and Mole, 2009; Kama et al., 2011; Getty et al., 2013; Tecedor et al., 2013; Oetjen et al., 2016; Mirza et al., 2019). The precise function of CLN3 is unknown but it has been linked to a variety of cellular processes including intracellular trafficking and protein secretion (Table 1) (Fossale et al., 2004; Luiro et al., 2004; Luiro et al., 2006; Metcalf et al., 2008; Uusi-Rauva et al., 2012; Tecedor et al., 2013; Schultz et al., 2014; Kovacs et al., 2015; Huber, 2017; Yasa et al., 2020). For a recent review on the current understanding of CLN3 function, see Cotman and Lefrancois (2021).

Research in various model organisms further bolsters the evidence pointing to the importance of CLN3 function in autophagy. For example, work on the Schizosaccharomyces pombe (yeast) homolog of human CLN3, Btn1p (Table 2), used synthetic genetic array analyses to show that a mutant version of $b \operatorname{tn} 1$ harbouring a mutation equivalent to the most common pathogenic mutation in CLN3 disease, has positive and negative genetic interactions with genes associated with autophagy and mitophagy, respectively (Table 3) (Gachet et al., 2005; Minnis et al., 2021). Mitophagy is another form of autophagy that selectively degrades mitochondria (Youle and Narendra, 2011). Work in another model organism, D. discoideum, also supports a role for CLN3 in autophagy. The D. discoideum genome encodes a single CLN3-like protein denoted as Cln3 (Table 2) (Huber et al., 2014). In D. discoideum, Cln3 localizes to the Golgi complex, contractile vacuole $(\mathrm{CV})$ system, and compartments of the endocytic pathway (e.g., endosomes, lysosomes) (Huber et al., 2014; Huber, 2017; Huber et al., 2016). During the growth phase of the life cycle, loss of $\operatorname{cln} 3$ increases endo-lysosomal $\mathrm{pH}$ (Huber and Mathavarajah, 2019). Consistent with the localization of Cln3 to the CV system, which regulates osmoregulation, loss of $\operatorname{cln} 3$ affects the ability of cells to respond to osmotic stress (Mathavarajah et al., 2018). Intriguingly, this phenotype is exaggerated in the presence of the autophagy inhibitor ammonium chloride suggesting a role for $\mathrm{Cln} 3$ in autophagy (Mathavarajah et al., 2018). Loss of $\operatorname{cln} 3$ in $D$. discoideum causes cells to develop precociously, which is a common phenotype of $D$. discoideum mutants with impaired autophagy that can be explained by the inability of cells to either sense nutrients in their environment or process nutrients that have been internalized (Huber et al., 2014; Mesquita et al., 2017). Loss of $\operatorname{cln} 3$ also affects the expression, activity, and secretion of several lysosomal enzymes (Figure 3) (Huber, 2017; Mathavarajah et al., 2018; Huber and Mathavarajah, 2019). While the loss of $c \ln 3$ 
displays altered autophagy like tpp1A in $D$. discoideum, further investigation is required to provide additional support to validate its connection to autophagy.

Notably, reduced trafficking and levels of lysosomal enzymes have also been reported in mammalian CLN3 disease models (Fossale et al., 2004; Metcalf et al., 2008; Appu et al., 2019; Schmidtke et al., 2019). In mice and human cellular models, early-stage defects in the autophagy pathway have been described. In mice and a murine cerebellar cell model harbouring the most common mutation observed in CLN3 disease patients $\left(C \ln 3^{\Delta \mathrm{ex} 7 / 8}\right.$ ) (Table 2), an accumulation of LC3-positive autophagosomes/autolysosomes is detectable at an early disease stage, even prior to measurable accumulation of lysosomal storage material (Cao et al., 2006). Evidence in these models and in patient cells suggests the accumulation of autophagosomes/autolysosomes arises from reduced autophagic degradation (Figure 3) (Cao et al., 2006; Chang et al., 2011; Vidal-Donet et al., 2013; Lojewski et al., 2014; Chandrachud et al., 2015; Petcherski et al., 2019). The mechanisms causing reduced autophagic degradation upon CLN3-deficiency are incompletely understood but may be linked to altered RAB7-mediated trafficking and/or altered $\mathrm{Ca}^{2+}$ signalling (Figure 3) (Huber et al., 2014; Chandrachud et al., 2015; Petcherski et al., 2019; Yasa et al., 2020; Yasa et al., 2021). Thus, restoration of autophagic degradation in CLN3deficiency models has emerged as a promising therapeutic target (Chang et al., 2011; Chandrachud et al., 2015; Hong et al., 2016; Palmieri et al., 2017; Petcherski et al., 2019; Kinarivala et al., 2020). Interestingly, in one study that utilized a human retinal pigment epithelial cell line and siRNA knockdown of CLN3, an enhancement in autophagic degradation was reported (Zhong et al., 2020). While further work is needed to better understand these findings from those previously described, a possible explanation is in the different model systems and mechanisms of inducing CLN3-deficiency, which led to an acute depletion of CLN3 in the knockdown system, versus chronic CLN3-deficiency induced by gene mutation/knockout systems. Thus, accumulated evidence indicates that CLN3 is associated with the autophagy pathway by affecting the expression and activity of lysosomal enzymes, as well as modulating vesicular trafficking and autophagic degradation.

\section{DNAJC5/CLN4}

Mutations in DnaJ heat shock protein family Hsp40 member C5 (DNAJC5) cause an adult-onset form of NCL known as CLN4 disease, which is also referred to as Kufs or Parry disease (Table 1) (Schulz et al., 2013; Mole and Cotman, 2015). The DNAJC5 gene encodes a cytosolic vesicle-associated co-chaperone that localizes to vesicles around the nucleus, lysosomes, endo-lysosomes, synaptic vesicles, the cytoplasm, and the plasma membrane (Table 1) (Tobaben et al., 2001; Benitez and Sands, 2017; Xu et al., 2018; Lee et al., 2021). DNAJC5 regulates vesicular fusion complexes such as synaptosomal-associated protein (SNAP) 25 (SNAP25), a key protein involved in synaptic vesicle/plasma membrane fusion, and the SNAP receptor (SNARE) protein, which controls synaptic activity (Selak et al., 2009; Burre et al., 2010; Lau et al., 2010; Mohrmann et al., 2010; Sharma et al., 2012;
Zhang et al., 2013). Mice lacking Dnajc5, the mouse homolog of human DNAJC5 (Table 2), display progressive neurodegeneration, which is thought to be a result of defective SNAP25 function (Chandra et al., 2005; Sharma et al., 2012). Research in Dnajc5-deficient mice shows that SNAP25 is misfolded but is still functionally active, thereby impairing the assembly of SNARE (Tobaben et al., 2001; Chandra et al., 2005; Sharma et al., 2012). Furthermore, unfolded SNAP25 degradation requires the DNAJC5/heat shock cognate $71 \mathrm{kDa}$ protein (HSC70)/small glutamine-rich tetratricopeptide complex to avoid automatic degradation by the proteasome. In Dnajc5deficient mice, the lack of DNAJC5 results in the removal of unfolded functionally active SNAP25 before its refolding by the aforementioned complex thus impairing SNARE complex assembly and function (Tobaben et al., 2001; Tobaben et al., 2003: Chandra et al., 2005; Cadieux-Dion et al., 2013). This work indicates that DNAJC5 plays a role in endo-lysosomal trafficking, which indirectly links its role to autophagy. In mice and humans, SNAP25 and dynamin-1 interact with DNAJC5 to regulate exocytosis and endocytosis, which are processes associated with the autophagy pathway (Figure 3) (Rozas et al., 2012; Sharma et al., 2012; Zhang et al., 2012). Dynamin-1 modulates endocytosis through oligomer formation at vesicles where it invaginates, pinches, and then separates the vesicle from the cellular membrane through GTPase activity (Sweitzer and Hinshaw, 1998). Additionally, in mice, loss of Dnajc5 decreases dynamin-1 levels (Zhang et al., 2012; Zhang and Chandra, 2014). As dynamin plays an indispensable role in endocytosis, DNAJC5 may also function in endocytosis. Thus, DNAJC5 may be involved in autophagy through its regulation of dynamin-1 (Rozas et al., 2012; Zhang et al., 2012; Zhang and Chandra, 2014).

In human cells, DNAJC5 is also implicated in the secretion of a-synuclein ( $\alpha$-Syn) through misfolding-associated protein secretion (Lee et al., 2021). In HEK293T cells, DNAJC5 localizes to lysosomes and endo-lysosomes. Analyses between DNAJC5 and endo-lysosomes reveal both elevated DNAJC5 and enhanced vesicular endo-lysosomal association with misfolded proteins. This suggests that DNAJC5 modulates endo-lysosomal function through misfolded protein clearance, which occurs via the endosomal sorting complex required for transport (ESCRT) complex (Lee et al., 2021). The ESCRT complex traffics endolysosomal-related proteins to endo-lysosomes to undergo microautophagy (Sahu et al., 2011; Zhu et al., 2017; Lee et al., 2021). Within a HEK293T ESCRT model lacking VPS, the trafficking of DNAJC5 and endo-lysosomal misfolded proteins like $a$-Syn is reduced and not present at all, respectively (Figure 3) (Lee et al., 2021). This supports other research that found that HSC70 is essential for microautophagy, which further confirms that DNAJC5 is a chaperone specific to HSC70 (Sahu et al., 2011; Lee et al., 2021) In another study, primary fibroblasts carrying the DNAJC5 p. L115R point mutation display elevated SNAP23 protein levels, which impacts SNAP/SNARE lysosomal endocytosis (Figure 3) (Benitez and Sands, 2017). Additionally, mouse fibroblasts harbouring the DNAJC5 p. L115R mutation show increased activity of lysosomal enzymes ( $\beta$-glucuronidase, $\beta$-hexosaminidase, PPT1) intracellularly and extracellularly 
(Figure 3) (Benitez and Sands, 2017). DNAJC5 aggregation, as revealed by the p. L115R mutation, is normally removed and degraded through the autophagy-lysosomal pathway via autolysosomes. However, in CLN4 disease, the degradation of DNAJC5 is drastically increased. Similarly, mice fibroblasts carrying the DNAJC5 p. L115R mutation and treated with lysosomal and autophagy inhibitors display reduced breakdown and removal of DNAJC5 (Benitez and Sands, 2017). Moreover, DNAJC5 p. L115R mutant human primary fibroblasts showed reduced RAB7 levels, which is indicative of elevated autophagosome-lysosome fusion (Benitez and Sands, 2017). This suggests that the autophagic and lysosomal dysfunction seen in CLN4 disease is likely influenced by the improper aggregation and localization of mutated DNAJC5. Overall, DNAJC5 is associated with autophagy through endolysosomal trafficking and autophagy-related vesicular fusion events.

Finally, Caenorhabditis elegans (worm) encodes a homolog of human DNAJC5 denoted as DNJ-14 (Table 2). In worms, loss of $d n j-14$ reduces neuronal cell bodies and elevates punctate intracellular content (Kashyap et al., 2014). Transcriptional profiling of $d n j-14$ mutants revealed a significant downregulation of $\mathrm{Ub}$ genes such as E3 ubiquitin ligases, which is noteworthy since ubiquitination is a key element of autophagy that tags proteins for degradation (Table 3) (McCue et al., 2015). From this work, it would appear that DNAJC5 in worms plays some role in protein tagging for degradation, however further work is required to link these findings to the autophagic pathway. Together, work in worms, mice, and humans supports a role for DNAJC5 in autophagy, including endo-lysosomal trafficking, regulating enzymatic activity, autophagosome-lysosome fusion, and targeting protein cargo for degradation.

\section{CLN5}

Mutations in CLN5 cause late infantile, juvenile, and adult-onset forms of NCL referred to as CLN5 disease (Table 1) (Cannelli et al., 2007; Xin et al., 2010; Mole and Cotman, 2015). CLN5 encodes a 407 amino acid protein that initially localizes to the ER as a type II transmembrane protein, which is subsequently cleaved by members of the signal peptide peptidase family of proteases to generate a mature 358 amino acid protein (Table 1) (Cárcel-Trullols et al., 2015; Jules et al., 2017). The CLN5 protein is glycosylated and trafficked to the lysosomal lumen but is also present extracellularly (Table 1) (Isosomppi et al., 2002; Moharir et al., 2013; Hughes et al., 2014; Huber and Mathavarajah, 2018a). Its sorting to lysosomes is not fully understood, as it is independent of the mannose-6-phosphate receptor (M6PR) and sortilin, suggesting that it uses another pathway, or that both M6PR and sortilin can be used interchangeably (Schmiedt et al., 2010; Mamo et al., 2012). Research suggests CLN5 has glycoside hydrolase activity and the protein is predicted to participate in a variety of biological processes including, but not limited to, cell proliferation, biometal homeostasis, sphingolipid metabolism, lysosomal $\mathrm{pH}$ maintenance, endosome-to-trans Golgi network retrieval of sortilin by modulating RAB7 function and retromer recruitment, and autophagy (Table 1) (El Haddad et al., 2012; Mamo et al., 2012; Grubman et al., 2014; Best et al., 2017; Leinonen et al., 2017; Huber and Mathavarajah, 2018a; Adams et al., 2019; Doccini et al., 2020; Yasa et al., 2021). For a recent review on the current understanding of CLN5 function, see Basak et al. (2021b).

In glioblastoma multiforme, CLN5 knockdown promotes apoptosis but inhibits cell proliferation, migration, and invasion (Xing et al., 2021). CLN5 knockdown also inhibits the activation of Akt and the mTOR signalling pathways by decreasing the levels of phosphorylated Akt and mTOR (Figure 2). From this, it may be suggested that CLN5 is involved in modulating an autophagic response via phosphorylation events related to mTOR.

Like TPP1, D. discoideum is the only lower eukaryotic model organism to encode a homolog of human CLN5 denoted as Cln5 (Table 2) (Huber, 2016). In D. discoideum, Cln5 localizes to the $\mathrm{ER}$, punctate distributions in the cytoplasm, cell periphery, CV system, and extracellularly (Huber and Mathavarajah, 2018a; Huber and Mathavarajah, 2018b). Secretion of $\mathrm{Cln} 5$ is reduced when autophagy is inhibited pharmacologically (e.g., ammonium chloride, CQ) or genetically (loss of autophagy protein 1 (atg1) or atg9) (Huber and Mathavarajah, 2018b; McLaren et al., 2021). In addition to osmoregulation, the CV system in D. discoideum also regulates unconventional protein secretion (Sesaki et al., 1997). Thus, these observations indicate that $\operatorname{Cln} 5$ is secreted via an unconventional pathway linked to autophagy induction.

Loss of $\operatorname{cln} 5$ in $D$. discoideum leads to phenotypes associated with aberrant autophagy. $\ln 5$-deficiency reduces cell proliferation but has no effect on pinocytosis suggesting that the ability of $c \ln 5$-deficient cells to process internalized nutrients is compromised (McLaren et al., 2021). In addition, the proliferation and viability of $c \ln 5$-deficient cells are severely impacted when cells are grown in autophagy-stimulating media (McLaren et al., 2021). At the molecular level, loss of $\operatorname{cln} 5$ increases autophagic degradation and the basal level of autophagy during growth and increases the numbers of Ubpositive proteins (Figure 3) (McLaren et al., 2021). In addition, loss of $\operatorname{cln} 5$ alters the amounts and activities of several lysosomal enzymes, several of which are Cln5-binding proteins (Figure 3) (Huber and Mathavarajah, 2018a; McLaren et al., 2021). Finally, like D. discoideum tpp1A- cells, cln5deficiency causes cells to develop precociously. Loss of $\operatorname{cln} 5$ also compromises the development of cells treated with the autophagy inhibitor ammonium chloride (McLaren et al., 2021). Finally, recent work shows that loss of atg9 increases the amount of intracellular Cln5 (Xiong et al., 2021). Since Atg9 functions in membrane trafficking to autophagosomes, this finding suggests Cln5 may also play a role in vesicular trafficking within the autophagic pathway (Calvo-Garrido et al., 2010; Tung et al., 2010).

Like many neurodegenerative diseases, defective autophagy is observed in animal models of CLN5 disease (Best et al., 2017; Leinonen et al., 2017; Adams et al., 2019; Doccini et al., 2020). For example, mixed neuronal cell cultures derived from CLN5deficient sheep (Table 2) display decreased autophagy compared to cell cultures from wild-type sheep (Best et al., 
2017). The cause of decreased autophagy in these cell lines is not fully understood, however, lysosomes from these cells display decreased acidity. This could result in decreased lysosomal function, which would directly impact the degradation of cargo within autophagosomes by lysosomal enzymes. These observations align with findings from mice, a small animal model that also encodes a homolog of human CLN5 (Table 2). In a rodent model of CLN5 disease, defects in autophagy are observed in the retina (Leinonen et al., 2017). Compared to control mice, CLN5-deficiency increases the levels of p62 and BECN1, as well as the ratio of LC3-II to LC3-I (Figure 2 and Figure 3). These data suggest a lack of autophagosome-lysosome fusion in CLN5-deficient mice, resulting in the accumulation of these autophagic proteins (Leinonen et al., 2017).

Many cell culture models are currently being used to better understand the mechanisms underlying autophagic defects in CLN5 disease. These include patient-derived fibroblasts, and HeLa and HEK293 cells that have been manipulated genetically using CRISPR/Cas9 to delete CLN5 or treated with RNAi to reduce the amount of CLN5 in cells (Adams et al., 2019; Yasa et al., 2021). When CLN5 is knocked down in cells and patient fibroblasts, LC3-II accumulation occurs in non-stressed conditions and amino acid-starved cells can degrade LC3 and p62 (Figure 2) (Adams et al., 2019). This suggests an upregulation of autophagy, with no defects in degradation. Supporting this observation, with the use of mRFP-GFP-LC3 probe in nonstarved cells, more red fluorescence was observed in CLN5deficient patient-derived fibroblasts compared to wild-type cells, suggesting efficient fusion between autophagosomes and lysosomes (Adams et al., 2019). Results from this work diverges from work previously done in both the sheep and mouse models of CLN5 disease. In contrast, work done in CLN5-deficient HeLa cells generated using CRISPR/Cas9 shows significantly reduced red fluorescence in amino acid starved cells using a mTagRFPmWasabi-LC3 autophagy probe (Yasa et al., 2021). These cells also displayed reduced co-localization of the autophagy marker LC3 with the lysosomal marker LAMP1, as well as reduced perinuclear movement of lysosomes as measured by the lysosomal marker CD63, a process necessary for efficient autophagy (Nakamura and Yoshimori, 2017). Similar results are also observed in human cortical-like glutamatergic neurons that were genetically modified using CRISPR/Cas9-mediated gene editing to prevent CLN5 expression. These cells display reduced lysosomal function, as well as disrupted lysosomal movement, both of which can have a negative impact on autophagic degradation (Figure 3) (Basak et al., 2021a). It is difficult to resolve conflicting results between cells with reduced expression of CLN5 and those that are completely deficient. Perhaps the difference between an acute knockdown versus a prolonged knockout explains the discrepancy. However, most models show a defect in autophagy and not an increase. Furthermore, studies with knockdown and the loss of CLN5 show lysosomal enzyme defects, which one would predict should have a negative impact on autophagy (Mamo et al., 2012; Basak et al., 2021a; Yasa et al., 2021). Nonetheless, these findings suggest a role for CLN5 in autophagy. These findings, combined with observations from $D$. discoideum, mice and sheep, suggest that CLN5 plays an important role in autophagy by regulating mTOR signalling, lysosomal function, autophagyrelated vesicular trafficking, and autophagosome-lysosome fusion.

\section{CLN6}

Mutations in CLN6 cause both late infantile and adult-onset forms of NCL referred to as CLN6 disease (Table 1) (Schulz et al., 2013; Mole and Cotman, 2015). The CLN6 gene encodes an uncharacterized transmembrane protein that resides on the ER membrane and is predicted to play a role in biometal homeostasis and autophagy (Mole et al., 2004; Thelen et al., 2012; Kanninen et al., 2013; von Eisenhart-Rothe et al., 2018). Ovine neural cultures with naturally occurring CLN6 mutations (Table 2) have been vital to our understanding of the role of CLN6 in the context of lysosomal storage accumulation and autophagy (Tammen et al., 2006). For example, Best and others revealed reduced lysosomal acidification, but no change in LAMP1 expression, in CLN6-deficient ovine cultures (Best et al., 2017) (Table 3). The numbers of autophagic compartments (preautophagosomes. autophagosomes, autolysosomes), as well as the size of autophagosomes and autolysosomes in CLN6deficient sheep neural cultures were increased (Best et al., 2017). Similar results were observed in mice, another model organism used to study CLN6 disease (Table 2) (von Eisenhart-Rothe et al., 2018). Retinas from CLN6 disease mice display reduced numbers of LC3-positive autophagosomes, along with lowered colocalization of LC3 to autophagosomes, suggesting that autophagosomal formation is inhibited (Figure 2) (von Eisenhart-Rothe et al., 2018). Lentiviral CLN6 overexpression in CLN6-deficient sheep enhances acidification within lysosomes and lowers cytoplasmic vacuole clearance (Best et al., 2017). Thus, CLN6 appears to play a role in both lysosomal acidification and regulating autophagic structures. This is supported by findings from patient-derived samples that indicate that mutations in CLN6 impair the turnover of autophagic vacuoles (Figure 3) (Cannelli et al., 2009). Overall, CLN6 appears to play a role in lysosomal acidification and autophagic degradation.

As CLN6-deficiency impacts the early components in the autophagic process, its impact also cascades into the degradative process in autophagy. CLN6 is proposed to function in trafficking lysosomal enzymes from the ER to Golgi (Bajaj et al., 2020). Lysosomal fractions isolated from Cln6-deficient mice display reduced amounts and activities of PPT1, TPP1, CTSD, and CTSB (Figure 3) (Bajaj et al., 2020). Along with these findings, loss of $C \ln 6$ also causes differential expression of Tpp1 and several Cts genes (Ctsa, Ctsb, Ctsd) (Table 3) (Bajaj et al., 2020). In Cln6-deficient mouse embryonic fibroblasts (MEFs), there is decreased localization of PPT1 and CTSD with LAMP1 (Bajaj et al., 2020). As the enzymes that are key in autophagic degradation are affected by the loss of $C \ln 6$-deficiency, the mechanism of targeting proteins for autophagic degradation is compromised as well. In CLN6 disease mice, the levels of autophagic markers, Ub-positive proteins, and p62-positive proteins are elevated (Figure 3) 
(Thelen et al., 2012; von Eisenhart-Rothe et al., 2018). LC3-II/ LC3-I levels are further enhanced, with no effect on p62 levels, with the treatment of the autophagy inhibitor CQ in retinas from CLN6 disease mice (Figure 2) (von Eisenhart-Rothe et al., 2018). Although total p62 levels within the retina are unaltered, p62 accumulation occurred within the cytosol suggesting impaired autophagic degradation (von Eisenhart-Rothe et al., 2018). Combined, data from mice, sheep, and humans shows that CLN6 may play a role in trafficking lysosomal enzymes and cargo to autophagosomes, which facilitates autophagic degradation.

\section{MFSD8/CLN7}

Mutations in major facilitator superfamily domain containing 8 (MFSD8) cause a late infantile-onset form of NCL referred to as CLN7 disease (Table 1) (Schulz et al., 2013; Mole and Cotman, 2015). MFSD8 is a lysosomal transmembrane protein with unknown function but is predicted to function as a transporter (Pao et al., 1998; Siintola et al., 2007). D. melanogaster encodes a homolog of human MFSD8 denoted as Cln7 (Table 2) that participates in autophagy through the mTOR pathway (Connolly et al., 2019). In fruit flies, Cln7 colocalizes and interacts with Rheb (Figure 2) (Connolly et al., 2019). RHEB is a GTPase that interacts with and activates mTORC1 (Yang et al., 2017). The interaction of RHEB with mTORC1 is noteworthy since RHEB anchors mTORC1, as well as the Ragulator complex, on the cytosolic face of lysosomal membranes (Rogala et al., 2019). The regulation of autophagic processes is controlled by various mechanisms including TFEB activation and mTORC1 inactivation (Puertollano, 2014). mTORC1 inactivation is known to initiate autophagosome formation furthering the process of autophagy (Puertollano, 2014). In $C \ln 7$-deficient fruit flies, mTORC1 activity is affected thus altering autophagy (Figure 2) (Connolly et al., 2019). $M f s d 8$ deficiency also impairs the mTOR pathway in mice, another model organism that contains a homolog of human MFSD8 (Table 2), where abolished phosphorylation of p70 S6 kinase (p70S6K) was observed (Figure 2) (Danyukova et al., 2018). p70S6K is a serine-threonine kinase that has various roles within the cell such as growth and is modulated by the mTOR pathway (Bahrami et al., 2014). Furthermore, enlarged autolysosomes, as well as impaired ALR, were revealed in $M f s d 8$-deficient mice (Figure 3) (Danyukova et al., 2018). From these findings, it was suggested that the development of lysosomes from autolysosomes were affected due to poor tubular structures, which are protrusions extending from autolysosomes that generate lysosomes when separated from the extension (Chen and $\mathrm{Yu}$, 2013; Munson et al., 2015; Danyukova et al., 2018). Interestingly, the mTOR pathway has roles within autophagy, where elevated activity in the mTOR pathway induces tubular structures in ALR (Yu et al., 2010). Combined, these findings suggest that MFSD8 may associate with RHEB to anchor mTORC1 on the cytosolic side of lysosomal membranes thereby affecting autophagy at various stages including initiating autophagosome formation as well as lysosome formation via ALR.

Features of lysosomal and autophagic dysregulation are also observed in both mice and post-mortem tissues obtained from individuals with CLN7 disease (Brandenstein et al., 2016; Danyukova et al., 2018; Geier et al., 2019; von Kleist et al., 2019). MFSD8-deficiency affects lysosomal function as demonstrated by elevated LAMP1 and LAMP2 levels in mice and in tissues from CLN7 disease individuals (Figure 3) (Brandenstein et al., 2016; Geier et al., 2019). In cerebellar granule neuron precursors isolated from $M f s d 8$-deficient mice, lysosomes are increased in size (von Kleist et al., 2019). As lysosomal dysregulation was observed, the loss of $M f s d 8$ in mice alters the levels of lysosomal proteases, including Ctsd (reduced) and Ctss (elevated), which elevates protease activity (Table 3) (Danyukova et al., 2018). Other studies demonstrate altered lysosomal enzyme activity, including enhanced CTSB and CTSZ activity in MEFs, along with both elevated amounts and activity of CTSD in MEFs and tissues derived from CLN7 disease individuals (Figure 3) (Brandenstein et al., 2016; Geier et al., 2019). Interestingly, loss of $M f s d 8$ in mice also reduces the levels of other CLN proteins such as PPT1 and CLN5, which are both suggested to play a role in autophagy (Figure 3) (Danyukova et al., 2018; Adams et al., 2019; Atiskova et al., 2019). As most of these lysosomal proteins are involved in autophagy via proteolysis, reduced protein turnover rate is altered in tissues from individuals with CLN7 disease (Geier et al., 2019). This may also be due to the accumulation of Ub-tagged proteins, as well as elevated p62 levels, which is shown in various locations in $M f_{s} d 8$ deficient mouse brains (Figure 3) (Brandenstein et al., 2016). While $M f_{s} d 8$-deficient mice are capable of undergoing autophagy at a cellular level, loss of $M f s d 8$ enhances cell death under prolonged nutrient deprivation (Danyukova et al., 2018). Tissues from CLN7 disease individuals also display elevated numbers of autophagosomal and lysosomal compartments, as well as reduced size of lysosomes, suggesting impairments to autophagosomal-lysosomal clearance (Geier et al., 2019). Collectively, work from fruit flies, mice, and humans indicates that MFSD8 participates in the autophagy pathway through the regulation of mTORC1 and protein degradation.

\section{CLN8}

CLN8 disease is a late infantile-onset form of NCL that is caused by mutations in the CLN8 gene (Table 1) (Passantino et al., 2013; Schulz et al., 2013; Mole and Cotman, 2015; Gao et al., 2018). CLN8 is an ER transmembrane protein that has been linked to lipid synthesis and transport, membrane trafficking, autophagy, and mitophagy (Lonka et al., 2000; Passantino et al., 2013; di Ronza et al., 2018). In mice, which also contains a homolog of human CLN8, CLN8 is an ER to Golgi cargo receptor that is required for lysosomal biogenesis (Table 1 and 2) (Passantino et al., 2013; di Ronza et al., 2018; Bajaj et al., 2020). CLN8 in mice interacts with coat protein complex II (COPII) to help traffic lysosomal enzymes from the ER to the Golgi (Figure 2) (di Ronza et al., 2018). Furthermore, CLN8 also interacts with various CLN proteins (PPT1, TPP1, CTSD) and other lysosomal proteins including GM2 ganglioside activator (GM2A) and $\mathrm{N}$-acetylgalactosamine-sulfate sulfatase (GALNS) (Figure 3) (di Ronza et al., 2018). Whereas GM2A is a protein that is involved in GM2 ganglioside metabolism, GALNS is an enzyme that acts on polyanionic substrates (Wu et al., 1996; 
Rivera-Colón et al., 2012). Loss of CLN8 in HeLa cells affects the maturation of lysosomal enzymes, and mice lacking $C \ln 8$ display reduced amounts and activities of lysosomal enzymes (Figure 3) (di Ronza et al., 2018). Overall, it is clear that CLN8 participates in lysosomal biogenesis.

Studies in mice and human cell models link CLN8 function to mitochondria and mitophagy. In COS-1 and HeLa cells, CLN8 interacts with proteins involved in lipid transport, endosomal trafficking, apoptosis, and autophagy/mitophagy (Passantino et al., 2013). Among these proteins, GABA type A receptorassociated protein-like 2 (GATE16), BCL2/adenovirus E1B $19 \mathrm{kDa}$ protein-interacting protein 3 (BNIP3), and BCL2/ adenovirus $\mathrm{E} 1 \mathrm{~B} 19 \mathrm{kDa}$ protein-interacting protein 3-like (BNIP3L) are all known and regular interactors of CLN8 that are directly involved in the autophagic process along with Golgi transport, mitophagy, and apoptosis (Figure 3) (Passantino et al., 2013). GATE16 interacts with autophagosomes and plays a critical role in their development, maturation, and transport (Passantino et al., 2013). BNIP3 and BNIP3L function with other proteins to carry out proper autophagic and mitophagic clearance (Passantino et al., 2013). In addition, mitochondria fuse with autophagosomes during mitophagy (Youle and Narendra, 2011). Interestingly, using recombinant CLN8 in COS-1 cells, CLN8 was shown to interact with vesicle-associated membrane protein A (VAPA), a protein involved in lipid metabolism and membrane fusion with potential links to autophagy (Figure 3) (Passantino et al., 2013). VAPA is known to interact with RAB7 as well as the RAB7-RILP complex, both of which are involved in autophagy (Passantino et al., 2013). In summary, there are many CLN8 interactors that modulate autophagy. Collectively, CLN8 participates in autophagy through its role in lysosomal enzyme trafficking as well as its interactions with autophagy-related proteins. However, as with all forms of NCL, more research is necessary to fully identify and understand the scope and involvement of CLN8 in autophagy.

Cln8-deficiency in mice also leads to defective phospholipid synthesis, thus altering the lipid composition and transport of mitochondria-associated membranes (MAMs) (Table 2) (Vance et al., 1997). MAMs are microdomains that facilitate the efficient and specific transport of lipids, ions, and signalling molecules from mitochondria to other organelles such as the ER (Wang et al., 2000; Fujimoto et al., 2012; Lynes et al., 2012). MAMs can bind to the ER and co-regulate cellular processes such as metabolism and autophagy (Missiroli et al., 2016; Theurey et al., 2016). In $C \ln 8$-deficient mice, it is believed that the defective MAMs are a result of alterations in the levels and types of phospholipids in MAMs, as well as the levels and activities of phospholipid synthesizing enzymes such as phosphatidylethanolamine $\mathrm{N}$-methyltransferase 2 (PEMT2) (Figure 3) (Vance et al., 1997). While the exact function of CLN8 in MAMs and autophagy/mitophagy has yet to be determined, it is clear that the dysregulation of MAMs through lipid transport and synthesis plays a role in autophagy-related processes. As such, examining the role of CLN8 in mitochondria may lead to a clearer picture of autophagic dysregulation due to altered lipid synthesis and transport. In summary, these studies support multiple roles for
CLN8 in autophagy, including lysosomal biogenesis, lipid metabolism, and the trafficking of autophagic vesicles.

\section{CTSD/CLN10}

Mutations in CTSD cause congenital, neonatal, late infantile, juvenile, and adult-onset forms of NCL that are collectively referred to as CLN10 disease (Table 1) (Schulz et al., 2013; Mole and Cotman, 2015; Varvagiannis et al., 2018). CTSD is an aspartyl endopeptidase that is $\mathrm{N}$-glycosylated and undergoes proteolytic processing to form a mature enzyme that localizes to lysosomes and extracellularly (Table 1) (Poole et al., 1973; Decker et al., 1980; Faust et al., 1985; Erickson, 1989; Rijnboutt et al., 1992; Metcalf and Fusek, 1993; Takeshima et al., 1995). CTSD is linked to a variety of cellular processes including apoptosis and autophagy (Johansson et al., 2003; Benes et al., 2008; Hah et al., 2012). The role of CTSD in autophagy has been explored in a variety of model systems including $D$. discoideum, the lepidopteran insect Helicoverpa armigera, and mice (Table 2). In $D$. discoideum, loss of atg9 and atg16 reduces the intracellular amount of CtsD, suggesting that CtsD may function in membrane trafficking to autophagosomes or linking autophagy to the Ub-proteasome system (Calvo-Garrido et al., 2010; Tung et al., 2010; Xiong et al., 2018; Xiong et al., 2021). In mice myocardial cells, autophagic clearance correlates with increased expression of Ctsd (Wu et al., 2017). Like other CLN proteins, mTOR signalling is affected by the loss of Ctsd in mice (Ketterer et al., 2020). Although the levels of LAMP2, RAB7, ULK1, and BECN1 are unaltered in Ctsd-deficient mice, Ctsddeficiency in a mouse breast cancer model reduces the localization of mTORC1 to lysosomes when cells are placed in amino acid-limiting conditions (Figure 2) (Ketterer et al., 2020; Iwama et al., 2021). The altered localization is thought to be attributed to proteins that function in tethering mTORC1 to lysosomes, including the Ragulator complex (e.g., Raptor is involved in mTORC1 signalling while Raptor and ras-related GTP binding protein C are both involved in mTORC1 lysosomal attachment), however, this is not the case (Sancak et al., 2008; Lawrence and Zoncu, 2019; Ketterer et al., 2020). Rather, markers of impaired autophagy, including increased LC3-II/LC3-I ratios and increased $p 62 \mathrm{mRNA}$ levels, are observed under non-starved conditions and all these findings are thought to be due to altered signalling of mTORC1 as phosphorylation of p70S6K is reduced in cells derived from a Ctsd-deficient mouse (Figure 2) (Ketterer et al., 2020). Thus, like MFSD8, mTOR signalling is affected by Ctsd-deficiency in mice.

In H. armigera, macroautophagy triggers CTSD maturation to promote apoptosis (Di et al., 2021). Ctsd has also been linked to autophagy during ovarian follicular atresia in Nile tilapia (Sales et al., 2019). In SH-SY5Y cells carrying various mutations linked to CLN10 disease (including catalytically inactive mutations), the formation of pro-CTSD and mature CTSD is affected, resulting in lowered amounts of CTSD or no CTSD protein being produced at all (Crabtree et al., 2014; Bunk et al., 2021). As some of the CTSD mutations cause either enhanced or decreased CTSD activity, the catalytically inactive CTSD SH-SY5Y cell line also displays enhanced CTSB activity (Figure 3) (Crabtree et al., 2014; Bunk et al., 2021). Similar results of reduced levels of mature 
CTSD and reduced CTSD activity were also observed in SH-SY5Y cells harbouring a heterozygous CTSD mutation, as well as in a Ctsd-deficient MEF model (Bae et al., 2015; Marques et al., 2020). In addition, while Crabtree et al. (2014) and Bunk et al. (2021) showed that biomarkers of autophagic dysregulation (e.g., changes in LC3 levels, LAMP1, and LAMP2) are not affected by overexpression of wild-type CTSD or mutated CTSD variants, poor colocalization of CTSD with LAMP2 was shown in SHSY5Y cells harbouring certain CTSD variants (Figure 3). Although Crabtree et al. (2014) and Bunk et al. (2021) determined no changes in key indicators of dysregulated autophagy in SH-SY5Y cells carrying a heterozygous CTSD mutation, the levels of $\mathrm{p} 62$ and polyubiquitinated proteins were elevated, which resulted in lysosomal substrate accumulation (Figure 3) (Bae et al., 2015). As CTSD activity is lowered in Ctsd-deficient MEFs, the addition of recombinant human CTSD corrected the reduced activity (Marques et al., 2020). In another study, high levels of CTSD activate autophagy by increasing acidic autophagic vacuoles, LC3-II formation, and GFP-LC3 puncta in HeLa cells (Figure 3) (Hah et al., 2012). The addition of human CTSD into Ctsd-deficient mice recovers various markers of dysregulated autophagy, such as altered levels of p62, LAMP1, LC3-II/LC3-I, and lysosomal enzymes (saposin C/D amounts and $\beta$-hexosaminidase activity) (Figure 2 and Figure 3) (Marques et al., 2020). It also reduces lysosomal subunit C of mitochondrial ATP synthase, a component of ceroid lipofuscin (Marques et al., 2020). In a Ctsd-deficient mouse model, expression of recombinant human CTSD can correct lysosomal hypertrophy, storage accumulation, and impaired autophagic degradation in the viscera and central nervous system (Figure 3) (Marques et al., 2020). In rat vascular smooth muscle cells, advanced glycation end products (AGEs) promote proliferation and suppress autophagy by reducing the expression of Ctsd (Ma et al., 2015). Overexpression of Ctsd prevents AGE-mediated suppression of autophagy. Together, these results suggest that mutations in CTSD impact autophagy by affecting the localization and function of CTSD and other lysosomal enzymes.

Furthermore, the role of CTSD in autophagy has also been explored in human cancers. For example, in human colon adenocarcinoma cells, CTSD expression is increased when cells are treated with the antineoplastic agent, dichloroacetate, which induces autophagy by inhibiting pyruvate dehydrogenase kinase (Gong et al., 2013). CTSD expression is also linked to autophagy in nasopharyngeal lymphomas (Hasui et al., 2011). The autophagy inhibitor, lucathone, impairs autophagic degradation and induces apoptotic cell death in breast cancer cells by stimulating the expression of CTSD (Carew et al., 2011). In support of this, CTSD is suggested to play a key role in regulating the switch from apoptosis to autophagy (Zheng et al., 2008). In glioblastoma multiforme, CTSD is highly expressed in radioresistant clones, which correlates to an increased level of autophagy (Zheng et al., 2020). The CTSD protein level is positively correlated with the autophagy marker LC3-II/I and negatively correlated with p62, In addition, knocking down CTSD with small interfering RNA increases radiosensitivity in glioblastoma cells. Inhibiting CTSD increases the formation of autophagosomes but decreases the formation of autolysosomes, indicating that CTSD regulates the radiosensitivity of glioblastoma multiforme by affecting the fusion of autophagosomes and lysosomes (Zheng et al., 2020). Combined, these observations support a role for CTSD in regulating $\mathrm{mTOR}$ signalling, lysosomal protein abundance and activity, and the formation of autophagosomes and autolysosomes.

\section{PGRN/CLN11}

Progranulin (PGRN, officially known as GRN) is a soluble glycoprotein that is proteolytically processed into $6 \mathrm{kDa}$ granulins within endo-lysosomes by cathepsins (Table 1) (Toh et al., 2011; Zhou et al., 2017; Mohan et al., 2021). Although its function is not well defined, GRN is known to localize within lysosomes and extracellularly, and has been linked to cell migration, inflammation, and processes related to cancer progression (Table 1) (Zhou et al., 1993; Tian et al., 2016; Daya et al., 2018; Paushter et al., 2018; Voshtani et al., 2019). Mutations in GRN cause an adult-onset form of NCL referred to as CLN11 disease as well as frontotemporal lobar dementia in heterozygous individuals (Table 1) (Smith et al., 2012; Schulz et al., 2013; Mole and Cotman, 2015). Loss of GRN also impacts autophagy. Currently, the involvement of GRN in autophagy has been explored in mice and humans (Table 2). In murine Grnlacking neuroblastoma neuro 2 a cells, genes encoding proteins involved in the trafficking, sorting, and fusion of vesicles related to the autophagy-lysosome pathway (endosomes, lysosomes, autophagosomes) are differentially expressed (Table 3) (Altmann et al., 2016; Elia et al., 2019). For example, gammaaminobutyric acid receptor-associated protein-like 1 (Gabarapl1) and target of Myb1 protein 1 (Tom1) are differentially expressed (Elia et al., 2019). GABARAPL1 is involved in autophagosome formation and maturation, cargo sequestration, and autophagic degradation (Okazaki et al., 2000; Chakrama et al., 2010). TOM1 localizes to endosomes and is involved in trafficking endosomal proteins for autolysosome fusion and influencing autophagosome maturation (Okazaki et al., 2000; Chakrama et al., 2010; Tumbarello et al., 2012; Boyer-Guittaut et al., 2014; ManilSegalen et al., 2014; Szalai et al., 2015). Similarly, the gene encoding for the lysosomal sorting protein receptor sortilin, which functions in directing proteases including CTSD and CTSH towards lysosomes, is also differentially expressed (Canuel et al., 2008; Braulke and Bonifacino, 2009; Elia et al., 2019). In summary, although the loss of Grn in mice causes the differential expression of autophagy-related genes, the direct effects of the loss of Grn on autophagy needs to be validated at the protein level.

Recent work in mice links GRN to autophagy through the mTOR and AMP-activated protein kinase (AMPK) pathways (Zhou et al., 2019b). Work in yeast showed that AMPK alpha (AMPKa) phosphorylates Ulk1 to activate autophagy (Kim et al., 2011). Additionally, AMPKa regulates autophagosome formation and the fusion of autophagosomes with lysosomes (Jang et al., 2018). In HEK293T cells, the loss of AMPKa1 impairs autophagy during starvation (Jang et al., 2018). In mice, loss of Grn increases the expression of genes linked to lysosomal 
biogenesis, including Tfeb (Table 3) (Tanaka et al., 2014). Furthermore, Grn-deficient diabetic mice in high-glucose conditions display lowered phosphorylation of AMPKa and calmodulin-dependent protein kinase I (CAMKI), which reduces autophagic initiation (Figure 2) (Zhou et al., 2019b). Increased levels of phosphorylated Akt are observed with GRN supplemented in C57BL/6 J mice diet, as well as a combined treatment of GRN and insulin, which demonstrates that autophagic signalling is affected under certain glucose conditions (Liu et al., 2015). In human podocytes, GRNsupplemented media causes differential phosphorylation of proteins linked to autophagosome formation including ULK1, VPS34, and BECN1 under high-glucose events (Figure 2) (Zhou et al., 2019b). GRN treatment also rescues the altered phosphorylation of AMPKa, mTOR, and p70S6K (Figure 2). Also in human podocytes, when either $A M P K \alpha 1$ or $A M P K \alpha 2$ are silenced, the restorative effects of exogenous GRN treatment on autophagy under glucose-rich conditions are lost, indicating that AMPKa1 and possibly AMPKa2 are the proteins that GRN induce its effects within autophagy (Zhou et al., 2019b). When GRN-lacking HeLa cells are treated with the mTOR inhibitor rapamycin, restorative effects of p62 accumulation reduction are observed (Altmann et al., 2016) Thus, loss of GRN affects autophagy by impacting phosphorylation in the AMPK pathway, which impacts autophagosome formation via VPS and ULK1.

In mice, loss of Grn reduces the amount of ATG12 protein and increases the amount of ATG13 protein, which are both involved in autophagosome formation (Figure 2) (Altmann et al., 2016). GRN co-localizes with the ATG5-ATG12 complex, ATG4b, LC3b, p62, and LAMP1 at structures resembling autophagosomes (Altmann et al., 2016). GRN has also been shown to interact with ATG4b, ATG12, p62, and LC3-II in a variety of human cell lines (HEK293, SH-SY5Y, HeLa) and tissues (bone marrow, brain) (Altmann et al., 2016; Tegeder, 2016). In macrophage cell cultures derived from mouse bone marrow, loss of Grn increases the amount of LC3-II and numbers of autophagosomes (Figure 2) (Chang et al., 2017). When Grn-deficient bone marrow cultures derived from mice were exposed to Listeria monocytogenes, poor inflammatory response and xenophagy were observed (Chang et al., 2017). Loss of Grn in mice leads to accumulation of p62 and LC3-II in autophagosomes (Figure 2 and Figure 3) (Zhao et al., 2021). Furthermore, ovalbumin treatment in Grn-deficient mice display elevated amounts in p62, LC3-II, and ATG5-ATG12 amounts, which are indicators of accumulation of autophagosomes (Figure 2) (Zhao et al., 2021). p62 accumulation is also observed in HeLa cells lacking GRN, which also display reduced basal autophagy (Altmann et al., 2016). GRN also interacts with proteins that are associated with the fusion of lysosomes with autophagosomes. In HEK293T cells, a region of GRN called granulin E, interacts with RAB2A (Figure 3) (Zhao et al., 2021). Intriguingly, like in Grn-deficient mice and GRN-deficient human fibroblasts, knockdown of $R A B 2$ in human fibroblasts increases the levels of p62 and LC3-II (Zhao et al., 2021). RAB2-deficiency in human fibroblasts also reduces the level of GRN (Zhao et al., 2021). Like other Grn-lacking mouse models that display autophagic dysregulation, lysosomal dysregulation is apparent as LAMP1 and CTSD protein levels are increased (Tanaka et al., 2014). Grndeficiency in mice also causes differential enrichment of proteolytic enzymes involved in autophagy including TPP1, CTSD, and CTSZ (Figure 3) (Huang et al., 2020). When recombinant human GRN is added into the medium of Grndeficient mouse podocytes under high glucose conditions (to simulate diabetic conditions) or GRN is supplemented into the diets of $\mathrm{C} 57 \mathrm{BL} / 6 \mathrm{~J}$ mice, recovery of reduced mitophagy and mitochondrial biogenesis, as well as increased expression of $\operatorname{Atg} 7$ and LC3-II expression, are observed (Figure 2 and Table 3) (Zhou et al., 2015; Guo et al., 2017; Zhou et al., 2019a). Furthermore, GRN supplemented into the diet of mice reduces the amount of p62 (Figure 3) (Zhou et al., 2015; Guo et al., 2017). The autophagy activator trehalose corrects the reduced GRN expression and restored the amount of GRN localizing to the cytoplasm in haploinsufficient GRN patient-derived primary fibroblasts (Holler et al., 2016). Together, these findings show that GRN-deficiency impacts lysosomal enzyme abundance, autophagosome formation, and cargo tagging.

GRN, ATG7, and LC3-II are all elevated in patients with metabolic syndrome (MS), which are a family of diseases linked to dysfunctional metabolic processes leading to both fat accumulation and insulin insensitivity (Li et al., 2014; Rochlani et al., 2017; Regufe et al., 2020). As with Grn-lacking mice models, MS patients display similar mRNA and protein profiles of ATG7 and LC3-II (Figure 2 and Table 3) (Liu et al., 2014). These findings of autophagy impairment are associated with an inflammatory response, which modulate autophagy by generating immune cells (e.g., neutrophils, macrophages, and lymphocytes), as well as inducing transcriptional changes in cytokine production (Li et al., 2014; Qian et al., 2017). $\mathrm{HaCaT}$ cells are human keratinocytes under inflammatory conditions that demonstrate high endogenous levels of GRN (Tian et al., 2016). Knockdown of GRN elevates the levels of $\beta$-catenin, which impacts the $\mathrm{Wnt} / \beta$-catenin signalling pathway (Tian et al., 2016). GRN-deficient $\mathrm{HaCaT}$ cells display reduced LC3-II levels, and inhibition of the $\mathrm{Wnt} / \beta$-catenin signalling pathway through IWP-2 treatment elevates the levels of LC3II affected by GRN-deficiency (Tian et al., 2016). Under other inflammatory-based conditions like asthma, recombinant GRN delivered nasally ameliorates indicators of impaired autophagy such as lowering protein levels of LC3, BECN1, and the number of autophagosomes in mice (Liu et al., 2021). Liu et al. (2021) show and postulate that these autophagic indicators may be regulated by GRN via high mobility group box 1 (HMGB1), a protein that is upstream of the MAPK/ERK pathway and is suppressed by GRN, which negatively modulates autophagy (Figure 2). As GRN is known to be a protective biomolecule in the context of several neurodegenerative diseases, GRN may be asserting its protective effect against excitotoxicity within the autolysosomal pathway despite being an extracellular protein (Davis et al., 2021; Terryn et al., 2021). Thus, these findings suggest that GRN regulates autophagy by initiating autophagosome formation, influencing lysosomal protein production, and participating in cargo degradation. 


\section{ATP13A2/CLN12}

Mutations in polyamine-transporting ATPase 13A2 (ATP13A2) cause a juvenile-onset form of NCL referred to as CLN12 disease, as well as Kufor Rakeb Syndrome, a juvenile-onset form of Parkinson's disease (Table 1) (Schulz et al., 2013; Mole and Cotman, 2015). In canines, loss of ATP13A2 causes an adultonset form of the disease (Bras et al., 2012). ATP13A2 encodes a P-type ATPase with an unknown function but is predicted to function as an active transporter of inorganic cations (Table 1) (Ramirez et al., 2006; Ramonet et al., 2012; Cárcel-Trullols et al., 2015). ATP13A2 is known to localize to the membranes of endosomes and lysosomes as well as multivesicular bodies (Table 1) (Ramirez et al., 2006; Ramonet et al., 2012; Tsunemi et al., 2014; Cárcel-Trullols et al., 2015). Mutations in ATP13A2 are known to impair many biological processes, one of which is autophagy. A role for ATP13A2 in autophagy has been documented in multiple model systems. For example, $C$. elegans encodes a homolog of human ATP13A2 referred to as CATP-6 (Table 2). Loss of catp-6 in C. elegans and loss of $A T P 13 A 2$ in cells derived from patients with Parkinson's disease, impact lysosomal function by preventing lysosomal acidification and lysosomal enzyme maturation, which ultimately affects the degradative capacity of lysosomes (Dehay et al., 2012b; Anand et al., 2020). It also reduces the expression of genes required for autophagy and lysosomal function and affects mitochondrial health. In addition, loss of catp- 6 dysregulates iron metabolism, which is consistent with previous work suggesting iron toxicity-induced neurodegeneration in patients carrying mutations in ATP13A2 (Rajagopalan et al., 2016). In Danio rerio (zebrafish), the homolog of human ATP13A2 is denoted as Atp13a2 (Table 2). Loss of atp13a2 in zebrafish, as well as in Oryzias latipes (medaka fish) (Table 2), causes dopaminergic neurodegeneration and lysosomal dysfunction (Matsui et al., 2013; Nyuzuki et al., 2020). atp13a2-deficiency also reduces the level of Ctsd in brain tissue and impairs intracellular trafficking suggesting alterations to the autophagy pathway (Figure 3) (Matsui et al., 2013; Nyuzuki et al., 2020). Collectively, these results suggest ATP13A2 is involved in autophagy by modulating lysosomal acidification and biogenesis.

The role of ATP13A2 in autophagy also extends into small animal models, including mice, and humans. Mice deficient of Atp13a2 (Table 2) display protein trafficking defects and agerelated motor dysfunction that is preceded by gliosis, as well as the accumulation of both ceroid lipofuscin and ubiquitinated protein aggregates (Kett et al., 2015). Loss of Atp13a2 also impairs the degradation capacity of lysosomes in mouse primary neurons leading to the accumulation of $a-S y n$ (Usenovic et al., 2012). Decreased expression of Atp13a2 is also associated with defective autophagy in midbrain dopaminergic neurons from a 1-methyl4-phenyl-1,2,3,6-tetrahydropyridine-induced Parkinson's disease mouse model (Wan et al., 2020). Human fibroblasts carrying ATP13A2 mutations display reduced degradative capacity due to impaired lysosomal acidification and decreased proteolytic processing of lysosomal enzymes, ultimately reducing the clearance of autolysosomes (Figure 3) (Usenovic et al., 2012; Dehay et al., 2012a). Loss of ATP13A2 in humans also negatively regulates the expression and post-translational levels of synaptotagmin-11 (SYT11), which leads to lysosomal dysfunction and impaired degradation of autolysosomes (Table 3) (Bento C. F. et al., 2016). Thus, these findings provide additional evidence linking ATP13A2 to autophagy, specifically cargo degradation within autolysosomes.

Other research suggests that ATP13A2 may serve as a novel prognostic biomarker for colon cancer and a potential target for colon cancer therapy due to increased expression of ATP13A2 linking to shorter overall survival of colon cancer patients (Chen et al., 2020). Conversely, decreased expression of ATP13A2 decreases tumorigenesis by blocking autophagic degradation (Figure 3). In melanoma and neuroblastoma cell lines subjected to proteotoxic stress, overexpression of full-length ATP13A2, catalytically-inactive ATP13A2, or the N-terminal domain of ATP13A2 reduces the accumulation of Ubconjugated proteins by serving as a scaffold for trafficking intracellular cargo (Figure 3) (Demirsoy et al., 2017). Conversely, depletion of ATP13A2 increases the accumulation of Ub-conjugated proteins (Figure 3). Knockdown of ATP13A2 fragments mitochondria and increases the production of reactive oxygen species in SH-SY5Y neuroblastoma cells and primary cortical neurons from mice (Gusdon et al., 2012). Loss of ATP13A2 also decreases autophagic degradation but has no effect on the basal levels of the autophagosome marker LC3-II (Figure 2 and Figure 3). Together, these findings suggest that ATP13A2-deficiency impacts autophagy by affecting the trafficking and degradation of ubiquitinated proteins.

Thioredoxin-interacting protein activates oxidative stress and inhibits autophagic degradation by inhibiting thioredoxin (Deng et al., 2020). In HEK293 cells, overexpression of thioredoxininteracting protein induces LC3-II expression but fails to degrade the Ub-binding protein $\mathrm{p} 62$, which is an autophagosome cargo protein that targets proteins for degradation by autophagy ( $\mathrm{Su}$ et al., 2017). Increased expression of thioredoxin-interacting protein also reduces the expression of $A T P 13 A 2$. Intriguingly, overexpression of $A T P 13 A 2$ attenuates the impaired autophagic degradation in cells overexpressing thioredoxin-interacting protein. Finally, Wang et al. (2019) used Atp13a2-deficient mice, brains from $D$. melanogaster subjected to RNAi against the D. melanogaster homolog of ATP13A2, ATP13A2-null HEK293, and HeLa cells to show that loss of ATP13A2 impairs autophagosome-lysosome fusion and damages mitochondria by affecting the recruitment of histone deacetylase 6 (HDAC6) and cortactin to lysosomes (Figure 3). Combined, these findings further suggest that ATP13A2 functions in multiple steps of the autophagy pathway including lysosomal biogenesis, autophagosome-lysosome fusion, protein trafficking, autophagic degradation, and mitochondrial homeostasis.

\section{CTSF/CLN13}

CTSF is a cysteine protease that localizes both to lysosomes and extracellularly (Table 1) (Wang et al., 1998; Nägler et al., 1999; Öörni et al., 2004; Kaakinen et al., 2007; Cárcel-Trullols et al., 2015). Mutations in CTSF cause an adult-onset form of NCL referred to as CLN13 disease (Table 1) (Schulz et al., 2013; Mole and Cotman, 2015). In D. discoideum, loss of atg16 (increases 
cysteine protease (Cpr) E (CprE) and CprF or atg9 and atg16 (decreases CprD and CprF) affects the intracellular levels of several homologs of human CTSF suggesting that CTSF homologs in $D$. discoideum may function in membrane trafficking to autophagosomes or linking autophagy to the Ubproteasome system (Calvo-Garrido et al., 2010; Tung et al., 2010; Xiong et al., 2018; Xiong et al., 2021). In HEK293T cells, CTSF localizes to vesicles and co-localizes with LAMP2 (Jerič et al., 2013). Mutant forms of CTSF that are truncated on the $\mathrm{N}$-terminal end form insoluble perinuclear-juxtanuclear aggregates that accumulate within aggresome-like p62-positive inclusions and co-localize with the autophagy marker LC3B, but not with LAMP2 (Figure 3). Aggresomes are cytoplasmic vesicles that contain aggregates of misfolded proteins and p62 modulates autophagic degradation of polyubiquitinated cargo via interactions with LC3 (Johnston et al., 1998; Pankiv et al., 2007). These findings suggest that $\mathrm{N}$-terminally truncated forms of CTSF are cleared via autophagy. While these data do not suggest a direct involvement of CTSF in autophagy, they do show that levels of the protein are regulated by autophagy genes and that the protein interacts with autophagy-related proteins (e.g., LAMP2).

\section{CONCLUSION AND FUTURE PERSPECTIVES}

This review highlights the roles of CLN genes and proteins in autophagy. Since mutations in CLN genes cause neurodegeneration that is associated with compromised autophagy, targeting this essential cellular process may provide new therapeutic opportunities. For example, in CLN3 disease, multiple preclinical studies have shown promise for pharmacologic approaches to stimulate autophagy/autophagic degradation (Chang et al., 2011; Palmieri et al., 2017; Petcherski et al., 2019; Kinarivala et al., 2020; Soldati et al., 2021). Notably, two upcoming clinical trials for CLN3 disease to test compounds that promote TFEB activation, which enhances autophagy, have been announced by Theranexus and the Beyond Batten disease Foundation (BBDF-1010, Investigational New Drug approval announced, beyondbatten. org) and Polaryx (PLX-200, ClinicalTrials.gov identifier: NCT04637282). Compounds/targets that enhance autophagic degradation are also candidates for the treatment of other forms of NCL; in particular, forms that show reduced degradation upon loss of function of the CLN protein (e.g.,

\section{REFERENCES}

Adams, J., Feuerborn, M., Molina, J. A., Wilden, A. R., Adhikari, B., Budden, T., et al. (2019). Autophagy-lysosome Pathway Alterations and Alpha-Synuclein Up-Regulation in the Subtype of Neuronal Ceroid Lipofuscinosis, CLN5 Disease. Sci. Rep. 9, 151. doi:10.1038/s41598-018-36379-z

Ahtiainen, L., Luiro, K., Kauppi, M., Tyynelä, J., Kopra, O., and Jalanko, A. (2006). Palmitoyl Protein Thioesterase 1 (PPT1) Deficiency Causes Endocytic Defects Connected to Abnormal Saposin Processing. Exp. Cel. Res. 312, 1540-1553. doi:10.1016/j.yexcr.2006.01.034
MFSD8/CLN7, ATP13A2/CLN12). For many of the NCLs caused by lysosomal enzyme deficiencies, pharmacologic approaches leading to enhanced lysosomal biogenesis and stimulation of autophagy also merit further study, since this may partially compensate for the impact of enzyme deficiency on lysosomal function. Further studies are needed that will more thoroughly dissect the mechanisms of autophagic dysregulation for each of the subtypes of NCL, but it is likely that multiple forms of NCL could benefit from common approaches targeting the autophagy pathway. Aberrant autophagy is also linked to other forms of neurodegeneration including Alzheimer, Huntington, and Parkinson disease (Croce and Yamamoto, 2019; Hou et al., 2020; Festa et al., 2021). Therefore, advances towards therapies targeting autophagy are very likely to impact drug development efforts across the NCLs and other neurological diseases. Finally, the NCL research community has generated a variety of experimental models to study the NCLs, ranging from model organisms such as yeast and D. discoideum, to small (e.g., mice) and large animal (e.g., dogs, sheep) models, and patient-derived human models (Huber et al., 2020; Minnis et al., 2020). Collectively, these systems can be used to further explore the precise roles of CLN genes and proteins in regulating autophagy.

\section{AUTHOR CONTRIBUTIONS}

RH: conceptualization, writing-original draft, review and editing, and supervision. WK: conceptualization, writing- original draft, review and editing. MW-S: writing-original draft AT: writing-original draft SL: writing-original draft SC: writing-original draft All authors read and approved the final draft of the manuscript

\section{FUNDING}

This review was supported by grants from the Natural Sciences and Engineering Research Council of Canada (Discovery Grant to RH, RGPIN-2018-04855) and the Canadian Institutes of Health Research (Project Grant to RH, PJT-165873, Project Grant to SL, PJT-173419). SC receives funding from the National Institutes of Neurological Disorders and Stroke (NINDS) R56NS113891 and from Dr. Sandra Nusinoff Lehrman and Stephen Lehrman. WK was supported by a Queen Elizabeth II Graduate Scholarship in Science and Technology and an Ontario Graduate Scholarship.

Ahtiainen, L., Van Diggelen, O. P., Jalanko, A., and Kopra, O. (2003). Palmitoyl Protein Thioesterase 1 Is Targeted to the Axons in Neurons. J. Comp. Neurol. 455, 368-377. doi:10.1002/cne.10492

Alessi, D. R., and Cohen, P. (1998). Mechanism of Activation and Function of Protein Kinase B. Curr. Opin. Genet. Develop. 8, 55-62. doi:10.1016/s0959-437x(98)80062-2 Altmann, C., Hardt, S., Fischer, C., Heidler, J., Lim, H.-Y., Häussler, A., et al. (2016). Progranulin Overexpression in Sensory Neurons Attenuates Neuropathic Pain in Mice: Role of Autophagy. Neurobiol. Dis. 96, 294-311. doi:10.1016/j.nbd.2016.09.010

Anand, N., Holcom, A., Broussalian, M., Schmidt, M., Chinta, S. J., Lithgow, G. J. et al. (2020). Dysregulated Iron Metabolism in C. elegans catp-6/ATP13A2 
Mutant Impairs Mitochondrial Function. Neurobiol. Dis. 139, 104786. doi:10. 1016/j.nbd.2020.104786

Appu, A. P., Bagh, M. B., Sadhukhan, T., Mondal, A., Casey, S., and Mukherjee, A. B. (2019). Cln3 -mutations Underlying Juvenile Neuronal Ceroid Lipofuscinosis Cause Significantly Reduced Levels of Palmitoyl-protein Thioesterases-1 (Ppt1)-protein and Ppt1-enzyme Activity in the Lysosome. Jrnl Inher Metab. Disea 42, 944-954. doi:10.1002/jimd.12106

Atiskova, Y., Bartsch, S., Danyukova, T., Becker, E., Hagel, C., Storch, S., et al. (2019). Mice Deficient in the Lysosomal Enzyme Palmitoyl-Protein Thioesterase 1 (PPT1) Display a Complex Retinal Phenotype. Sci. Rep. 9, 14185. doi:10.1038/s41598-019-50726-8

Bae, E. J., Yang, N. Y., Lee, C., Kim, S., Lee, H. J., and Lee, S. J. (2015). Haploinsufficiency of Cathepsin D Leads to Lysosomal Dysfunction and Promotes Cell-To-Cell Transmission of $\alpha$-synuclein Aggregates. Cell. Death Dis. 6, e1901. doi:10.1038/cddis.2015.283

Bagh, M. B., Peng, S., Chandra, G., Zhang, Z., Singh, S. P., Pattabiraman, N., et al. (2017). Misrouting of V-ATPase Subunit V0a1 Dysregulates Lysosomal Acidification in a Neurodegenerative Lysosomal Storage Disease Model. Nat. Commun. 8, 14612. doi:10.1038/ncomms14612

Bahrami-B, F., Ataie-Kachoie, P., Pourgholami, M. H., and Morris, D. L. (2014). P70 Ribosomal Protein S6 Kinase (Rps6kb1): An Update. J. Clin. Pathol. 67, 1019-1025. doi:10.1136/jclinpath-2014-202560

Bajaj, L., Sharma, J., di Ronza, A., Zhang, P., Eblimit, A., Pal, R., et al. (2020). A CLN6-CLN8 Complex Recruits Lysosomal Enzymes at the ER for Golgi Transfer. J. Clin. Invest. 130, 4118-4132. doi:10.1172/JCI130955

Basak, I., Hansen, R. A., Ward, M. E., and Hughes, S. M. (2021a). Deficiency of the Lysosomal Protein CLN5 Alters Lysosomal Function and Movement. Biomolecules 11, 1412. doi:10.3390/biom 11101412

Basak, I., Wicky, H. E., McDonald, K. O., Xu, J. B., Palmer, J. E., Best, H. L., et al. (2021b). A Lysosomal enigma CLN5 and its Significance in Understanding Neuronal Ceroid Lipofuscinosis. Cell. Mol. Life Sci. 78, 4735-4763. doi:10.1007/ s00018-021-03813-x

Beck-Wödl, S., Harzer, K., Sturm, M., Buchert, R., Rieß, O., Mennel, H. D., et al. (2018). Homozygous TBC1 Domain-Containing Kinase (TBCK) Mutation Causes a Novel Lysosomal Storage Disease - a New Type of Neuronal Ceroid Lipofuscinosis (CLN15)? Acta Neuropathol. Commun. 6, 145. doi:10. 1186/s40478-018-0646-6

Benes, P., Vetvicka, V., and Fusek, M. (2008). Cathepsin D-Many Functions of One Aspartic Protease. Crit. Rev. Oncology/Hematology 68, 12-28. doi:10.1016/j. critrevonc.2008.02.008

Benitez, B. A., and Sands, M. S. (2017). Primary Fibroblasts from CSPa Mutation Carriers Recapitulate Hallmarks of the Adult Onset Neuronal Ceroid Lipofuscinosis. Sci. Rep. 7, 6332. doi:10.1038/s41598-017-06710-1

Bento, C. F., Renna, M., Ghislat, G., Puri, C., Ashkenazi, A., Vicinanza, M., et al. (2016b). Mammalian Autophagy: How Does it Work? Annu. Rev. Biochem. 85, 685-713. doi:10.1146/annurev-biochem-060815-014556

Bento, C. F., Ashkenazi, A., Jimenez-Sanchez, M., and Rubinsztein, D. C. (2016a). The Parkinson's Disease-Associated Genes ATP13A2 and SYT11 Regulate Autophagy via a Common Pathway. Nat. Commun. 7, 11803. doi:10.1038/ ncomms 11803

Best, H. L., Neverman, N. J., Wicky, H. E., Mitchell, N. L., Leitch, B., and Hughes, S. M. (2017). Characterisation of Early Changes in Ovine CLN5 and CLN6 Batten Disease Neural Cultures for the Rapid Screening of Therapeutics. Neurobiol. Dis. 100, 62-74. doi:10.1016/j.nbd.2017.01.001

Bossy, B., Perkins, G., and Bossy-Wetzel, E. (2008). Clearing the Brains Cobwebs: The Role of Autophagy in Neuroprotection. Curr. Neuropharmacol 6, 97-101. doi:10.2174/157015908784533897

Boyer-Guittaut, M., Poillet, L., Liang, Q., Bôle-Richard, E., Ouyang, X., Benavides, G. A., et al. (2014). The Role of GABARAPL1/GEC1 in Autophagic Flux and Mitochondrial Quality Control in MDA-MB-436 Breast Cancer Cells. Autophagy 10, 986-1003. doi:10.4161/auto.28390

Brandenstein, L., Schweizer, M., Sedlacik, J., Fiehler, J., and Storch, S. (2016). Lysosomal Dysfunction and Impaired Autophagy in a Novel Mouse Model Deficient for the Lysosomal Membrane Protein Cln7. Hum. Mol. Genet. 25, 777-791. doi:10.1093/hmg/ddv615

Bras, J., Verloes, A., Schneider, S. A., Mole, S. E., and Guerreiro, R. J. (2012). Mutation of the Parkinsonism Gene ATP13A2 Causes Neuronal CeroidLipofuscinosis. Hum. Mol. Genet. 21, 2646-2650. doi:10.1093/hmg/dds089
Braulke, T., and Bonifacino, J. S. (2009). Sorting of Lysosomal Proteins. Biochim. Biophys. Acta (Bba) - Mol. Cel Res. 1793, 605-614. doi:10.1016/j.bbamcr.2008. 10.016

Bucci, C., Bakke, O., and Progida, C. (2010). Rab7b and Receptors Trafficking. Communicative Integr. Biol. 3, 401-404. doi:10.4161/cib.3.5.12341

Bunk, J., Prieto Huarcaya, S., Drobny, A., Dobert, J. P., Walther, L., Rose-John, S., et al. (2021). Cathepsin D Variants Associated with Neurodegenerative Diseases Show Dysregulated Functionality and Modified $\alpha$-Synuclein Degradation Properties. Front. Cel Dev. Biol. 9, 581805. doi:10.3389/fcell.2021.581805

Burré, J., Sharma, M., Tsetsenis, T., Buchman, V., Etherton, M. R., and Südhof, T. C. (2010). $\alpha$-Synuclein Promotes SNARE-Complex Assembly In Vivo and In Vitro. Science 329, 1663-1667. doi:10.1126/science.1195227

Cadieux-Dion, M., Andermann, E., Lachance-Touchette, P., Ansorge, O., Meloche, C., Barnabé, A., et al. (2013). Recurrent Mutations inDNAJC5cause Autosomal Dominant Kufs Disease. Clin. Genet. 83, 571-575. doi:10.1111/cge.12020

Calvo-Garrido, J., Carilla-Latorre, S., Kubohara, Y., Santos-Rodrigo, N., Mesquita, A., Soldati, T., et al. (2010). Autophagy in Dictyostelium: Genes and Pathways, Cell Death and Infection. Autophagy 6, 686-701. doi:10.4161/auto.6.6.12513

Cannelli, N., Garavaglia, B., Simonati, A., Aiello, C., Barzaghi, C., Pezzini, F., et al. (2009). Variant Late Infantile Ceroid Lipofuscinoses Associated with Novel Mutations in CLN6. Biochem. Biophysical Res. Commun. 379, 892-897. doi:10. 1016/j.bbrc.2008.12.159

Cannelli, N., Nardocci, N., Cassandrini, D., Morbin, M., Aiello, C., Bugiani, M., et al. (2007). Revelation of a Novel CLN5 Mutation in Early Juvenile Neuronal Ceroid Lipofuscinosis. Neuropediatrics 38, 46-49. doi:10.1055/s-2007-981449

Cantalupo, G., Alifano, P., Roberti, V., Bruni, C. B., and Bucci, C. (2001). Rabinteracting Lysosomal Protein (RILP): The Rab7 Effector Required for Transport to Lysosomes. EMBO. J. 20, 683-693. doi:10.1093/emboj/20.4.683

Canuel, M., Korkidakis, A., Konnyu, K., and Morales, C. R. (2008). Sortilin Mediates the Lysosomal Targeting of Cathepsins D and H. Biochem. Biophysical Res. Commun. 373, 292-297. doi:10.1016/j.bbrc.2008.06.021

Cao, Y., Espinola, J. A., Fossale, E., Massey, A. C., Cuervo, A. M., MacDonald, M. E., et al. (2006). Autophagy Is Disrupted in a Knock-In Mouse Model of Juvenile Neuronal Ceroid Lipofuscinosis. J. Biol. Chem. 281, 20483-20493. doi:10.1074/ jbc.m602180200

Cárcel-Trullols, J., Kovács, A. D., and Pearce, D. A. (2015). Cell Biology of the NCL Proteins: What They Do and Don't Do. Biochim. Biophys. Acta 1852, 2242-2255. doi:10.1016/j.bbadis.2015.04.027

Carew, J. S., Espitia, C. M., Esquivel, J. A., Mahalingam, D., Kelly, K. R., Reddy, G., et al. (2011). Lucanthone Is a Novel Inhibitor of Autophagy that Induces Cathepsin D-Mediated Apoptosis. J. Biol. Chem. 286, 6602-6613. doi:10.1074/ jbc.m110.151324

Chakrama, F. Z., Seguin-Py, S., Le Grand, J. N., Fraichard, A., Delage-Mourroux, R., Despouy, G., et al. (2010). GABARAPL1 (GEC1) Associates with Autophagic Vesicles. Autophagy 6, 495-505. doi:10.4161/auto.6.4.11819

Chandra, S., Gallardo, G., Fernández-Chacón, R., Schlüter, O. M., and Südhof, T. C. (2005). a-Synuclein Cooperates with CSPa in Preventing Neurodegeneration. Cell 123, 383-396. doi:10.1016/j.cell.2005.09.028

Chandrachud, U., Walker, M. W., Simas, A. M., Heetveld, S., Petcherski, A., Klein, M., et al. (2015). Unbiased Cell-Based Screening in a Neuronal Cell Model of Batten Disease Highlights an Interaction between Ca2+ Homeostasis, Autophagy, and CLN3 Protein Function. J. Biol. Chem. 290, 14361-14380. doi:10.1074/jbc.m114.621706

Chang, J.-W., Choi, H., Cotman, S. L., and Jung, Y.-K. (2011). Lithium Rescues the Impaired Autophagy Process in $\mathrm{CbCln} 3 \Delta$ ex $7 / 8 / \Delta$ ex $7 / 8$ Cerebellar Cells and Reduces Neuronal Vulnerability to Cell Death via IMPase Inhibition. J. Neurochem. 116, 659-668. doi:10.1111/j.1471-4159.2010.07158.x

Chang, M. C., Srinivasan, K., Friedman, B. A., Suto, E., Modrusan, Z., Lee, W. P., et al. (2017). Progranulin Deficiency Causes Impairment of Autophagy and TDP-43 Accumulation. J. Exp. Med. 214, 2611-2628. doi:10.1084/jem. 20160999

Chattopadhyay, S., Roberts, P. M., and Pearce, D. A. (2003). The Yeast Model for Batten Disease: a Role for Btn2p in the Trafficking of the Golgi-Associated Vesicular Targeting Protein, Yiflp. Biochem. Biophysical Res. Commun. 302, 534-538. doi:10.1016/s0006-291x(03)00209-2

Chen, Q., Zhong, L., Zhou, C., Feng, Y., Liu, Q.-x., Zhou, D., et al. (2020). Knockdown of Parkinson's Disease-Related Gene ATP13A2 Reduces 
Tumorigenesis via Blocking Autophagic Flux in colon Cancer. Cell. Biosci. 10, 144. doi:10.1186/s13578-020-00506-z

Chen, Y., and Yu, L. (2013). Autophagic Lysosome Reformation. Exp. Cel Res. 319, 142-146. doi:10.1016/j.yexcr.2012.09.004

Cho, S., and Dawson, G. (2000). Palmitoyl Protein Thioesterase 1 Protects against Apoptosis Mediated by Ras-Akt-Caspase Pathway in Neuroblastoma Cells. J. Neurochem. 74, 1478-1488. doi:10.1046/j.1471-4159.2000.0741478.x

Chong, J. X., Caputo, V., Phelps, I. G., Stella, L., Worgan, L., Dempsey, J. C., et al. (2016). Recessive Inactivating Mutations in TBCK, Encoding a Rab GTPaseActivating Protein, Cause Severe Infantile Syndromic Encephalopathy. Am. J. Hum. Genet. 98, 772-781. doi:10.1016/j.ajhg.2016.01.016

Codlin, S., and Mole, S. E. (2009). S. pombe Btn1, the Orthologue of the Batten Disease geneCLN3, Is Required for Vacuole Protein Sorting of Cpylp and Golgi Exit of Vps10p. J. Cel Sci 122, 1163-1173. doi:10.1242/jcs.038323

Connolly, K. J., O'Hare, M. B., Mohammed, A., Aitchison, K. M., Anthoney, N. C., Taylor, M. J., et al. (2019). The Neuronal Ceroid Lipofuscinosis Protein Cln7 Functions in the Postsynaptic Cell to Regulate Synapse Development. Sci. Rep. 9, 15592. doi:10.1038/s41598-019-51588-w

Cotman, S. L., and Lefrancois, S. (2021). CLN3, at the Crossroads of Endocytic Trafficking. Neurosci. Lett. 762, 136117. doi:10.1016/j.neulet.2021.136117

Crabtree, D., Dodson, M., Ouyang, X., Boyer-Guittaut, M., Liang, Q., Ballestas, M. E., et al. (2014). Over-expression of an Inactive Mutant Cathepsin D Increases Endogenous Alpha-Synuclein and Cathepsin B Activity in SH-Sy5y Cells. J. Neurochem. 128, 950-961. doi:10.1111/jnc.12497

Croce, K. R., and Yamamoto, A. (2019). A Role for Autophagy in Huntington's Disease. Neurobiol. Dis. 122, 16-22. doi:10.1016/j.nbd.2018.08.010

Danyukova, T., Ariunbat, K., Thelen, M., Brocke-Ahmadinejad, N., Mole, S. E., and Storch, S. (2018). Loss of CLN7 Results in Depletion of Soluble Lysosomal Proteins and Impaired mTOR Reactivation. Hum. Mol. Genet. 27, 1711-1722. doi:10.1093/hmg/ddy076

Davis, S. E., Roth, J. R., Aljabi, Q., Hakim, A. R., Savell, K. E., Day, J. J., et al. (2021). Delivering Progranulin to Neuronal Lysosomes Protects against Excitotoxicity. J. Biol. Chem. 297, 100993. doi:10.1016/j.jbc.2021.100993

Daya, M., Loilome, W., Techasen, A., Thanee, M., Sa-Ngiamwibool, P., Titapun, A., et al. (2018). Progranulin Modulates Cholangiocarcinoma Cell Proliferation, Apoptosis, and Motility via the PI3K/pAkt Pathway. Onco Targets Ther. 11, 395-408. doi:10.2147/ott.s155511

Decker, R. S., Poole, A. R., and Wildenthal, K. (1980). Distribution of Lysosomal Cathepsin D in Normal, Ischemic, and Starved Rabbit Cardiac Myocytes. Circ. Res. 46, 485-494. doi:10.1161/01.res.46.4.485

Dehay, B., Ramirez, A., Martinez-Vicente, M., Perier, C., Canron, M. H., Doudnikoff, E., et al. (2012b). Loss of P-type ATPase ATP13A2/PARK9 Function Induces General Lysosomal Deficiency and Leads to Parkinson Disease neurodegenerationATP13A2/PARK9 Regulates Endo-/lysosomal Cargo Sorting and Proteostasis through a Novel PI(3, 5)P2-Mediated Scaffolding Function. Proc. Natl. Acad. Sci. U S Ahum. Mol. Genet. 10926, 9611-9616. doi:10.1073/pnas.1112368109

Dehay, B., Martinez-Vicente, M., Ramirez, A., Perier, C., Klein, C., Vila, M., et al. (2012a). Lysosomal Dysfunction in Parkinson Disease. Autophagy 8, 1389-1391. doi:10.4161/auto.21011

Demirsoy, S., Martin, S., Motamedi, S., van Veen, S., Holemans, T., Van den Haute, C., et al. (2017). ATP13A2/PARK9 Regulates Endo-/Lysosomal Cargo Sorting and Proteostasis Through a Novel PI( 3,5$)$ P2-Mediated Scaffolding Function. Hum. Mol. Genet. 26, 1656-1669.

Deng, W., Li, Y., Ren, Z., He, Q., Jia, Y., Liu, Y., et al. (2020). Thioredoxininteracting Protein: a Critical Link between Autophagy Disorders and Pancreatic $\beta$-cell Dysfunction. Endocrine 70, 526-537. doi:10.1007/s12020020-02471-6

Di Malta, C., Cinque, L., and Settembre, C. (2019). Transcriptional Regulation of Autophagy: Mechanisms and Diseases. Front. Cel Dev. Biol. 7, 114. doi:10.3389/ fcell.2019.00114

di Ronza, A., Bajaj, L., Sharma, J., Sanagasetti, D., Lotfi, P., Adamski, C. J., et al. (2018). CLN8 Is an Endoplasmic Reticulum Cargo Receptor that Regulates Lysosome Biogenesis. Nat. Cel. Biol. 20, 1370-1377. doi:10.1038/s41556-0180228-7

Di, Y. Q., Han, X. L., Kang, X. L., Wang, D., Chen, C. H., Wang, J. X., et al. (2021). Autophagy Triggers CTSD (Cathepsin D) Maturation and Localization inside
Cells to Promote Apoptosis. Autophagy 17, 1170-1192. doi:10.1080/15548627. 2020.1752497

Dibble, C. C., and Cantley, L. C. (2015). Regulation of mTORC1 by PI3K Signaling. Trends Cel Biol. 25, 545-555. doi:10.1016/j.tcb.2015.06.002

Doccini, S., Morani, F., Nesti, C., Pezzini, F., Calza, G., Soliymani, R., et al. (2020). Proteomic and Functional Analyses in Disease Models Reveal CLN5 Protein Involvement in Mitochondrial Dysfunction. Cell Death Discov. 6, 18. doi:10. 1038/s41420-020-0250-y

Domowicz, M. S., Chan, W. C., Claudio-Vázquez, P., Henry, J. G., Ware, C. B., Andrade, J., et al. (2019). Global Brain Transcriptome Analysis of a Tpp1 Neuronal Ceroid Lipofuscinoses Mouse Model. ASN. Neuro. 11, 1759091419843393. doi:10.1177/1759091419843393

Dooley, H. C., Razi, M., Polson, H. E. J., Girardin, S. E., Wilson, M. I., and Tooze, S. A. (2014). WIPI2 Links LC3 Conjugation with PI3P, Autophagosome Formation, and Pathogen Clearance by Recruiting Atg12-5-16L1. Mol. Cel 55, 238-252. doi:10.1016/j.molcel.2014.05.021

Elia, L. P., Mason, A. R., Alijagic, A., and Finkbeiner, S. (2019). Genetic Regulation of Neuronal Progranulin Reveals a Critical Role for the Autophagy-Lysosome Pathway. J. Neurosci. 39, 3332-3344. doi:10.1523/jneurosci.3498-17.2019

Erickson, A. H. (1989). Biosynthesis of Lysosomal Endopeptidases. J. Cel. Biochem. 40, 31-41. doi:10.1002/jcb.240400104

Ezaki, J., Takeda-Ezaki, M., Koike, M., Ohsawa, Y., Taka, H., Mineki, R., et al. (2003). Characterization of Cln3p, the Gene Product Responsible for Juvenile Neuronal Ceroid Lipofuscinosis, as a Lysosomal Integral Membrane Glycoprotein. J. Neurochem. 87, 1296-1308. doi:10.1046/j.1471-4159.2003. 02132.x

Faust, P. L., Kornfeld, S., and Chirgwin, J. M. (1985). Cloning and Sequence Analysis of cDNA for Human Cathepsin D. Proc. Natl. Acad. Sci. 82, 4910-4914. doi:10.1073/pnas.82.15.4910

Feng, Y., He, D., Yao, Z., and Klionsky, D. J. (2014). The Machinery of Macroautophagy. Cell. Res. 24, 24-41. doi:10.1038/cr.2013.168

Festa, B. P., Barbosa, A. D., Rob, M., and Rubinsztein, D. C. (2021). The Pleiotropic Roles of Autophagy in Alzheimer's Disease: From Pathophysiology to Therapy. Curr. Opin. Pharmacol. 60, 149-157. doi:10.1016/j.coph.2021.07.011

Fossale, E., Wolf, P., Espinola, J. A., Lubicz-Nawrocka, T., Teed, A. M., Gao, H., et al. (2004). Membrane Trafficking and Mitochondrial Abnormalities Precede Subunit C Deposition in a Cerebellar Cell Model of Juvenile Neuronal Ceroid Lipofuscinosis. BMC. Neurosci. 5, 57. doi:10.1186/1471-2202-5-57

Fujimoto, M., Hayashi, T., and Su, T.-P. (2012). The Role of Cholesterol in the Association of Endoplasmic Reticulum Membranes with Mitochondria. Biochem. Biophysical Res. Commun. 417, 635-639. doi:10.1016/j.bbrc.2011. 12.022

Fujita, N., Itoh, T., Omori, H., Fukuda, M., Noda, T., and Yoshimori, T. (2008). The Atg16L Complex Specifies the Site of LC3 Lipidation for Membrane Biogenesis in Autophagy. MBoC 19, 2092-2100. doi:10.1091/mbc.e07-12-1257

Gachet, Y., Codlin, S., Hyams, J. S., and Mole, S. E. (2005). btn1, theSchizosaccharomyces Pombehomologue of the Human Batten Disease geneCLN3, Regulates Vacuole Homeostasis. J. Cel. Sci. 118, 5525-5536. doi:10.1242/jcs.02656

Gao, Z., Xie, H., Jiang, Q., Wu, N., Chen, X., and Chen, Q. (2018). Identification of Two Novel Null Variants in CLN8 by Targeted Next-Generation Sequencing: First Report of a Chinese Patient with Neuronal Ceroid Lipofuscinosis Due to CLN8 Variants. BMC. Med. Genet. 19, 21. doi:10.1186/s12881-018-0535-7

Geier, E. G., Bourdenx, M., Storm, N. J., Cochran, J. N., Sirkis, D. W., Hwang, J.-H., et al. (2019). Rare Variants in the Neuronal Ceroid Lipofuscinosis Gene MFSD8 Are Candidate Risk Factors for Frontotemporal Dementia. Acta Neuropathol. 137, 71-88. doi:10.1007/s00401-018-1925-9

Getty, A., Kovács, A. D., Lengyel-Nelson, T., Cardillo, A., Hof, C., Chan, C.-H., et al. (2013). Osmotic Stress Changes the Expression and Subcellular Localization of the Batten Disease Protein CLN3. Plos. One. 8, e66203. doi:10.1371/journal.pone. 0066203

Glick, D., Barth, S., and Macleod, K. F. (2010). Autophagy: Cellular and Molecular Mechanisms. J. Pathol. 221, 3-12. doi:10.1002/path.2697

Gong, F., Peng, X., Sang, Y., Qiu, M., Luo, C., He, Z., et al. (2013). Dichloroacetate Induces Protective Autophagy in LoVo Cells: Involvement of Cathepsin D/thioredoxin-like Protein 1 and Akt-mTOR-Mediated Signaling. Cel. Death Dis. 4, e913. doi:10.1038/cddis.2013.438 
Grubman, A., Pollari, E., Duncan, C., Caragounis, A., Blom, T., Volitakis, I., et al. (2014). Deregulation of Biometal Homeostasis: The Missing Link for Neuronal Ceroid Lipofuscinoses? Metallomics 6, 932-943. doi:10.1039/c4mt00032c

Guo, F., Liu, X., Cai, H., and Le, W. (2018). Autophagy in Neurodegenerative Diseases: Pathogenesis and Therapy. Brain Pathol. 28, 3-13. doi:10.1111/bpa. 12545

Guo, Q., Xu, L., Li, H., Sun, H., Liu, J., Wu, S., et al. (2017). Progranulin Causes Adipose Insulin Resistance via Increased Autophagy Resulting from Activated Oxidative Stress and Endoplasmic Reticulum Stress. Lipids Health Dis. 16, 25-28. doi:10.1186/s12944-017-0425-6

Gusdon, A. M., Zhu, J., Van Houten, B., and Chu, C. T. (2012). ATP13A2 Regulates Mitochondrial Bioenergetics through Macroautophagy. Neurobiol. Dis. 45, 962-972. doi:10.1016/j.nbd.2011.12.015

Haddad, S. E., Khoury, M., Daoud, M., Kantar, R., Harati, H., Mousallem, T., et al. (2012). CLN5 and CLN8 Protein Association with Ceramide Synthase: Biochemical and Proteomic Approaches. Electrophoresis 33, 3798-3809. doi:10.1002/elps.201200472

Hah, Y.-S., Noh, H. S., Ha, J. H., Ahn, J. S., Hahm, J. R., Cho, H. Y., et al. (2012). Cathepsin D Inhibits Oxidative Stress-Induced Cell Death via Activation of Autophagy in Cancer Cells. Cancer Lett. 323, 208-214. doi:10.1016/j.canlet. 2012.04.012

Haskell, R. E., Derksen, T. A., and Davidson, B. L. (1999). Intracellular Trafficking of the JNCL Protein CLN3. Mol. Genet. Metab. 66, 253-260. doi:10.1006/mgme. 1999.2802

Hasui, K., Wang, J., Jia, X., Tanaka, M., Nagai, T., Matsuyama, T., et al. (2011). Enhanced Autophagy and Reduced Expression of Cathepsin D Are Related to Autophagic Cell Death in Epstein-Barr Virus-Associated Nasal Natural Killer/ T-Cell Lymphomas: An Immunohistochemical Analysis of Beclin-1, LC3, Mitochondria (AE-1), and Cathepsin D in Nasopharyngeal Lymphomas. Acta Histochem. Cytochem. 44, 119-131. doi:10.1267/ahc.10024

Hellsten, E., Vesa, J., Olkkonen, V. M., Jalanko, A., and Peltonen, L. (1996). Human Palmitoyl Protein Thioesterase: Evidence for Lysosomal Targeting of the Enzyme and Disturbed Cellular Routing in Infantile Neuronal Ceroid Lipofuscinosis. EMBO J. 15, 5240-5245. doi:10.1002/j.1460-2075.1996. tb00909.x

Holler, C. J., Taylor, G., McEachin, Z. T., Deng, Q., Watkins, W. J., Hudson, K., et al. (2016). Trehalose Upregulates Progranulin Expression in Human and Mouse Models of GRN Haploinsufficiency: A Novel Therapeutic lead to Treat Frontotemporal Dementia. Mol. Neurodegeneration 11, 46. doi:10.1186/ s13024-016-0114-3

Hong, M., Song, K. D., Lee, H.-K., Yi, S., Lee, Y. S., Heo, T.-H., et al. (2016). Fibrates Inhibit the Apoptosis of Batten Disease Lymphoblast Cells via Autophagy Recovery and Regulation of Mitochondrial Membrane Potential. In Vitro Cell.Dev.Biol.-Animal 52, 349-355. doi:10.1007/s11626-015-9979-7

Hou, X., Watzlawik, J. O., Fiesel, F. C., and Springer, W. (2020). Autophagy in Parkinson's Disease. J. Mol. Biol. 432, 2651-2672. doi:10.1016/j.jmb.2020. 01.037

Huang, M., Modeste, E., Dammer, E., Merino, P., Taylor, G., Duong, D. M., et al. (2020). Network Analysis of the Progranulin-Deficient Mouse Brain Proteome Reveals Pathogenic Mechanisms Shared in Human Frontotemporal Dementia Caused by GRN Mutations. Acta Neuropathol. Commun. 8, 163. doi:10.1186/ s40478-020-01037-x

Huber, R. J., Hughes, S. M., Liu, W., Morgan, A., Tuxworth, R. I., and Russell, C. (2020). The Contribution of Multicellular Model Organisms to Neuronal Ceroid Lipofuscinosis Research. Biochim. Biophys. Acta (Bba) - Mol. Basis Dis. 1866, 165614. doi:10.1016/j.bbadis.2019.165614

Huber, R. J. (2017). Loss of Cln3 Impacts Protein Secretion in the Social Amoeba Dictyostelium. Cell Signal. 35, 61-72. doi:10.1016/j.cellsig.2017.03.022

Huber, R. J., and Mathavarajah, S. (2018a). Cln5 Is Secreted and Functions as a Glycoside Hydrolase in Dictyostelium. Cell Signal. 42, 236-248. doi:10.1016/j. cellsig.2017.11.001

Huber, R. J., and Mathavarajah, S. (2019). Comparative Transcriptomics Reveals Mechanisms Underlying Cln3-Deficiency Phenotypes in Dictyostelium. Cell Signal. 58, 79-90. doi:10.1016/j.cellsig.2019.02.004

Huber, R. J., and Mathavarajah, S. (2018b). Secretion and Function of Cln5 during the Early Stages of Dictyostelium Development. Biochim. Biophys. Acta (Bba) Mol. Cel Res. 1865, 1437-1450. doi:10.1016/j.bbamcr.2018.07.017
Huber, R. J., Myre, M. A., and Cotman, S. L. (2016). Aberrant Adhesion Impacts Early Development in a Dictyostelium Model for Juvenile Neuronal Ceroid Lipofuscinosis. Cell Adhes. Migration 11, 399-418. doi:10.1080/19336918.2016. 1236179

Huber, R. J., Myre, M. A., and Cotman, S. L. (2014). Loss of Cln3 Function in the Social Amoeba Dictyostelium discoideum Causes Pleiotropic Effects that Are Rescued by Human CLN3. PLoS One 9, e110544. doi:10.1371/journal.pone. 0110544

Huber, R. J. (2016). Using the Social Amoeba Dictyostelium to Study the Functions of Proteins Linked to Neuronal Ceroid Lipofuscinosis. J. Biomed. Sci. 23, 83. doi:10.1186/s12929-016-0301-0

Hughes, S. M., Hope, K. M., Xu, J. B., Mitchell, N. L., and Palmer, D. N. (2014). Inhibition of Storage Pathology in Prenatal CLN5-Deficient Sheep Neural Cultures by Lentiviral Gene Therapy. Neurobiol. Dis. 62, 543-550. doi:10. 1016/j.nbd.2013.11.011

Hurley, J. H., and Young, L. N. (2017). Mechanisms of Autophagy Initiation. Annu. Rev. Biochem. 86, 225-244. doi:10.110.1146/annurev-biochem061516-044820

Isosomppi, J., Vesa, J., Jalanko, A., and Peltonen, L. (2002). Lysosomal Localization of the Neuronal Ceroid Lipofuscinosis CLN5 Protein. Hum. Mol. Genet. 11, 885-891. doi:10.1093/hmg/11.8.885

Iwama, H., Mehanna, S., Imasaka, M., Hashidume, S., Nishiura, H., Yamamura, K.i., et al. (2021). Cathepsin B and D Deficiency in the Mouse Pancreas Induces Impaired Autophagy and Chronic Pancreatitis. Sci. Rep. 11, 6596. doi:10.1038/ s41598-021-85898-9

Jang, M., Park, R., Kim, H., Namkoong, S., Jo, D., Huh, Y. H., et al. (2018). AMPK Contributes to Autophagosome Maturation and Lysosomal Fusion. Sci. Rep. 8, 12637. doi:10.1038/s41598-018-30977-7

Järvelä, I., Sainio, M., Rantamäki, T., Olkkonen, V. M., Carpén, O., Peltonen, L., et al. (1998). Biosynthesis and Intracellular Targeting of the CLN3 Protein Defective in Batten Disease. Hum. Mol. Genet. 7, 85-90. doi:10.1093/hmg/7. 1.85

Jerič, B., Dolenc, I., Mihelič, M., Klarić, M., Zavašnik-Bergant, T., Gunčar, G., et al. (2013). N-terminally Truncated Forms of Human Cathepsin F Accumulate in Aggresome-like Inclusions. Biochim. Biophys. Acta 1833, 2254-2266. doi:10. 1016/j.bbamcr.2013.05.007

Johansson, A. C., Steen, H., and Pentikäinen, M. O. (2003). Cathepsin D Mediates Cytochrome C Release and Caspase Activation in Human Fibroblast Apoptosis Induced by Staurosporine. Cell. Death Diff. 10, 1253-1259. doi:10.1038/sj.cdd. 4401290

Johnston, J. A., Ward, C. L., and Kopito, R. R. (1998). Aggresomes: A Cellular Response to Misfolded Proteins. J. Cel. Biol. 143, 1883-1898. doi:10.1083/jcb. 143.7.1883

Jordens, I., Fernandez-Borja, M., Marsman, M., Dusseljee, S., Janssen, L., Calafat, J., et al. (2001). The Rab7 Effector Protein RILP Controls Lysosomal Transport by Inducing the Recruitment of Dynein-Dynactin Motors. Curr. Biol. 11, 1680-1685. doi:10.1016/s0960-9822(01)00531-0

Jules, F., Sauvageau, E., Dumaresq-doiron, K., Mazzaferri, J., Haug-Kröper, M., Fluhrer, R., et al. (2017). CLN5 Is Cleaved by Members of the SPP/SPPL Family to Produce a Mature Soluble Protein. Exp. Cel Res. 357, 40-50. doi:10.1016/j. yexcr.2017.04.024

Junaid, M. A., Wu, G., and Pullarkat, R. K. (2000). Purification and Characterization of Bovine Brain Lysosomal Pepstatin-Insensitive Proteinase, the Gene Product Deficient in the Human Late-Infantile Neuronal Ceroid Lipofuscinosis. J. Neurochem. 74, 287-294. doi:10.1046/j. 1471-4159.2000.0740287.x

Jung, C. H., Ro, S.-H., Cao, J., Otto, N. M., and Kim, D.-H. (2010). MTOR Regulation of Autophagy. FEBS. Lett. 584, 1287-1295. doi:10.1016/j.febslet. 2010.01.017

Kaakinen, R., Lindstedt, K. A., Sneck, M., Kovanen, P. T., and Öörni, K. (2007). Angiotensin II Increases Expression and Secretion of Cathepsin F in Cultured Human Monocyte-Derived Macrophages: An Angiotensin II Type 2 ReceptorMediated Effect. Atherosclerosis 192, 323-327. doi:10.1016/j.atherosclerosis. 2006.08.001

Kama, R., Kanneganti, V., Ungermann, C., and Gerst, J. E. (2011). The Yeast Batten Disease Orthologue Btn1 Controls Endosome-Golgi Retrograde Transport via SNARE Assembly. J. Cel. Biol. 195, 203-215. doi:10.1083/jcb.201102115 
Kang, R., Zeh, H. J., Lotze, M. T., and Tang, D. (2011). The Beclin 1 Network Regulates Autophagy and Apoptosis. Cell Death Differ 18, 571-580. doi:10. 1038/cdd.2010.191

Kanninen, K. M., Grubman, A., Caragounis, A., Duncan, C., Parker, S. J., Lidgerwood, G. E., et al. (2013). Altered Biometal Homeostasis Is Associated with CLN6 mRNA Loss in Mouse Neuronal Ceroid Lipofuscinosis. Biol. Open. 2, 635-646. doi:10.1242/bio.20134804

Kashyap, S. S., Johnson, J. R., McCue, H. V., Chen, X., Edmonds, M. J., Ayala, M., et al. (2014). Caenorhabditis elegans Dnj-14, the Orthologue of the DNAJC5 Gene Mutated in Adult Onset Neuronal Ceroid Lipofuscinosis, Provides a New Platform for Neuroprotective Drug Screening and Identifies a SIR-2.1independent Action of Resveratrol. Hum. Mol. Genet. 23, 5916-5927. doi:10. 1093/hmg/ddu316

Kett, L. R., Stiller, B., Bernath, M. M., Tasset, I., Blesa, J., Jackson-Lewis, V., et al. (2015). -Synuclein-Independent Histopathological and Motor Deficits in Mice Lacking the Endolysosomal Parkinsonism Protein Atp13a2. J. Neurosci. 35, 5724-5742. doi:10.1523/jneurosci.0632-14.2015

Ketterer, S., Mitschke, J., Ketscher, A., Schlimpert, M., Reichardt, W., Baeuerle, N., et al. (2020). Cathepsin D Deficiency in Mammary Epithelium Transiently Stalls Breast Cancer by Interference with mTORC1 Signaling. Nat. Commun. 11, 5133. doi:10.1038/s41467-020-18935-2

Kida, E., Kaczmarski, W., Golabek, A. A., Kaczmarski, A., Michalewski, M., and Wisniewski, K. E. (1999). Analysis of Intracellular Distribution and Trafficking of the CLN3 Protein in Fusion with the Green Fluorescent Proteinin Vitro. Mol. Genet. Metab. 66, 265-271. doi:10.1006/mgme.1999.2837

Kim, J., Kundu, M., Viollet, B., and Guan, K.-L. (2011). AMPK and mTOR Regulate Autophagy through Direct Phosphorylation of Ulk1. Nat. Cel. Biol. 13, 132-141. doi:10.1038/ncb2152

Kim, S.-J., Zhang, Z., Sarkar, C., Tsai, P.-C., Lee, Y.-C., Dye, L., et al. (2008). Palmitoyl Protein Thioesterase-1 Deficiency Impairs Synaptic Vesicle Recycling at Nerve Terminals, Contributing to Neuropathology in Humans and Mice. J. Clin. Invest. 118, 3075-3086. doi:10.1172/jci33482

Kinarivala, N., Morsy, A., Patel, R., Carmona, A. V., Sajib, M. S., Raut, S., et al. (2020). An iPSC-Derived Neuron Model of CLN3 Disease Facilitates Small Molecule Phenotypic Screening. ACS Pharmacol. Transl. Sci. 3, 931-947. doi:10. 1021/acsptsci.0c00077

Kjos, I., Borg Distefano, M., Sætre, F., Repnik, U., Holland, P., Jones, A. T., et al. (2017). Rab7b Modulates Autophagic Flux by Interacting with Atg4B. EMBO. Rep. 18, 1727-1739. doi:10.15252/embr.201744069

Kohan, R., Halac, I. N. d., Anzolini, V. T., Cismondi, A., Ramírez, A. M. O., Capra, A. P., et al. (2005). Palmitoyl Protein Thioesterasel (PPT1) and Tripeptidyl Peptidase-I (TPP-I) Are Expressed in the Human Saliva. A Reliable and Noninvasive Source for the Diagnosis of Infantile (CLN1) and Late Infantile (CLN2) Neuronal Ceroid Lipofuscinoses. Clin. Biochem. 38, 492-494. doi:10.1016/j. clinbiochem.2004.12.007

Kousi, M., Anttila, V., Schulz, A., Calafato, S., Jakkula, E., Riesch, E., et al. (2012). Novel Mutations consolidateKCTD7as a Progressive Myoclonus Epilepsy Gene. J. Med. Genet. 49, 391-399. doi:10.1136/jmedgenet-2012-100859

Kovács, A. D., Hof, C., and Pearce, D. A. (2015). Abnormally Increased Surface Expression of AMPA Receptors in the Cerebellum, Cortex and Striatum of Cln3 Mice. Neurosci. Lett. 607, 29-34. doi:10.1016/j.neulet.2015.09.012

Kremmidiotis, G., Lensink, I. L., Bilton, R. L., Woollatt, E., Chataway, T. K., Sutherland, G. R., et al. (1999). The Batten Disease Gene Product (CLN3p) Is a Golgi Integral Membrane Protein. Hum. Mol. Genet. 8, 523-531. doi:10.1093/ $\mathrm{hmg} / 8.3 .523$

Kuchitsu, Y., and Fukuda, M. (2018). Revisiting Rab7 Functions in Mammalian Autophagy: Rab7 Knockout Studies. Cells 7, 215. doi:10.3390/cells7110215

Lau, C. G., Takayasu, Y., Rodenas-Ruano, A., Paternain, A. V., Lerma, J., Bennett, M. V. L., et al. (2010). SNAP-25 Is a Target of Protein Kinase C Phosphorylation Critical to NMDA Receptor Trafficking. J. Neurosci. 30, 242-254. doi:10.1523/ jneurosci.4933-08.2010

Lawrence, R. E., and Zoncu, R. (2019). The Lysosome as a Cellular centre for Signalling, Metabolism and Quality Control. Nat. Cel. Biol. 21, 133-142. doi:10. 1038/s41556-018-0244-7

Lee, J., Xu, Y., Saidi, L., Xu, M., Zinsmaier, K., and Ye, Y. (2021). Abnormal Triaging of Misfolded Proteins by Adult Neuronal Ceroid LipofuscinosisAssociated CSPa Mutants Causes Lipofuscin Accumulation. BioRXiv [Preprint].
Lehtovirta, M., Kyttälä, A., Eskelinen, E. L., Hess, M., Heinonen, O., and Jalanko, A. (2001). Palmitoyl Protein Thioesterase (PPT) Localizes into Synaptosomes and Synaptic Vesicles in Neurons: Implications for Infantile Neuronal Ceroid Lipofuscinosis (INCL). Hum. Mol. Genet. 10, 69-75. doi:10.1093/hmg/10.1.69

Leinonen, H., Keksa-goldsteine, V., Ragauskas, S., Kohlmann, P., Sing, Y., Savchenko, E., et al. (2017). Retinal Degeneration in A Mouse Model of CLN5 Disease Is Associated with Compromised Autophagy. Sci. Rep. 7, 1597. doi:10.1038/s41598-017-01716-1

Levine, B., and Klionsky, D. J. (2004). Development by Self-Digestion. Develop. Cel 6, 463-477. doi:10.1016/s1534-5807(04)00099-1

Li, H., Zhou, B., Xu, L., Liu, J., Zang, W., Wu, S., et al. (2014). Circulating PGRN Is Significantly Associated with Systemic Insulin Sensitivity and Autophagic Activity in Metabolic Syndrome. Endocrinol 155, 3493-3507. doi:10.1210/en. 2014-1058

Li, W.-w., Li, J., and Bao, J.-k. (2012). Microautophagy: Lesser-Known Self-Eating. Cel. Mol. Life Sci. 69, 1125-1136. doi:10.1007/s00018-011-0865-5

Lin, L., Sohar, I., Lackland, H., and Lobel, P. (2001). The Human CLN2 Protein/ tripeptidyl-Peptidase I Is a Serine Protease that Autoactivates at Acidic pH. J. Biol. Chem. 276, 2249-2255. doi:10.1074/jbc.m008562200

Lippai, M., and Lőw, P. (2014). The Role of the Selective Adaptor P62 and Ubiquitin-like Proteins in Autophagy. Biomed. Res. Int. 2014, 832704. doi:10.1155/2014/832704

Liu, J., Li, H., Zhou, B., Xu, L., Kang, X., Yang, W., et al. (2015). PGRN Induces Impaired Insulin Sensitivity and Defective Autophagy in Hepatic Insulin Resistance. Mol. Endocrinol. 29, 528-541. doi:10.1210/me.2014-1266

Liu, M., Shan, M., Zhang, Y., and Guo, Z. (2021). Progranulin Protects against Airway Remodeling through the Modulation of Autophagy via HMGB1 Suppression in House Dust Mite-Induced Chronic Asthma. J. Inflamm. Res. 14, 3891-3904. doi:10.2147/jir.s322724

Liu, W. J., Ye, L., Huang, W. F., Guo, L. J., Xu, Z. G., Wu, H. L., et al. (2016). p62 Links the Autophagy Pathway and the Ubiqutin-Proteasome System upon Ubiquitinated Protein Degradation. Cell. Mol. Biol. Lett. 21, 29. doi:10.1186/ s11658-016-0031-z

Liu, Y., Yan, X., and Zhou, T. (2013). TBCK Influences Cell Proliferation, Cell Size and mTOR Signaling Pathway. Plos. One. 8, e71349. doi:10.1371/journal.pone. 0071349

Lojewski, X., Staropoli, J. F., Biswas-Legrand, S., Simas, A. M., Haliw, L., Selig, M. K., et al. (2014). Human iPSC Models of Neuronal Ceroid Lipofuscinosis Capture Distinct Effects of TPP1 and CLN3 Mutations on the Endocytic Pathway. Hum. Mol. Genet. 23, 2005-2022. doi:10.1093/hmg/ddt596

Lonka, L., Kyttälä, A., Ranta, S., Jalanko, A., and Lehesjoki, A. (2000). The Neuronal Ceroid Lipofuscinosis CLN8 Membrane Protein Is a Resident of the Endoplasmic Reticulum. Hum. Mol. Genet. 9, 1691-1697. doi:10.1093/hmg/ 9.11.1691

Lu, J. Y., Verkruyse, L. A., and Hofmann, S. L. (1996). Lipid Thioesters Derived from Acylated Proteins Accumulate in Infantile Neuronal Ceroid Lipofuscinosis: Correction of the Defect in Lymphoblasts by Recombinant Palmitoyl-Protein Thioesterase. Proc. Natl. Acad. Sci. 93, 10046-10050. doi:10. 1073/pnas.93.19.10046

Luiro, K., Kopra, O., Blom, T., Gentile, M., Mitchison, H. M., Hovatta, I., et al. (2006). Batten Disease (JNCL) Is Linked to Disturbances in Mitochondrial, Cytoskeletal, and Synaptic Compartments. J. Neurosci. Res. 84, 1124-1138. doi:10.1002/jnr.21015

Luiro, K., Yliannala, K., Ahtiainen, L., Maunu, H., Jarvela, I., Kyttala, A., et al. (2004). Interconnections of CLN3, Hook1 and Rab Proteins Link Batten Disease to Defects in the Endocytic Pathway. Hum. Mol. Genet. 13, 3017-3027. doi:10.1093/hmg/ddh321

Lyly, A., Marjavaara, S. K., Kyttälä, A., Uusi-Rauva, K., Luiro, K., Kopra, O., et al. (2008). Deficiency of the INCL Protein Pptl Results in Changes in Ectopic F1ATP Synthase and Altered Cholesterol Metabolism. Hum. Mol. Genet. 17, 1406-1417. doi:10.1093/hmg/ddn028

Lynes, E. M., Bui, M., Yap, M. C., Benson, M. D., Schneider, B., Ellgaard, L., et al. (20122012). Palmitoylated TMX and Calnexin Target to the MitochondriaAssociated Membrane. EMBO. J. 31, 457-470. doi:10.1038/emboj.2011.384

Ma, M., Guo, X., Chang, Y., Li, C., Meng, X., Li, S., et al. (2015). Advanced Glycation End Products Promote Proliferation and Suppress Autophagy via Reduction of Cathepsin D in Rat Vascular Smooth Muscle Cells. Mol. Cel. Biochem. 403, 73-83. doi:10.1007/s11010-015-2338-x 
Majeski, A. E., and Fred Dice, J. (2004). Mechanisms of Chaperone-Mediated Autophagy. Int. J. Biochem. Cel Biol. 36, 2435-2444. doi:10.1016/j.biocel.2004. 02.013

Mamo, A., Jules, F., Dumaresq-Doiron, K., Costantino, S., and Lefrancois, S. (2012). The Role of Ceroid Lipofuscinosis Neuronal Protein 5 (CLN5) in Endosomal Sorting. Mol. Cel. Biol. 32, 1855-1866. doi:10.1128/mcb. 06726-11

Manil-Ségalen, M., Lefebvre, C., Jenzer, C., Trichet, M., Boulogne, C., SatiatJeunemaitre, B., et al. (2014). The C. elegans LC3 Acts Downstream of GABARAP to Degrade Autophagosomes by Interacting with the HOPS Subunit VSP39. Dev. Cel. 28, 43-55. doi:10.1016/j.devcel.2013.11.022

Maria Cuervo, A. (2004). Autophagy: in Sickness and in Health. Trends Cel Biol. 14, 70-77. doi:10.1016/j.tcb.2003.12.002

Marques, A. R. A., Di Spiezio, A., Thießen, N., Schmidt, L., Grötzinger, J., Lüllmann-Rauch, R., et al. (2020). Enzyme Replacement Therapy with Recombinant Pro-CTSD (Cathepsin D) Corrects Defective Proteolysis and Autophagy in Neuronal Ceroid Lipofuscinosis. Autophagy 16, 811-825. doi:10. 1080/15548627.2019.1637200

Martina, J. A., Chen, Y., Gucek, M., and Puertollano, R. (2012). MTORC1 Functions as a Transcriptional Regulator of Autophagy by Preventing Nuclear Transport of TFEB. Autophagy 8, 903-914. doi:10.4161/auto.19653

Maruyama, T., and Noda, N. N. (2018). Autophagy-regulating Protease Atg4: Structure, Function, Regulation and Inhibition. J. Antibiot. 71, 72-78. doi:10. 1038/ja.2017.104

Mathavarajah, S., McLaren, M. D., and Huber, R. J. (2018). Cln3 Function is Linked to Osmoregulation in a Dictyostelium Model of Batten Disease. Biochim. Biophys. Acta. - Mol. Basis. Dis. 1864, 3559-3573.

Matsui, H., Sato, F., Sato, S., Koike, M., Taruno, Y., Saiki, S., et al. (2013). ATP13A2 Deficiency Induces a Decrease in Cathepsin D Activity, Fingerprint-like Inclusion Body Formation, and Selective Degeneration of Dopaminergic Neurons. FEBS. Lett. 587, 1316-1325. doi:10.1016/j.febslet.2013.02.046

McCue, H. V., Chen, X., Barclay, J. W., Morgan, A., and Burgoyne, R. D. (2015). Expression Profile of a Caenorhabditis elegans Model of Adult Neuronal Ceroid Lipofuscinosis Reveals Down Regulation of Ubiquitin E3 Ligase Components. Sci. Rep. 5, 14392. doi:10.1038/srep14392

McLaren, M. D., Mathavarajah, S., Kim, W. D., Yap, S. Q., and Huber, R. J. (2021). Aberrant Autophagy Impacts Growth and Multicellular Development in a Dictyostelium Knockout Model of CLN5 Disease. Front. Cel Dev. Biol. 9, 657406. doi:10.3389/fcell.2021.657406

Mesquita, A., Cardenal-Muñoz, E., Dominguez, E., Muñoz-Braceras, S., NuñezCorcuera, B., Phillips, B. A., et al. (2017). Autophagy in Dictyostelium: Mechanisms, Regulation and Disease in a Simple Biomedical Model. Autophagy 13, 24-40. doi:10.1080/15548627.2016.1226737

Metcalf, D. J., Calvi, A. A., Seaman, M. N., Mitchison, H. M., and Cutler, D. F. (2008). Loss of the Batten Disease Gene CLN3 Prevents Exit from the TGN of the Mannose 6-phosphate Receptor. Traffic 9, 1905-1914. doi:10.1111/j.16000854.2008.00807.x

Metcalf, P., and Fusek, M. (1993). Two crystal Structures for Cathepsin D: the Lysosomal Targeting Signal and Active Site. EMBO J. 12, 1293-1302. doi:10. 1002/j.1460-2075.1993.tb05774.x

Metz, K. A., Teng, X., Coppens, I., Lamb, H. M., Wagner, B. E., Rosenfeld, J. A., et al. (2018). KCTD7 Deficiency Defines a Distinct Neurodegenerative Disorder with a Conserved Autophagy-lysosome Defect. Ann. Neurol. 84, 766-780. doi:10.1002/ana.25351

Midorikawa, R., Yamamoto-Hino, M., Awano, W., Hinohara, Y., Suzuki, E., Ueda, R., et al. (2010). Autophagy-dependent Rhodopsin Degradation Prevents Retinal Degeneration in Drosophila. J. Neurosci. 30, 10703-10719. doi:10. 1523/jneurosci.2061-10.2010

Minnis, C. J., Thornton, C. D., FitzPatrick, L. M., and McKay, T. R. (2020). Cellular Models of Batten Disease. Biochim. Biophys. Acta (Bba) - Mol. Basis Dis. 1866, 165559. doi:10.1016/j.bbadis.2019.165559

Minnis, C. J., Townsend, S., Petschnigg, J., Tinelli, E., Bähler, J., Russell, C., et al. (2021). Global Network Analysis in Schizosaccharomyces pombe Reveals Three Distinct Consequences of the Common 1-kb Deletion Causing Juvenile CLN3 Disease. Sci. Rep. 11, 6332. doi:10.1038/s41598-021-85471-4

Mirza, M., Vainshtein, A., DiRonza, A., Chandrachud, U., Haslett, L. J., Palmieri, M., et al. (2019). The CLN3 Gene and Protein: What We Know. Mol. Genet. Genomic Med. 7, e859. doi:10.1002/mgg3.859
Missiroli, S., Bonora, M., Patergnani, S., Poletti, F., Perrone, M., Gafa, R., et al. (2016). PML at Mitochondria-Associated Membranes Is Critical for the Repression of Autophagy and Cancer Development. Cel Rep. 16, 2415-2427. doi:10.1016/j.celrep.2016.07.082

Mizushima, N., Ohsumi, Y., and Yoshimori, T. (2002). Autophagosome Formation in Mammalian Cells. Cell Struct. Funct. 27, 421-429. doi:10.1247/csf.27.421

Mizushima, N. (2010). The Role of the Atg1/ULK1 Complex in Autophagy Regulation. Curr. Opin. Cel Biol. 22, 132-139. doi:10.1016/j.ceb.2009.12.004

Mohan, S., Sampognaro, P. J., Argouarch, A. R., Maynard, J. C., Welch, M., Patwardhan, A., et al. (2021). Processing of Progranulin into Granulins Involves Multiple Lysosomal Proteases and Is Affected in Frontotemporal Lobar Degeneration. Mol. Neurodegeneration 16, 51. doi:10.1186/s13024-02100472-1

Moharir, A., Peck, S. H., Budden, T., and Lee, S. Y. (2013). The Role of N-Glycosylation in Folding, Trafficking, and Functionality of Lysosomal Protein CLN5. Plos. One. 8, e74299. doi:10.1371/journal.pone.0074299

Mohrmann, R., de Wit, H., Verhage, M., Neher, E., and Sørensen, J. B. (2010). Fast Vesicle Fusion in Living Cells Requires at Least Three SNARE Complexes. Science 330, 502-505. doi:10.1126/science.1193134

Mole, S. E., and Cotman, S. L. (2015). Genetics of the Neuronal Ceroid Lipofuscinoses (Batten Disease). Biochim. Biophys. Acta (Bba) - Mol. Basis Dis. 1852, 2237-2241. doi:10.1016/j.bbadis.2015.05.011

Mole, S. E., Michaux, G., Codlin, S., Wheeler, R. B., Sharp, J. D., and Cutler, D. F. (2004). CLN6, Which Is Associated with a Lysosomal Storage Disease, Is an Endoplasmic Reticulum Protein. Exp. Cel Res. 298, 399-406. doi:10.1016/j. yexcr.2004.04.042

Mrschtik, M., and Ryan, K. M. (2015). Lysosomal Proteins in Cell Death and Autophagy. FEBS. J. 282, 1858-1870. doi:10.1111/febs.13253

Munson, M. J., Allen, G. F., Toth, R., Campbell, D. G., Lucocq, J. M., and Ganley, I. G. (2015). mTOR Activates the VPS 34- UVRAG Complex to Regulate Autolysosomal Tubulation and Cell Survival. EMBO. J. 34, 2272-2290. doi:10.15252/embj.201590992

Nägler, D. K., Sulea, T., and Ménard, R. (1999). Full-Length cDNA of Human Cathepsin F Predicts the Presence of a Cystatin Domain at the N-Terminus of the Cysteine Protease Zymogen. Biochem. Biophys. Res. Commun. 257, 313-318.

Nakamura, S., and Yoshimori, T. (2017). New Insights into AutophagosomeLysosome Fusion. J. Cel. Sci. 130, 1209-1216. doi:10.1242/jcs.196352

Napolitano, G., Esposito, A., Choi, H., Matarese, M., Benedetti, V., Di Malta, C., et al. (2018). mTOR-Dependent Phosphorylation Controls TFEB Nuclear export. Nat. Commun. 9, 3312. doi:10.1038/s41467-018-05862-6

Nyuzuki, H., Ito, S., Nagasaki, K., Nitta, Y., Matsui, N., Saitoh, A., et al. (2020). Degeneration of Dopaminergic Neurons and Impaired Intracellular Trafficking in Atp13a2 Deficient Zebrafish. IBRO Rep. 9, 1-8. doi:10.1016/j.ibror.2020. 05.002

Oetjen, S., Kuhl, D., and Hermey, G. (2016). Revisiting the Neuronal Localization and Trafficking of CLN3 in Juvenile Neuronal Ceroid Lipofuscinosis. J. Neurochem. 139, 456-470. doi:10.1111/jnc.13744

Okazaki, N., Yan, J., Yuasa, S., Ueno, T., Kominami, E., Masuho, Y., et al. (2000). Interaction of the Unc-51-like Kinase and Microtubule-Associated Protein Light Chain 3 Related Proteins in the Brain: Possible Role of Vesicular Transport in Axonal Elongation. Mol. Brain Res. 85, 1-12. doi:10.1016/ s0169-328x (00)00218-7

Öörni, K., Sneck, M., Brömme, D., Pentikäinen, M. O., Lindstedt, K. A., Mäyränpää, M., et al. (2004). Cysteine Protease Cathepsin F Is Expressed in Human Atherosclerotic Lesions, Is Secreted by Cultured Macrophages, and Modifies Low Density Lipoprotein Particles In Vitro. J. Biol. Chem. 279, 34776-34784. doi:10.1074/jbc.M310814200

Palmer, D. N., Fearnley, I. M., Walker, J. E., Hall, N. A., Lake, B. D., Wolfe, L. S., et al. (1992). Mitochondrial ATP Synthase Subunitc Storage in the CeroidLipofuscinoses (Batten Disease). Am. J. Med. Genet. 42, 561-567. doi:10.1002/ ajmg. 1320420428

Palmieri, M., Pal, R., Nelvagal, H. R., Lotfi, P., Stinnett, G. R., Seymour, M. L., et al. (2017). MTORC1-independent TFEB Activation via Akt Inhibition Promotes Cellular Clearance in Neurodegenerative Storage Diseases. Nat. Commun. 8, 14338. doi:10.1038/ncomms 14338

Pankiv, S., Clausen, T. H., Lamark, T., Brech, A., Bruun, J.-A., Outzen, H., et al. (2007). P62/SQSTM1 Binds Directly to Atg8/LC3 to Facilitate Degradation of 
Ubiquitinated Protein Aggregates by Autophagy. J. Biol. Chem. 282, 24131-24145. doi:10.1074/jbc.m702824200

Pao, S. S., Paulsen, I. T., and Saier, M. H. (1998). Major Facilitator Superfamily. Microbiol. Mol. Biol. Rev. 62, 1-34. doi:10.1128/mmbr.62.1. 1-34.1998

Passantino, R., Cascio, C., Deidda, I., Galizzi, G., Russo, D., Spedale, G., et al. (2013). Identifying Protein Partners of CLN8, an ER-Resident Protein Involved in Neuronal Ceroid Lipofuscinosis. Biochim. Biophys. Acta (Bba) - Mol. Cel Res. 1833, 529-540. doi:10.1016/j.bbamcr.2012.10.030

Paushter, D. H., Du, H., Feng, T., and Hu, F. (2018). The Lysosomal Function of Progranulin, a Guardian against Neurodegeneration. Acta Neuropathol. 136, 1-17. doi:10.1007/s00401-018-1861-8

Persaud-Sawin, D.-A., McNamara, J. O., Rylova, S., Vandongen, A., and Boustany, R.-M. N. (2004). A Galactosylceramide Binding Domain Is Involved in Trafficking of CLN3 from Golgi to Rafts via Recycling Endosomes. Pediatr. Res. 56, 449-463. doi:10.1203/01.pdr.0000136152.54638.95

Petcherski, A., Chandrachud, U., Butz, E., Klein, M., Zhao, W.-N., Reis, S., et al. (2019). An Autophagy Modifier Screen Identifies Small Molecules Capable of Reducing Autophagosome Accumulation in a Model of CLN3-Mediated Neurodegeneration. Cells 8, 1531. doi:10.3390/cells8121531

Phillips, J. E., and Gomer, R. H. (2015). Partial Genetic Suppression of a Loss-OfFunction Mutant of the Neuronal Ceroid Lipofuscinosis-Associated Protease TPP1 in Dictyostelium discoideum. Dis. Model. Mech. 8, 147-156. doi:10.1242/ $\mathrm{dmm} .018820$

Poole, A. R., Hembry, R. M., and Dingle, J. T. (1973). Extracellular Localization of Cathepsin D in Ossifying Cartilage. Calc. Tis Res. 12, 313-321. doi:10.1007/ bf02013744

Progida, C., Cogli, L., Piro, F., De Luca, A., Bakke, O., and Bucci, C. (2010). Rab7b Controls Trafficking from Endosomes to the TGN. J. Cel. Sci. 123, 1480-1491. doi: $10.1242 /$ jcs. 051474

Puertollano, R. (2014). mTOR and Lysosome Regulation. F1000prime Rep. 6, 52. doi:10.12703/P6-52

Qi, X., Man, S. M., Malireddi, R. K. S., Karki, R., Lupfer, C., Gurung, P., et al. (2016). Cathepsin B Modulates Lysosomal Biogenesis and Host Defense against Francisella Novicida Infection. J. Exp. Med. 213, 2081-2097. doi:10.1084/ jem.20151938

Qian, M., Fang, X., and Wang, X. (2017). Autophagy and Inflammation. Clin. Transl. Med. 6, 24. doi:10.1186/s40169-017-0154-5

Quan, W., and Lee, M.-S. (2013). Role of Autophagy in the Control of Body Metabolism. Endocrinol. Metab. 28, 6-11. doi:10.3803/enm.2013.28.1.6

Rabanal-Ruiz, Y., Otten, E. G., and Korolchuk, V. I. (2017). MTORC1 as the Main Gateway to Autophagy. Essays. Biochem. 61, 565-584. doi:10.1042/ ebc20170027

Radke, J., Stenzel, W., and Goebel, H. H. (2015). Human NCL Neuropathology. Biochim. Biophys. Acta (Bba) - Mol. Basis Dis. 1852, 2262-2266. doi:10.1016/j. bbadis.2015.05.007

Rajagopalan, S., Rane, A., Chinta, S. J., and Andersen, J. K. (2016). Regulation of ATP13A2 via PHD2-HIF1 Signaling Is Critical for Cellular Iron Homeostasis: Implications for Parkinson's Disease. J. Neurosci. 36, 1086-1095. doi:10.1523/ jneurosci.3117-15.2016

Ramirez, A., Heimbach, A., Gründemann, J., Stiller, B., Hampshire, D., Cid, L. P., et al. (2006). Hereditary Parkinsonism with Dementia Is Caused by Mutations in ATP13A2, Encoding a Lysosomal Type 5 P-type ATPase. Nat. Genet. 38, 1184-1191. doi:10.1038/ng1884

Ramonet, D., Podhajska, A., Stafa, K., Sonnay, S., Trancikova, A., Tsika, E., et al. (2012). PARK9-associated ATP13A2 Localizes to Intracellular Acidic Vesicles and Regulates Cation Homeostasis and Neuronal Integrity. Hum. Mol. Genet. 21, 1725-1743. doi:10.1093/hmg/ddr606

Rebecca, V. W., Nicastri, M. C., Fennelly, C., Chude, C. I., Barber-Rotenberg, J. S., Ronghe, A., et al. (2019). PPT1 Promotes Tumor Growth and Is the Molecular Target of Chloroquine Derivatives in Cancer. Cancer Discov. 9, 220-229. doi:10. 1158/2159-8290.cd-18-0706

Regufe, V. M. G., Pinto, C. M. C. B., and Perez, P. M. V. H. C. (2020). Metabolic Syndrome in Type 2 Diabetic Patients: a Review of Current Evidence. Porto. Biomed. J. 5, e101. doi:10.1097/j.pbj.0000000000000101

Riebisch, A. K., Mühlen, S., Beer, Y. Y., and Schmitz, I. (2021). Autophagy-A Story of Bacteria Interfering with the Host Cell Degradation Machinery. Pathogens 10, 110. doi:10.3390/pathogens10020110
Rijnboutt, S., Stoorvogel, W., Geuze, H. J., and Strous, G. J. (1992). Identification of Subcellular Compartments Involved in Biosynthetic Processing of Cathepsin D. J. Biol. Chem. 267, 15665-15672. doi:10.1016/s0021-9258(19)49587-2

Rivera-Colón, Y., Schutsky, E. K., Kita, A. Z., and Garmen, S. C. (2012). The Structure of Human GALNS Reveals the Molecular Basis for Mucopolysaccharidosis IV A. J. Mol. Biol. 423, 736-751. doi:10.1016/j.jmb. 2012.08.020

Rochlani, Y., Pothineni, N. V., Kovelamudi, S., and Mehta, J. L. (2017). Metabolic Syndrome: Pathophysiology, Management, and Modulation by Natural Compounds. Ther. Adv. Cardiovasc. Dis. 11, 215-225. doi:10.1177/ 1753944717711379

Roczniak-Ferguson, A., Petit, C. S., Froehlich, F., Qian, S., Ky, J., Angarola, B., et al. (2012). The Transcription Factor TFEB Links mTORC1 Signaling to Transcriptional Control of Lysosome Homeostasis. Sci. Signal. 5, ra42. doi:10.1126/scisignal.2002790

Rogala, K. B., Gu, X., Kedir, J. F., Abu-Remaileh, M., Bianchi, L. F., Bottino, A. M. S., et al. (2019). Structural Basis for the Docking of mTORC1 on the Lysosomal Surface. Science 366, 468-475. doi:10.1126/science.aay0166

Romanov, J., Walczak, M., Ibiricu, I., Schüchner, S., Ogris, E., Kraft, C., et al. (2012). Mechanism and Functions of Membrane Binding by the Atg5-Atg12/Atg16 Complex during Autophagosome Formation. EMBO. J. 31, 4304-4317. doi:10. 1038/emboj.2012.278

Rozas, J. L., Gómez-Sánchez, L., Mircheski, J., Linares-Clemente, P., NietoGonzález, J. L., Vázquez, M. E., et al. (2012). Motorneurons Require Cysteine String Protein- $\alpha$ to Maintain the Readily Releasable Vesicular Pool and Synaptic Vesicle Recycling. Neuron 74, 151-165. doi:10.1016/j.neuron. 2012.02.019

Sahu, R., Kaushik, S., Clement, C. C., Cannizzo, E. S., Scharf, B., Follenzi, A., et al. (2011). Microautophagy of Cytosolic Proteins by Late Endosomes. Develop. Cel 20, 131-139. doi:10.1016/j.devcel.2010.12.003

Sales, C. F., Melo, R. M. C., Pinheiro, A. P. B., Luz, R. K., Bazzoli, N., and Rizzo, E. (2019). Autophagy and Cathepsin D Mediated Apoptosis Contributing to Ovarian Follicular Atresia in the Nile tilapia. Mol. Reprod. Dev. 86, 1592-1602. doi:10.1002/mrd.23245

Sancak, Y., Peterson, T. R., Shaul, Y. D., Lindquist, R. A., Thoreen, C. C., Bar-Peled, L., et al. (2008). The Rag GTPases Bind Raptor and Mediate Amino Acid Signaling to mTORC1. Sci 320, 1496-1501. doi:10.1126/science.1157535

Sardiello, M., Palmieri, M., di Ronza, A., Medina, D. L., Valenza, M., Gennarino, V. A., et al. (2009). A Gene Network Regulating Lysosomal Biogenesis and Function. Science 325, 473-477. doi:10.1126/science.1174447

Sarkar, C., Sadhukhan, T., Bagh, M. B., Appu, A. P., Chandra, G., Mondal, A., et al. (2020). Cln1 -mutations Suppress Rab7-RILP Interaction and Impair Autophagy Contributing to Neuropathology in a Mouse Model of Infantile Neuronal Ceroid Lipofuscinosis. Jrnl Inher Metab. Disea 43, 1082-1101. doi:10. 1002/jimd.12242

Saxton, R. A., and Sabatini, D. M. (2017). mTOR Signaling in Growth, Metabolism, and Disease. Cell 169, 361-371. doi:10.1016/j.cell.2017.02.004

Schmidtke, C., Tiede, S., Thelen, M., Käkelä, R., Jabs, S., Makrypidi, G., et al. (2019). Lysosomal Proteome Analysis Reveals that CLN3-Defective Cells Have Multiple Enzyme Deficiencies Associated with Changes in Intracellular Trafficking. J. Biol. Chem. 294, 9592-9604. doi:10.1074/jbc.ra119.008852

Schmiedt, M.-L., Bessa, C., Heine, C., Ribeiro, M. G., Jalanko, A., and Kyttälä, A. (2010). The Neuronal Ceroid Lipofuscinosis Protein CLN5: New Insights into Cellular Maturation, Transport, and Consequences of Mutations. Hum. Mutat. 31, 356-365. doi:10.1002/humu.21195

Schultz, M. L., Tecedor, L., Stein, C. S., Stamnes, M. A., and Davidson, B. L. (2014). CLN3 Deficient Cells Display Defects in the ARF1-Cdc42 Pathway and Actindependent Events. Plos. ONE. 9, e96647. doi:10.1371/journal.pone.0096647

Schulz, A., Kohlschütter, A., Mink, J., Simonati, A., and Williams, R. (2013). NCL Diseases - Clinical Perspectives. Biochim. Biophys. Acta (Bba) - Mol. Basis Dis. 1832, 1801-1806. doi:10.1016/j.bbadis.2013.04.008

Selak, S., Paternain, A. V., Aller, I. M., Picó, E., Rivera, R., and Lerma, J. (2009). A Role for SNAP25 in Internalization of Kainate Receptors and Synaptic Plasticity. Neuron 63, 357-371. doi:10.1016/j.neuron.2009.07.017

Sesaki, H., Wong, E. F. S., and Siu, C.-H. (1997). The Cell Adhesion Molecule DdCAD-1 in Dictyostelium Is Targeted to the Cell Surface by a Nonclassical Transport Pathway Involving Contractile Vacuoles. J. Cel. Biol. 138, 939-951. doi:10.1083/jcb.138.4.939 
Settembre, C., Di Malta, C., Polito, V. A., Arencibia, M. G., Vetrini, F., Erdin, S., et al. (2011). TFEB Links Autophagy to Lysosomal Biogenesis. Science 332, 1429-1433. doi:10.1126/science.1204592

Sharma, M., Burré, J., Bronk, P., Zhang, Y., Xu, W., and Südhof, T. C. (2012). CSP $\alpha$ Knockout Causes Neurodegeneration by Impairing SNAP-25 Function. EMBO. J. 31, 829-841. doi:10.1038/emboj.2011.467

Siintola, E., Topcu, M., Aula, N., Lohi, H., Minassian, B. A., Paterson, A. D., et al. (2007). The Novel Neuronal Ceroid Lipofuscinosis Gene MFSD8 Encodes a Putative Lysosomal Transporter. Am. J. Hum. Genet. 81, 136-146. doi:10.1086/ 518902

Sleat, D. E., Donnelly, R. J., Lackland, H., Liu, C.-G., Sohar, I., Pullarkat, R. K., et al. (1997). Association of Mutations in a Lysosomal Protein with Classical LateInfantile Neuronal Ceroid Lipofuscinosis. Science 277, 1802-1805. doi:10.1126/ science.277.5333.1802

Smith, K. R., Damiano, J., Franceschetti, S., Carpenter, S., Canafoglia, L., Morbin, M., et al. (2012). Strikingly Different Clinicopathological Phenotypes Determined by Progranulin-Mutation Dosage. Am. J. Hum. Genet. 90, 1102-1107. doi:10.1016/j.ajhg.2012.04.021

Smith, P. K., Sen, M. G., Fisher, P. R., and Annesley, S. J. (2019). Modelling of Neuronal Ceroid Lipofuscinosis Type 2 in Dictyostelium discoideum Suggests that Cytopathological Outcomes Result from Altered TOR Signalling. Cells 8, 469. doi:10.3390/cells 8050469

Soldati, C., Lopez-Fabuel, I., Wanderlingh, L. G., Garcia-Macia, M., Monfregola, J., Esposito, A., et al. (2021). Repurposing of Tamoxifen Ameliorates CLN3 and CLN7 Disease Phenotype. EMBO. Mol. Med. 13, e13742. doi:10.15252/emmm. 202013742

Spencer, B., Potkar, R., Trejo, M., Rockenstein, E., Patrick, C., Gindi, R., et al. (2009). Beclin 1 Gene Transfer Activates Autophagy and Ameliorates the Neurodegenerative Pathology in -Synuclein Models of Parkinson's and Lewy Body Diseases. J. Neurosci. 29, 13578-13588. doi:10.1523/jneurosci.4390-09. 2009

Staropoli, J. F., Karaa, A., Lim, E. T., Kirby, A., Elbalalesy, N., Romansky, S. G., et al. (2012). A Homozygous Mutation in KCTD7 Links Neuronal Ceroid Lipofuscinosis to the Ubiquitin-Proteasome System. Am. J. Hum. Genet. 91, 202-208. doi:10.1016/j.ajhg.2012.05.023

Stroupe, C. (2018). This Is the End: Regulation of Rab7 Nucleotide Binding in Endolysosomal Trafficking and Autophagy. Front. Cel Dev. Biol. 6, 129. doi:10. 3389/fcell.2018.00129

Stumpf, M., Müller, R., Gaßen, B., Wehrstedt, R., Fey, P., Karow, M. A., et al. (2017). A Tripeptidyl Peptidase 1 Is a Binding Partner of the Golgi pH Regulator (GPHR) in Dictyostelium. Dis. Model. Mech. 10, 897-907. doi:10. $1242 / \mathrm{dmm} .029280$

Su, C.-J., Feng, Y., Liu, T.-T., Liu, X., Bao, J.-J., Shi, A.-M., et al. (2017). Thioredoxin-interacting Protein Induced $\alpha$-synuclein Accumulation via Inhibition of Autophagic Flux: Implications for Parkinson's Disease. CNS. Neurosci. Ther. 23, 717-723. doi:10.1111/cns.12721

Sweitzer, S. M., and Hinshaw, J. E. (1998). Dynamin Undergoes a GTP-dependent Conformational Change Causing Vesiculation. Cell 93, 1021-1029. doi:10. 1016/s0092-8674(00)81207-6

Szalai, P., Hagen, L. K., Sætre, F., Luhr, M., Sponheim, M., Øverbye, A., et al. (2015). Autophagic Bulk Sequestration of Cytosolic Cargo Is Independent of LC3, but Requires GABARAPs. Exp. Cel Res. 333, 21-38. doi:10.1016/j.yexcr.2015.02.003

Takeshima, H., Sakaguchi, M., Mihara, K., Murakami, K., Omura, T., Himeno, M., et al. (1995). Intracellular Targeting of Lysosomal Cathepsin D in COS Cells. J. Biochem. 118, 981-988. doi:10.1093/jb/118.5.981

Tammen, I., Houweling, P. J., Frugier, T., Mitchell, N. L., Kay, G. W., Cavanagh, J. A. L., et al. (2006). A Missense Mutation (c.184C > T) in Ovine CLN6 Causes Neuronal Ceroid Lipofuscinosis in Merino Sheep whereas Affected South Hampshire Sheep Have Reduced Levels of CLN6 mRNA. Biochim. Biophys. Acta 1762, 898-905. doi:10.1016/j.bbadis.2006.09.004

Tanaka, Y., Chambers, J. K., Matsuwaki, T., Yamanouchi, K., and Nishihara, M. (2014). Possible Involvement of Lysosomal Dysfunction in Pathological Changes of the Brain in Aged Progranulin-Deficient Mice. Acta Neuropathol. Commun. 2, 78. doi:10.1186/s40478-014-0078-x

Tecedor, L., Stein, C. S., Schultz, M. L., Farwanah, H., Sandhoff, K., and Davidson, B. L. (2013). CLN3 Loss Disturbs Membrane Microdomain Properties and Protein Transport in Brain Endothelial Cells. J. Neurosci. 33, 18065-18079. doi:10.1523/jneurosci.0498-13.2013
Tegeder, I. (2016). Yeast-2-Hybrid Data File Showing Progranulin Interactions in Human Fetal Brain and Bone Marrow Libraries. Data in Brief 9, 1060-1062. doi:10.1016/j.dib.2016.11.031

Terryn, J., Verfaillie, C. M., and Van Damme, P. (2021). Tweaking Progranulin Expression: Therapeutic Avenues and Opportunities. Front. Mol. Neurosci. 14, 713031. doi:10.3389/fnmol.2021.713031

The International Batten Disease Consortium (1995). Isolation of a Novel Gene Underlying Batten Disease, CLN3. The International Batten Disease Consortium. Cell 82, 949-957.

Thelen, M., Dae, M., Schweizer, M., Hagel, C., Wong, A. M. S., Cooper, J. D., et al. (2012). Disruption of the Autophagy-Lysosome Pathway Is Involved in Neuropathology of the Nclf Mouse Model of Neuronal Ceroid Lipofuscinosis. Plos. One. 7, e35493. doi:10.1371/journal.pone.0035493

Theurey, P., Tubbs, E., Vial, G., Jacquemetton, J., Bendridi, N., Chauvin, M.-A., et al. (2016). Mitochondria-associated Endoplasmic Reticulum Membranes Allow Adaptation of Mitochondrial Metabolism to Glucose Availability in the Liver. J. Mol. Cel. Biol. 8, 129-143. doi:10.1093/jmcb/mjw004

Thumm, M., Egner, R., Koch, B., Schlumpberger, M., Straub, M., Veenhuis, M., et al. (1994). Isolation of Autophagocytosis Mutants ofSaccharomyces Cerevisiae. FEBS Lett. 349, 275-280. doi:10.1016/0014-5793(94)00672-5

Tian, R., Li, Y., and Yao, X. (2016). PGRN Suppresses Inflammation and Promotes Autophagy in Keratinocytes through the Wnt/ $\beta$-Catenin Signaling Pathway. Inflammation 39, 1387-1394. doi:10.1007/s10753-016-0370-y

Tobaben, S., Thakur, P., Fernández-Chacón, R., Südhof, T. C., Rettig, J., and Stahl, B. (2001). A Trimeric Protein Complex Functions as a Synaptic Chaperone Machine. Neuron 31, 987-999. doi:10.1016/s0896-6273(01)00427-5

Tobaben, S., Varoqueaux, F., Brose, N., Stahl, B., and Meyer, G. (2003). A Brainspecific Isoform of Small Glutamine-Rich Tetratricopeptide Repeat-Containing Protein Binds to Hsc70 and the Cysteine String Protein. J. Biol. Chem. 278, 38376-38383. doi:10.1074/jbc.m301558200

Toh, H., Chitramuthu, B. P., Bennett, H. P. J., and Bateman, A. (2011). Structure, Function, and Mechanism of Progranulin; the Brain and beyond. J. Mol. Neurosci. 45, 538-548. doi:10.1007/s12031-011-9569-4

Tsukada, M., and Ohsumi, Y. (1993). Isolation and Characterization of AutophagyDefective Mutants ofSaccharomyces Cerevisiae. FEBS Lett. 333, 169-174. doi:10.1016/0014-5793(93)80398-e

Tsunemi, T., Hamada, K., and Krainc, D. (2014). ATP13A2/PARK9 Regulates Secretion of Exosomes and -Synuclein. J. Neurosci. 34, 15281-15287. doi:10. 1523/jneurosci.1629-14.2014

Tumbarello, D. A., Waxse, B. J., Arden, S. D., Bright, N. A., Kendrick-Jones, J., and Buss, F. (2012). Autophagy Receptors Link Myosin VI to Autophagosomes to Mediate Tom1-dependent Autophagosome Maturation and Fusion with the Lysosome. Nat. Cel. Biol. 14, 1024-1035. doi:10.1038/ncb2589

Tung, S. M., Ünal, C., Ley, A., Peña, C., Tunggal, B., Noegel, A. A., et al. (2010). Loss of Dictyostelium ATG9 Results in a Pleiotropic Phenotype Affecting Growth, Development, Phagocytosis and Clearance and Replication of Legionella pneumophila. Cell. Microbiol. 12, 765-780. doi:10.1111/j.1462-5822.2010. 01432.x

Usenovic, M., Tresse, E., Mazzulli, J. R., Taylor, J. P., and Krainc, D. (2012). Deficiency of ATP13A2 Leads to Lysosomal Dysfunction, -Synuclein Accumulation, and Neurotoxicity. J. Neurosci. 32, 4240-4246. doi:10.1523/ jneurosci.5575-11.2012

Uusi-Rauva, K., Kyttälä, A., van der Kant, R., Vesa, J., Tanhuanpää, K., Neefjes, J., et al. (2012). Neuronal Ceroid Lipofuscinosis Protein CLN3 Interacts with Motor Proteins and Modifies Location of Late Endosomal Compartments. Cel. Mol. Life Sci. 69, 2075-2089. doi:10.1007/s00018-011-0913-1

Van Beersel, G., Tihon, E., Demine, S., Hamer, I., Jadot, M., and Arnould, T. (2013). Different Molecular Mechanisms Involved in Spontaneous and Oxidative Stress-Induced Mitochondrial Fragmentation in Tripeptidyl Peptidase-1 (TPP-1)-Deficient Fibroblasts. Biosci. Rep. 33, e00023. doi:10.1042/ BSR20120104

Vance, J. E., Stone, S. J., and Faust, J. R. (1997). Abnormalities in Mitochondria-Associated Membranes and Phospholipid Biosynthetic Enzymes in the Mnd/mnd Mouse Model of Neuronal Ceroid Lipofuscinosis. Biochim. Biophys. Acta (Bba) - Lipids Lipid Metab. 1344, 286-299. doi:10.1016/s0005-2760(96)00153-1

Vance, J. E., and Tasseva, G. (2013). Formation and Function of Phosphatidylserine and Phosphatidylethanolamine in Mammalian Cells. 
Biochim. Biophys. Acta (Bba) - Mol. Cel Biol. Lipids 1831, 543-554. doi:10. 1016/j.bbalip.2012.08.016

Varvagiannis, K., Hanquinet, S., Billieux, M., De Luca, R., Rimensberger, P., Lidgren, M., et al. (2018). Congenital Neuronal Ceroid Lipofuscinosis with a Novel CTSD Gene Mutation: A Rare Cause of Neonatal-Onset Neurodegenerative Disorder. Neuropediatrics 49, 150-153. doi:10.1055/s0037-1613681

Verkruyse, L. A., and Hofmann, S. L. (1996). Lysosomal Targeting of PalmitoylProtein Thioesterase. J. Biol. Chem. 271, 15831-15836. doi:10.1074/jbc.271.26. 15831

Vidal-Donet, J. M., Cárcel-Trullols, J., Casanova, B., Aguado, C., and Knecht, E. (2013). Alterations in ROS Activity and Lysosomal pH Account for Distinct Patterns of Macroautophagy in LINCL and JNCL Fibroblasts. Plos. One. 8, e55526. doi:10.1371/journal.pone.0055526

Vines, D., and Warburton, M. J. (1998). Purification and Characterisation of a Tripeptidyl Aminopeptidase I from Rat Spleen. Biochim. Biophys. Acta (Bba) Protein Struct. Mol. Enzymol. 1384, 233-242. doi:10.1016/s0167-4838(98) 00012-0

von Eisenhart-Rothe, P., Grubman, A., Greferath, U., Fothergill, L. J., Jobling, A. I., Phipps, J. A., et al. (2018). Failure of Autophagy-Lysosomal Pathways in Rod Photoreceptors Causes the Early Retinal Degeneration Phenotype Observed inCln6nclfMice. Invest. Ophthalmol. Vis. Sci. 59, 5082-5097. doi:10.1167/iovs. 18-24757

Von Kleist, L., Ariunbat, K., Braren, I., Stauber, T., Storch, S., and Danyukova, T. (2019). A Newly Generated Neuronal Cell Model of CLN7 Disease Reveals Aberrant Lysosome Motility and Impaired Cell Survival. Mol. Genet. Metab. 126, 196-205. doi:10.1016/j.ymgme.2018.09.009

Voshtani, R., Song, M., Wang, H., Li, X., Zhang, W., Tavallaie, M. S., et al. (2019). Progranulin Promotes Melanoma Progression by Inhibiting Natural Killer Cell Recruitment to the Tumor Microenvironment. Cancer Lett. 465, 24-35. doi:10. 1016/j.canlet.2019.08.018

Walczak, M., and Martens, S. (2013). Dissecting the Role of the Atg12-Atg5-Atg16 Complex during Autophagosome Formation. Autophagy 9, 424-425. doi:10. 4161/auto.22931

Wan, S. X., Pan, X., Qian, J. J., Shu, Y., Xu, P., Zhao, J., et al. (2020). Downregulation of ATP13A2 in Midbrain Dopaminergic Neurons Is Related to Defective Autophagy in a Mouse Model of Parkinson's Disease. Int. J. Clin. Exp. Pathol. 13, 1853-1858.

Wang, B., Shi, G.-P., Yao, P. M., Li, Z., Chapman, H. A., and Brömme, D. (1998). Human Cathepsin F. J. Biol. Chem. 273, 32000-32008. doi:10.1074/jbc.273.48. 32000

Wang, H.-J., Guay, G., Pogan, L., Sauvé, R., and Nabi, I. R. (2000). Calcium Regulates the Association between Mitochondria and a Smooth Subdomain of the Endoplasmic Reticulum. J. Cel. Biol. 150, 1489-1498. doi:10.1083/jcb.150.6. 1489

Wang, N., Tan, H.-Y., Li, S., and Feng, Y. (2017). Atg9b Deficiency Suppresses Autophagy and Potentiates Endoplasmic Reticulum Stress-Associated Hepatocyte Apoptosis in Hepatocarcinogenesis. Theranostics 7, 2325-2338. doi:10.7150/thno.18225

Wang, R., Tan, J., Chen, T., Han, H., Tian, R., Tan, Y., et al. (2019). ATP13A2 Facilitates HDAC6 Recruitment to Lysosome to Promote AutophagosomeLysosome Fusion. J. Cel. Biol. 218, 267-284. doi:10.1083/jcb.201804165

Williams, R. E. (2011). "Appendix 1: NCL Incidence and Prevalence Data," in Editors S. E. Mole, R. E. Williams, and H. H. Goebel. The Neuronal Ceroid Lipofuscinoses (Batten Disease) (London, United Kingdom: Oxford University Press), 361-365.

Wu, P., Yuan, X., Li, F., Zhang, J., Zhu, W., Wei, M., et al. (2017). Myocardial Upregulation of Cathepsin D by Ischemic Heart Disease Promotes Autophagic Flux and Protects against Cardiac Remodeling and Heart Failure. Circ. Heart Fail. 10, e004044. doi:10.1161/CIRCHEARTFAILURE.117.004044

Wu, Y. Y., Sonnino, S., Li, Y.-T., and Li, S.-C. (1996). Characterization of an Alternatively Spliced GM2 Activator Protein, GM2A Protein. J. Biol. Chem. 271, 10611-10615. doi:10.1074/jbc.271.18.10611

Xie, Z., Nair, U., and Klionsky, D. J. (2008). Dissecting Autophagosome Formation: The Missing Pieces. Autophagy 4, 920-922. doi:10.4161/auto.6692

Xin, W., Mullen, T. E., Kiely, R., Min, J., Feng, X., Cao, Y., et al. (2010). CLN5 Mutations Are Frequent in Juvenile and Late-Onset Non-Finnish Patients with NCL. Neurology 74, 565-571. doi:10.1212/wnl.0b013e3181cff70d
Xing, J., Li, Y., and Zhao, H. (2021). Knockdown of CLN5 Inhibits the Tumorigenic Properties of Glioblastoma Cells via the Akt/mTOR Signaling Pathway. Oncol. Lett. 21, 387. doi:10.3892/ol.2021.12648

Xiong, Q., Li, W., Li, P., Yang, M., Wu, C., and Eichinger, L. (2018). The Role of ATG16 in Autophagy and the Ubiquitin Proteasome System. Cells 8, 2. doi:10. 3390/cells8010002

Xiong, Q., Song, N., Li, P., Fischer, S., Konertz, R., Wagle, P., et al. (2021). RNAseq and Quantitative Proteomic Analysis of Dictyostelium Knock-Out Cells Lacking the Core Autophagy Proteins ATG9 And/or ATG16. BMC. Genomics. 22, 444. doi:10.1186/s12864-021-07756-2

Xiong, Q., Ünal, C., Matthias, J., Steinert, M., and Eichinger, L. (2015). The Phenotypes of ATG9, ATG16 and ATG9/16 Knock-Out Mutants Imply Autophagy-dependent and -independent Functions. Open Biol. 5, 150008. doi:10.1098/rsob.150008

Xu, Y., Cui, L., Dibello, A., Wang, L., Lee, J., Saidi, L., et al. (2018). DNAJC5 Facilitates USP19-dependent Unconventional Secretion of Misfolded Cytosolic Proteins. Cell. Discov. 4, 11. doi:10.1038/s41421-018-0012-7

Yadati, T., Houben, T., Bitorina, A., and Shiri-Sverdlov, R. (2020). The Ins and Outs of Cathepsins: Physiological Function and Role in Disease Management. Cells 9, 1679. doi:10.3390/cells9071679

Yamada, Y., and Schaap, P. (2019). Cyclic AMP Induction of Dictyostelium Prespore Gene Expression Requires Autophagy. Develop. Biol. 452, 114-126. doi:10.1016/j.ydbio.2019.04.017

Yang, H., Jiang, X., Li, B., Yang, H. J., Miller, M., Yang, A., et al. (2017). Mechanisms of mTORC1 Activation by RHEB and Inhibition by PRAS40. Nature 552, 368-373. doi:10.1038/nature25023

Yang, M., Liu, J., Shao, J., Qin, Y., Ji, Q., Zhang, X., et al. (2014). Cathepsin S-Mediated Autophagic Flux in Tumor-Associated Macrophages Accelerate Tumor Development by Promoting M2 Polarization. Mol. Cancer 13, 43. doi:10.1186/1476-4598-13-43

Yang, Z., Wilkie-Grantham, R. P., Yanagi, T., Shu, C.-W., Matsuzawa, S.-i., and Reed, J. C. (2015). ATG4B (Autophagin-1) Phosphorylation Modulates Autophagy. J. Biol. Chem. 290, 26549-26561. doi:10.1074/ jbc.m115.658088

Yasa, S., Modica, G., Sauvageau, E., Kaleem, A., Hermey, G., and Lefrancois, S. (2020). CLN3 Regulates Endosomal Function by Modulating Rab7A-Effector Interactions. J. Cel. Sci. 133, jcs234047. doi:10.1242/jcs.234047

Yasa, S., Sauvageau, E., Modica, G., and Lefrancois, S. (2021). CLN5 and CLN3 Function as a Complex to Regulate Endolysosome Function. Biochem. J. 478, 2339-2357. doi:10.1042/bcj20210171

Yorimitsu, T., and Klionsky, D. J. (2005). Autophagy: Molecular Machinery for Self-Eating. Cel Death Differ 12 (Suppl. 2), 1542-1552. doi:10.1038/sj.cdd. 4401765

Youle, R. J., and Narendra, D. P. (2011). Mechanisms of Mitophagy. Nat. Rev. Mol. Cel. Biol. 12, 9-14. doi:10.1038/nrm3028

Yu, L., McPhee, C. K., Zheng, L., Mardones, G. A., Rong, Y., Peng, J., et al. (2010). Termination of Autophagy and Reformation of Lysosomes Regulated by mTOR. Nature 465, 942-946. doi:10.1038/nature09076

Yun, H. R., Jo, Y. H., Kim, J., Nguyen, N. N. Y., Shin, Y., Kim, S. S., et al. (2020). Palmitoyl Protein Thioesterase 1 Is Essential for Myogenic Autophagy of C2C12 Skeletal Myoblast. Front. Physiol. 11, 569221. doi:10.3389/fphys.2020. 569221

Zhang, M., Chen, L., Wang, S., and Wang, T. (2009). Rab7: Roles in Membrane Trafficking and Disease. Biosci. Rep. 29, 193-209. doi:10.1042/BSR20090032

Zhang, Y.-Q., Henderson, M. X., Colangelo, C. M., Ginsberg, S. D., Bruce, C., Wu, T., et al. (2012). Identification of CSPa Clients Reveals a Role in Dynamin 1 Regulation. Neuron 74, 136-150. doi:10.1016/j.neuron.2012.01.029

Zhang, Y. Q., and Chandra, S. S. (2014). Oligomerization of Cysteine String Protein Alpha Mutants Causing Adult Neuronal Ceroid Lipofuscinosis. Biochi. Biophys. Acta 1842, 2136-2146. doi:10.1042/bsr20090032

Zhang, Z., Wang, D., Sun, T., Xu, J., Chiang, H.-C., Shin, W., et al. (2013). The SNARE Proteins SNAP25 and Synaptobrevin Are Involved in Endocytosis at Hippocampal Synapses. J. Neurosci. 33, 9169-9175. doi:10.1523/jneurosci. 0301-13.2013

Zhao, X., Liberti, R., Jian, J., Fu, W., Hettinghouse, A., Sun, Y., et al. (2021). Progranulin Associates with Rab2 and Is Involved in AutophagosomeLysosome Fusion in Gaucher Disease. J. Mol. Med. 99, 1639-1654. doi:10. 1007/s00109-021-02127-6 
Zheng, W., Chen, Q., Wang, C., Yao, D., Zhu, L., Pan, Y., et al. (2020). Inhibition of Cathepsin D (CTSD) Enhances Radiosensitivity of Glioblastoma Cells by Attenuating Autophagy. Mol. Carcinog 59, 651-660. doi:10.1002/mc.23194

Zheng, X., Chu, F., Mirkin, B. L., Sudha, T., Mousa, S. A., and Rebbaa, A. (2008). Role of the Proteolytic Hierarchy between Cathepsin L, Cathepsin D and Caspase-3 in Regulation of Cellular Susceptibility to Apoptosis and Autophagy. Biochim. Biophys. Acta (Bba) - Mol. Cel Res. 1783, 2294-2300. doi:10.1016/j. bbamcr.2008.07.027

Zhong, Y., Mohan, K., Liu, J., Al-Attar, A., Lin, P., Flight, R. M., et al. (2020). Loss of CLN3, the Gene Mutated in Juvenile Neuronal Ceroid Lipofuscinosis, Leads to Metabolic Impairment and Autophagy Induction in Retinal Pigment Epithelium. Biochim. Biophys. Acta (Bba) - Mol. Basis Dis. 1866, 165883. doi:10.1016/j.bbadis.2020.165883

Zhou, B., Li, H., Liu, J., Xu, L., Guo, Q., Sun, H., et al. (2015). Progranulin Induces Adipose Insulin Resistance and Autophagic Imbalance via TNFR1 in Mice. J. Mol. Endocrinol. 55, 231-243. doi:10.1530/jme-15-0075

Zhou, D., Zhou, M., Wang, Z., Fu, Y., Jia, M., Wang, X., et al. (2019a). PGRN Acts as a Novel Regulator of Mitochondrial Homeostasis by Facilitating Mitophagy and Mitochondrial Biogenesis to Prevent Podocyte Injury in Diabetic Nephropathy. Cel. Death Dis. 10, 524. doi:10.1038/s41419-0191754-3

Zhou, D., Zhou, M., Wang, Z., Fu, Y., Jia, M., Wang, X., et al. (2019b). Progranulin Alleviates Podocyte Injury via Regulating CAMKK/AMPK-mediated Autophagy under Diabetic Conditions. J. Mol. Med. 97, 1507-1520. doi:10.1007/s00109-019-01828-3

Zhou, J., Gao, G., Crabb, J. W., and Serrero, G. (1993). Purification of an Autocrine Growth Factor Homologous with Mouse Epithelin Precursor from a Highly
Tumorigenic Cell Line. J. Biol. Chem. 268, 10863-10869. doi:10.1016/s00219258(18)82064-6

Zhou, X., Paushter, D. H., Feng, T., Sun, L., Reinheckel, T., and Hu, F. (2017). Lysosomal Processing of Progranulin. Mol. Neurodegeneration 12, 62. doi:10. 1186/s13024-017-0205-9

Zhu, L., Jorgensen, J. R., Li, M., Chuang, Y. S., and Emr, S. D. (2017). ESCRTs Function Directly on the Lysosome Membrane to Downregulate Ubiquitinated Lysosomal Membrane Proteins. eLIFE 6, e26403. doi:10. 7554 /eLife. 26403

Conflict of Interest: The authors declare that the research was conducted in the absence of any commercial or financial relationships that could be construed as a potential conflict of interest.

Publisher's Note: All claims expressed in this article are solely those of the authors and do not necessarily represent those of their affiliated organizations, or those of the publisher, the editors, and the reviewers. Any product that may be evaluated in this article, or claim that may be made by its manufacturer, is not guaranteed or endorsed by the publisher.

Copyright (c) $2022 \mathrm{Kim}$, Wilson-Smillie, Thanabalasingam, Lefrancois, Cotman and Huber. This is an open-access article distributed under the terms of the Creative Commons Attribution License (CC BY). The use, distribution or reproduction in other forums is permitted, provided the original author(s) and the copyright owner(s) are credited and that the original publication in this journal is cited, in accordance with accepted academic practice. No use, distribution or reproduction is permitted which does not comply with these terms. 


\section{GLOSSARY}

a-Syn $\alpha$-synuclein

AGE advanced glycation end product

Akt/PKB protein kinase B

ALR autophagic lysosome reformation

AMPK AMP-activated protein kinase

atg1 autophagy protein 1

ATG3 ubiquitin-like-conjugating enzyme ATG3

ATG4 cysteine protease ATG4

ATG5 autophagy protein 5

ATG7 ubiquitin-like modifier-activating enzyme ATG7

ATG8 autophagy-related protein 8

atg9 autophagy protein 9

Atg9b autophagy-related protein 9b

ATG10 ubiquitin-like-conjugating enzyme ATG10

ATG12 ubiquitin-like protein ATG12

ATG13 autophagy-related protein 13

ATG14 BECN1-associated autophagy-related key regulator

Atg16 autophagy-related protein 16

ATG16-1 autophagy-related protein 16-1

ATG101 autophagy-related protein 101

ATP13A2 polyamine-transporting ATPase 13A2

BECN1 beclin-1

BNIP3 BCL2/adenovirus E1B $19 \mathrm{kDa}$ protein-interacting protein 3

BNIP3L BCL2/adenovirus E1B $19 \mathrm{kDa}$ protein-interacting protein 3-like

CAMKI calmodulin-dependent protein kinase I

CLN ceroid lipofuscinosis neuronal

COPII coat protein complex II

Cpr cysteine protease

CQ chloroquine

CTS cathepsin

CV contractile vacuole

DNAJC5 DnaJ heat shock protein family Hsp40 member C5

ERK1/2 extracellular signal-regulated protein kinase 1/2

ESCRT endosomal sorting complex required for transport

FIP200 focal adhesion kinase family interacting protein of $200 \mathrm{kDa}$

GABARAPL1 gamma-aminobutyric acid receptor-associated protein-like 1

GALNS N-acetylgalactosamine sulphate

GATE16 GABA type A receptor-associated protein-like 2

GM2A GM2 ganglioside activator

HDAC6 histone deacetylase 6
HMGB1 high mobility group box 1

HSC70 heat shock cognate 71-kDa protein

KCTD7 potassium channel tetramerization domain containing 7

LAMP lysosomal-associated membrane glycoprotein

LC3/ATG8 microtubule-associated protein 1A/1B-light chain 3/ autophagy-related gene 8

MAM mitochondria-associated membrane

MAPK mitogen-activated protein kinase

MEF mouse embryonic fibroblast

MFSD8 major facilitator superfamily domain containing 8

MS metabolic syndrome

mTOR mammalian target of rapamycin

mTORC1 mammalian target of rapamycin complex 1

NCL neuronal ceroid lipofuscinosis

p62/SQSTM1 p62/sequestosome 1

p70S6K p70 S6 kinase

PE phosphatidylethanolamine

PEMT2 phosphatidylethanolamine N-methyltransferase 2

PGRN/GRN progranulin

PI3K phosphoinositide-3-kinase

PIP3 phosphatidylinositol-3,4,5-triphosphate

Plc Phospholipase C

PPT1 palmitoyl protein thioesterase 1

Psd phosphatidylserine decarboxylase

RAB ras-related protein

RHEB ras homolog enriched in the brain

RILP RAB7-interacting lysosomal protein

SNAP synaptosomal-associated protein

SNARE synaptosomal-associated receptor protein

SYT11 synaptotagmin 11

TBCK TBC1 domain-containing kinase

TFEB transcription factor EB

TOM1 target of Myb1 protein 1

TPP1 tripeptidyl peptidase 1

Ub ubiquitin

ULK1 UNC51-like autophagy activating kinase 1

UVRAG UV radiation resistance-associated gene

V-ATPase vacuolar-type ATPase

VAPA vesicle-associated membrane protein A

VPS vacuolar protein sorting

WIPI2 WD repeat domain phosphoinositide-interacting protein 2. 